Lappeenrannan teknillinen korkeakoulu

Lappeenranta University of Technology

Maunu Kuosa

\title{
Numerical and Experimental Modelling of Gas Flow and Heat Transfer in the Air Gap of an Electric Machine
}

Thesis for the degree of Doctor of Science (Technology) to be presented with due permission for public examination and criticism in the Auditorium of the Student Union House at Lappeenranta University of Technology, Lappeenranta, Finland, on the $8^{\text {th }}$ of November 2002, at 12 o' clock noon. 
Supervisor Professor Jaakko Larjola

Department of Energy Technology

Lappeenranta University of Technology

Finland

Reviewers Dr. Tech. Juha Saari

Sundyne Corporation

Espoo

Finland

Ph. D. Andrew Martin

Department of Energy Technology

Royal Institute of Technology (KTH)

Sweden

Opponents Dr. Tech. Juha Saari

Sundyne Corporation

Espoo

Finland

D. Sc. (Tech.), Docent Timo Talonpoika

ALSTOM Finland Oy

Espoo

Finland 


\section{ABSTRACT}

\section{Maunu Kuosa}

Numerical and Experimental Modelling of Gas Flow and Heat Transfer in the Air Gap of an Electric Machine

Lappeenranta 2002

$97 \mathrm{p}$.

Acta Universitatis Lappeenrantaensis 129

Diss. Lappeenranta University of Technology

ISBN 951-764-688-7, ISSN 1456-4491

This work deals with the cooling of high-speed electric machines, such as motors and generators, through an air gap. It consists of numerical and experimental modelling of gas flow and heat transfer in an annular channel. Velocity and temperature profiles are modelled in the air gap of a high-speed test machine. Local and mean heat transfer coefficients and total friction coefficients are attained for a smooth rotor-stator combination at a large velocity range.

The aim is to solve the heat transfer numerically and experimentally. The FINFLO software, developed at Helsinki University of Technology, has been used in the flow solution, and the commercial IGG and Field view programs for the grid generation and post processing. The annular channel is discretized as a sector mesh. Calculation is performed with constant mass flow rate on six rotational speeds. The effect of turbulence is calculated using three turbulence models. The friction coefficient and velocity factor are attained via total friction power. The first part of the experimental section consists of finding the proper sensors and calibrating them in a straight pipe. Three sensors are tested in a straight pipe. After preliminary tests, a RdF-sensor is glued on the walls of stator and rotor surfaces. Telemetry is needed to be able to measure the heat transfer coefficients at the rotor. The mean heat transfer coefficients are measured in a test machine on four cooling air mass flow rates at a wide Couette Reynolds number range. The calculated values concerning the friction and heat transfer coefficients are compared with measured and semi-empirical data.

Heat is transferred from the hotter stator and rotor surfaces to the cooler air flow in the air gap, not from the rotor to the stator via the air gap, although the stator temperature is lower than the rotor temperature. The calculated friction coefficient fits well with the semi-empirical equations and preceding measurements. On constant mass flow rate the rotor heat transfer coefficient attains a saturation point at a higher rotational speed, while the heat transfer coefficient of the stator grows uniformly. The magnitudes of the heat transfer coefficients are almost constant with different turbulence models. The calibration of sensors in a straight pipe is only an advisory step in the selection process. Telemetry is tested in the pipe conditions and compared to the same measurements with a plain sensor. The magnitudes of the measured data and the data from the semi-empirical equation are higher for the heat transfer coefficients than the numerical data considered on the velocity range.

Friction and heat transfer coefficients are presented in a large velocity range in the report. The goals are reached acceptably using numerical and experimental research. The next challenge is to achieve results for grooved stator-rotor combinations. The work contains also results for an air gap with a grooved stator with 36 slots. The velocity field by the numerical method does not match in every respect the estimated flow mode. The absence of secondary Taylor vortices is evident when using time averaged numerical simulation.

Keywords: electric machine, air gap, heat transfer, CFD, experimental modelling UDC $536.25: 621.313$ 


\section{ACKNOWLEDGEMENTS}

This work started from a phone call by Jaakko Larjola when I was finishing a previous research project with high-speed safety bearings. He asked me to participate in the Graduate School in Computational Fluid Dynamics. This research has been carried out in the Department of Energy Technology at Lappeenranta University of Technology during the years 1998-2002 as a part of the national graduate school. It is composed of numerical and experimental modelling of fluid dynamics and heat transfer of cooling air flow in an air gap of a high-speed electric machine.

I would like to express my gratitude to professor Jaakko Larjola for offering me guidance and encouragement and professor Timo Siikonen for educating and training me in how to use the Finflo flow solver and for making it possible for me to work in the graduate school. I am grateful for professor Pertti Sarkomaa for his concern on these graduate studies and the financial support he provided for acquiring a proper workstation. I thank professor Heikki Martikka for his co-operation in making scientific co-publications and by providing a complementary study opportunity in the Department of Mechanical Engineering.

I express my sincere thanks for the reviewers of this thesis, Dr. Tech. Juha Saari, Sundyne Corporation and Ph.D. Andrew Martin, Royal Institute of Technology (KTH), for their valuable comments and corrections.

Thanks are due to Juha Saari and Hannu Esa for their support in getting familiar with the literature and choosing the right boundary conditions concerning the heat transfer and cooling of electric motors. The aid of Harri Pitkänen, Esa Salminen, Patrik Rautaheimo and Harri Heiska made it possible to overcome the challenges of the complicated flow simulation. I would also like to thank Jari Backman, Petri Sallinen, Jukka Lattu, Ilpo Taipale, Erkki Nikku and Jouni Ryhänen for their co-operation in the demanding laboratory work. The telemetry device using infrared technology was successfully built in the Department of Electrical Engineering at LUT by Tero Järveläinen, Osmo Anttalainen and Kimmo Tolsa. I thank all the team members of high-speed technology, especially Juha Honkatukia, Arttu Reunanen and Teemu Turunen-Saaresti for their co-operation, and my friends at the Department for the enjoyable atmosphere. I dedicate this work to my parents, Olavi and Eeva, for their love and support. 


\section{CONTENTS}

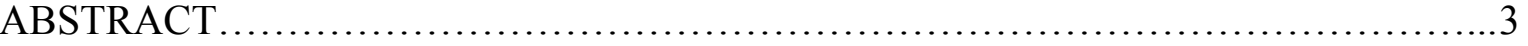

ACKNOWLEDGEMENTS ...................................................... 4

CONTENTS..................................................................... 5

NOMENCLATURE.............................................................. 7

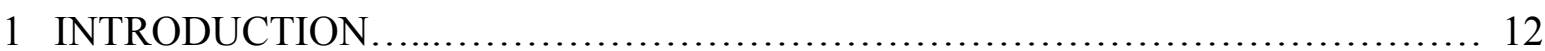

2 ESTIMATION OF FLOW MODE, FRICTION AND HEAT TRANSFER .............. 15

$2.1 \quad$ Introduction......................................................... 15

2.2 Electrical and Mechanical losses in a high-speed machine................ 16

$2.3 \quad$ Flow components.................................................... 17

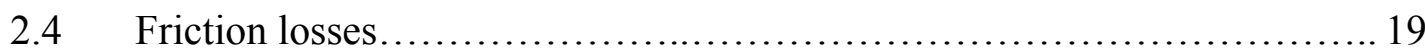

2.5 Heat transfer in an annular channel with rotating inner cylinder.............24

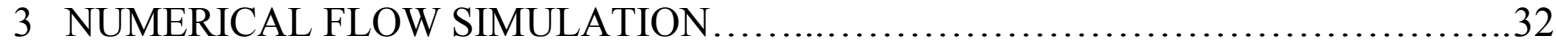

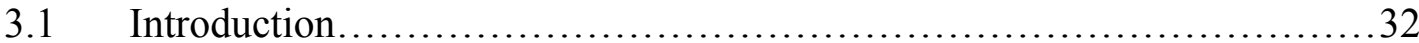

$3.2 \quad$ Finflo flow solver....................................................33

$3.3 \quad$ Flow equations............................................................ 33

3.4 Turbulence models.................................................... 36

3.5 Main dimensions, computational grid and boundary conditions............ 44

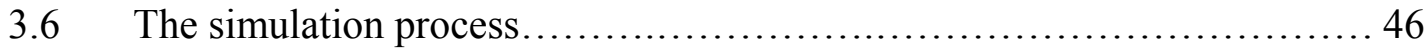

3.7 Convergence.................................................... 48

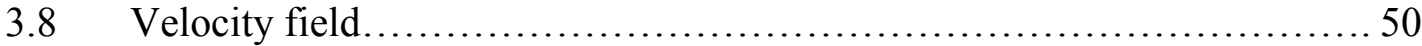

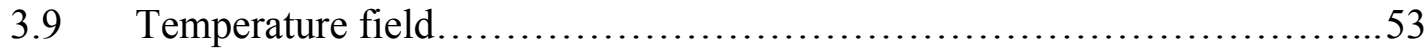

3.10 Turbulence values..................................................... 55

3.11 Summary of the velocity and temperature fields and turbulence values......57

3.12 Friction coefficient and velocity factor................................57

3.13 Local and mean heat transfer coefficients............................ 60

3.14 Results of air gap with grooved stator................................. 64

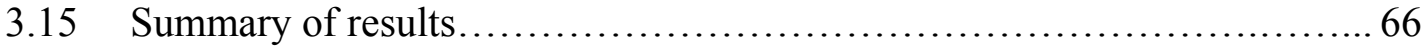


4 EXPERIMENTAL WORK ................................................... 68

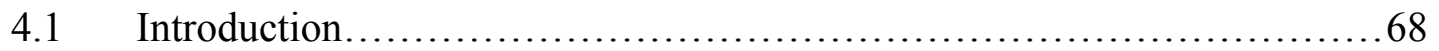

4.2 Design and implementation of measurements.............................69 69

4.2.1 Heat transfer sensors and thermocouples.......................69

4.2 .2 Telemetry.............................................. 71

4.2 .3 Calibration................................................. 72

4.2 .4 Rotor stresses............................................ 76

$4.3 \quad$ Measurements.................................................... 77

4.3.1 Introduction.............................................. 77

4.3.2 Test facility ............................................... 79

4.3.3 Measuring procedure................................... 80

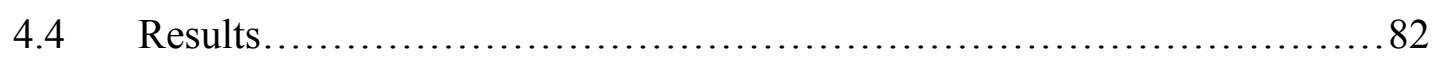

$4.5 \quad$ Errors and uncertainty.......................................... 84

4.6 Conclusions from the experimental work and comparison of the results with different methods................................................ 87

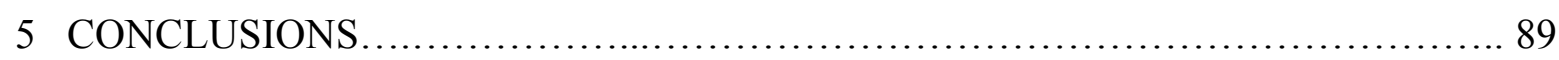

REFERENCES......................................................... 92 


\section{NOMENCLATURE}

\section{Capital letters}

\begin{tabular}{|c|c|}
\hline$A$ & area, $\mathrm{m}^{2}$ \\
\hline$A^{+}$ & constant, $k-\varepsilon$ model \\
\hline$C$ & constant, coefficient of discharge, dimensionless \\
\hline$C_{\mathrm{f}}$ & friction coefficient, dimensionless \\
\hline$C_{1}^{*}$ & rolling moment coefficient, dimensionless \\
\hline$C_{\mathrm{M}}$ & torque coefficient, dimensionless \\
\hline$C D_{\mathrm{k} \omega}$ & cross diffusion term \\
\hline$D$ & outer diameter, $\mathrm{m}$ \\
\hline E & internal (total) energy, $\mathrm{J}$ \\
\hline E & velocity approach factor, dimensionless \\
\hline$F, G, H$ & in-viscid flux vectors in the $\mathrm{x}-, \mathrm{y}$ - and $\mathrm{z}$-directions \\
\hline$F_{1}, F_{2}, F_{3}$ & functions in the $k$ - $\omega$ model \\
\hline$G r$ & Grashof number, dimensionless \\
\hline$J$ & conversion constant, 1 \\
\hline$L$ & axial air gap length, characteristic length, length of pipe, $m$ \\
\hline$M$ & torque, $\mathrm{Nm}$ \\
\hline$N$ & rotational speed, $1 / \mathrm{s}$ \\
\hline $\mathrm{Nu}$ & Nusselt number, dimensionless \\
\hline$P$ & losses, power, acceleration power, $\mathrm{W}$ \\
\hline$P$ & production of turbulent kinetic energy, $\mathrm{m}^{2} / \mathrm{s}^{3}$ \\
\hline$P_{\delta}$ & power pass air gap, $\mathrm{W}$ \\
\hline $\operatorname{Pr}$ & Prandtl number, dimensionless \\
\hline$Q$ & source term vector \\
\hline$R, R_{\mathrm{i}}$ & radius of rotor, inner radius, $\mathrm{m}$ \\
\hline $\operatorname{Re}$ & Reynolds number, dimensionless \\
\hline $\mathrm{Ra}, \mathrm{Re}_{\mathrm{a}}$ & Reynolds number of axial flow, dimensionless \\
\hline $\operatorname{Re}_{\delta}$ & Couette Reynolds number of tangential flow, dimensionless \\
\hline$S t$ & Stanton number, dimensionless \\
\hline$T$ & temperature, $\mathrm{K},{ }^{\circ} \mathrm{C}$ \\
\hline$T$ & torque, $\mathrm{Nm}$ \\
\hline$T a$ & Taylor number, dimensionless \\
\hline$U$ & vector of conservative variables \\
\hline
\end{tabular}




$\begin{array}{ll}U_{\mathrm{i}} & \text { peripheral velocity of inner cylinder, } \mathrm{m} / \mathrm{s} \\ \vec{V} & \text { velocity vector, } \mathrm{m} / \mathrm{s} \\ W & \text { axial velocity, } \mathrm{m} / \mathrm{s}\end{array}$

\section{Small letters}

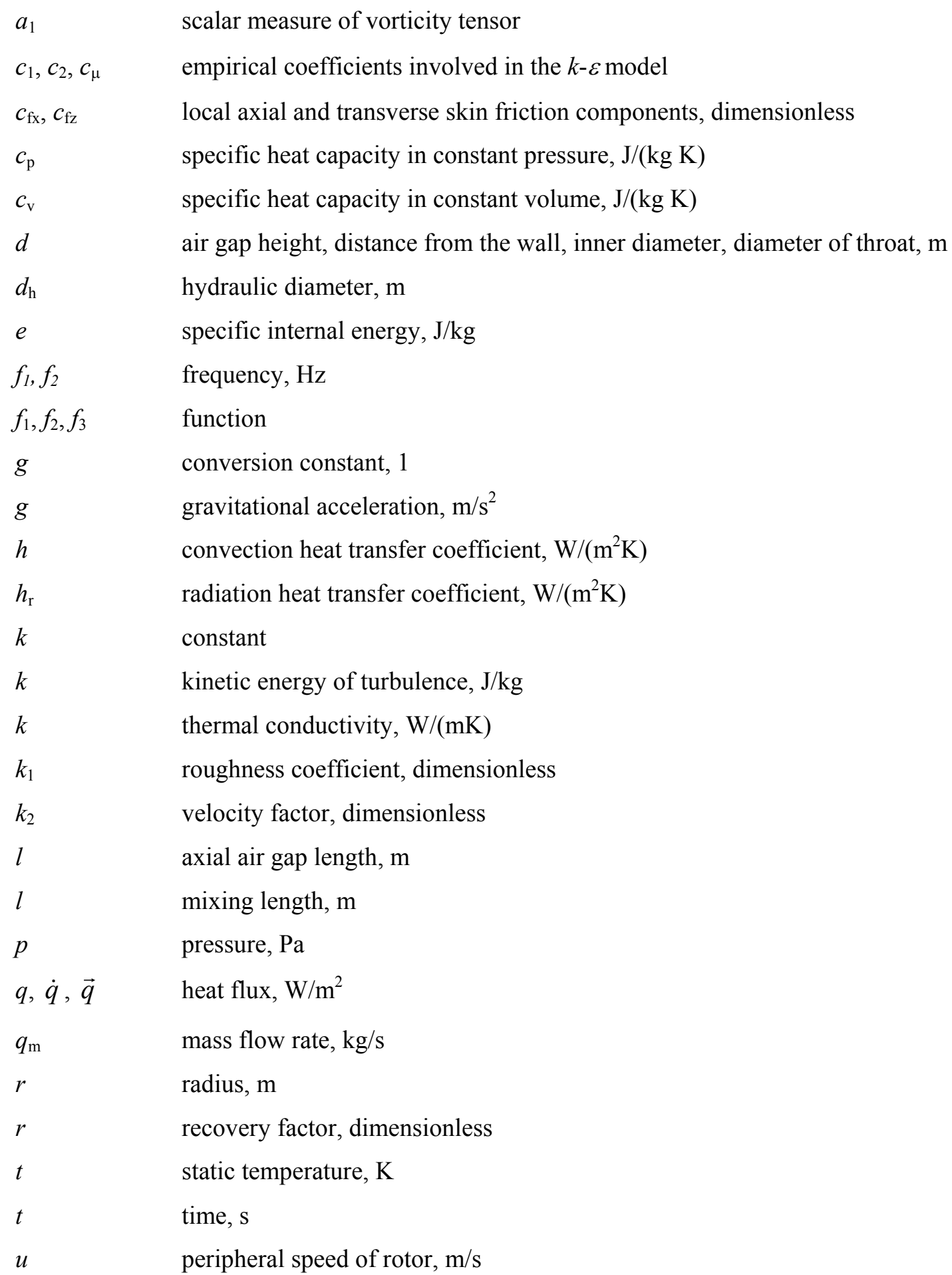




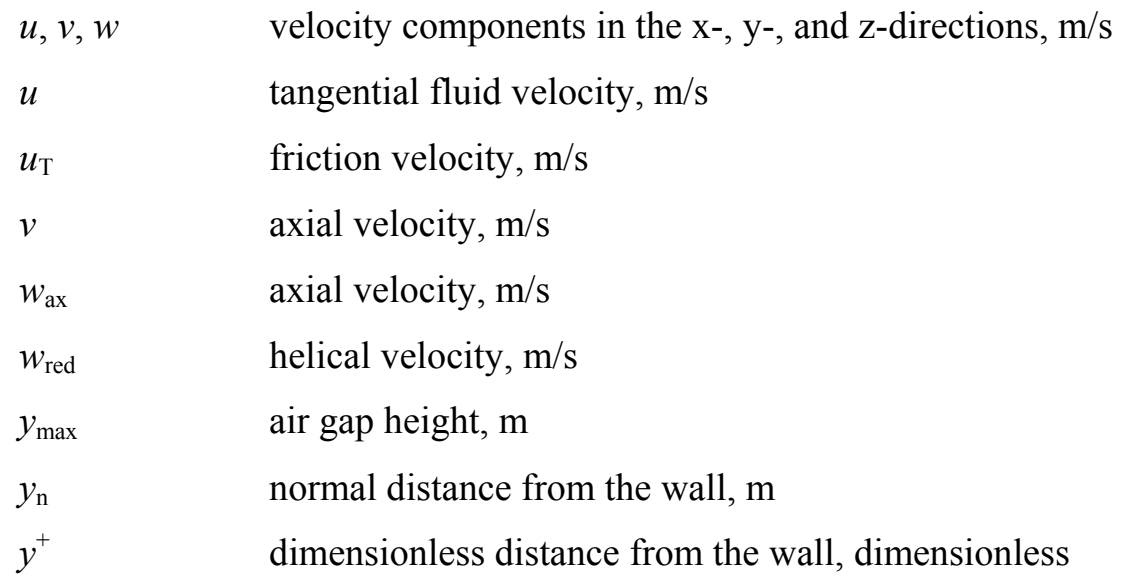

\section{Greek letters}

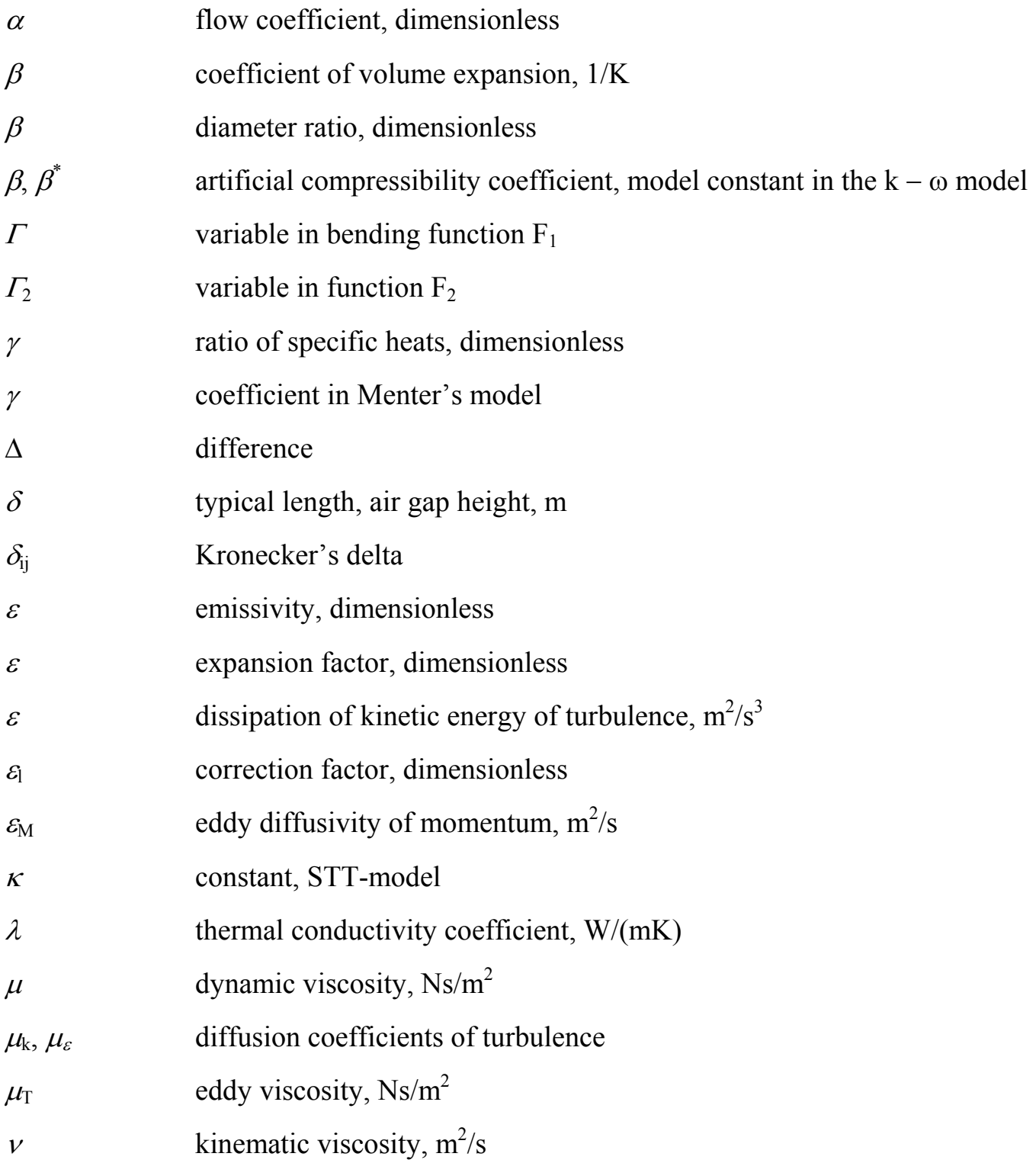




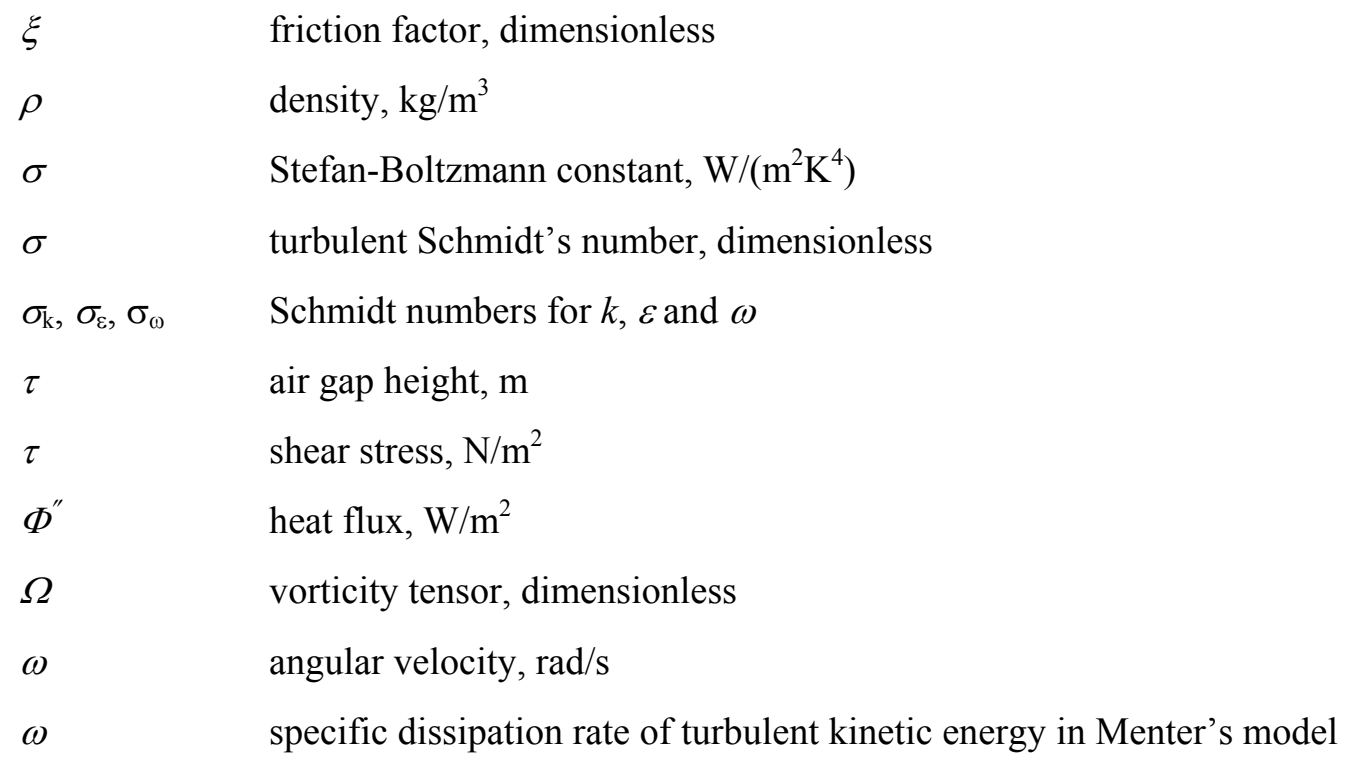

\section{Subscripts}

0

1

2

a

a

e

e

el

f

g

K

L

L

1

$\mathrm{m}$

r

ref

S

$\mathrm{S}$

$\mathrm{T}$

W reference, limit value

rotor, inner cylinder, state inside the pipe

stator, outer cylinder

adiabatic

axial

effective

net electric

electric

fluid

hot gas at free-stream condition

resistive losses

characteristic length

state in the laboratory

additional losses

mean

iron losses

reference

solid

surface

turbulent

wall 
$\begin{array}{ll}\mu & \text { friction, mechanical } \\ v & \text { viscous }\end{array}$

\section{Superscripts}

$\begin{array}{ll}\prime & \text { fluctuating component } \\ \mathrm{m}, \mathrm{n} & \text { empiric factor }\end{array}$
Abbreviations
$\mathrm{AC}$
alternating current
$\mathrm{AD}$
analogous to digital
$\mathrm{B}-\mathrm{L}$
Baldwin-Lomax
CFD
computational fluid dynamics
CPU
central processing unit
$\mathrm{CSC}$
Center for Scientific Computing
CTA
constant temperature anemometer
DA
digital to analogous
FEM finite element method
HUT Helsinki University of Technology
IR
infrared
ISA International Federation of the National Standardizing Associations
ISO International Standardization Organization
LUT Lappeenranta University of Technology
PC personal computer
$\mathrm{R} \quad$ rotor
RPM revolutions per minute
S stator
S-E semi-empiric
VDI Verein Deutscher Ingenieure 


\section{INTRODUCTION}

The department of Energy Technology at Lappeenranta University of Technology (LUT) has studied the use of high-speed technology since 1981. Several high-speed electric motors have been developed in co-operation with the department of Electrical Engineering of Helsinki University of Technology (HUT) and High Speed Tech Oy Ltd. In a previous part of the research, the friction coefficient of a high-speed test motor was measured by Saari in 1998.

This work deals with the cooling of high-speed machines, such as motors and generators, through an air gap. The typical size range, in $\mathrm{kW}$, of these asynchronous and synchronous machines can be $2-250 \mathrm{~kW}$. The rotor peripheral speed of 40-300 m/s (10 000-80 $000 \mathrm{RPM})$ has been selected. For these speeds no heat transfer data is available (e. g. Cazley 1958: 4700 RPM, Tachibana et al. 1960: 3-2840 RPM, Lee, Minkowycz 1989: 50-4000 RPM, Carew 1992: 500-1000 RPM, Hayase et al 1992: 1410 RPM, Pfitzer, Beer 1992: 50-2000 RPM, Shih, Hunt 1994: 1750 RPM, Jakoby et al. 1998: 10000 RPM). Lower rotation speeds are used in conventional electric motors. Heat flow exists from the inner to outer parts of the machine and heat transfer takes place between the rotor and stator surfaces. In the high-speed electric machine the cooling is mainly based on axial fluid flow through the air gap. Heat transfer takes place between the cooling air flow and the surfaces of the stator and the rotor.

The contribution of this thesis within the area of electric machine cooling includes enhancing the cooling air knowledge of compact electric machines by

- numeric simulation of heat transfer (local and mean heat transfer coefficients) between of the cooling air and the surfaces of the rotor and stator of a highspeed test machine at a large velocity range $(100-300 \mathrm{~m} / \mathrm{s})$

- $\quad$ solving the velocity and temperature profiles, turbulence quantities, friction coefficient and acceleration power (velocity factor) related to axial losses

- $\quad$ comparing the effects of turbulence with three turbulence models

- $\quad$ comparing the friction coefficient and velocity factor to existing semi-empiric data and the results of Saari

- attaining the mean heat transfer coefficients of the test machine by an experimental method and comparing this result to the numeric result and the result achieved with a semi-empiric equation previously used at LUT. 
A smooth rotor-stator combination is studied. Numeric simulation is done for one axial air flow velocity. The peripheral speed of the rotor is varied between $100-300 \mathrm{~m} / \mathrm{s}(30000-80$ 000 RPM). In the experiments the axial velocity of the cooling air flow is varied by four mass flow rates. The rotor peripheral speed is between $40-150 \mathrm{~m} / \mathrm{s}(10000-40000 \mathrm{RPM})$. The higher speeds are also studied by a numeric method for one mass flow rate and the lower speeds by an experimental method by four mass flow rates. The effect of the air gap height is checked with a semi-empiric equation. The coverage of the equation is also validated in the experimental part.

The numeric simulations and measurements were carried out for a high-speed induction motor, originally constructed for the testing of tilting pad gas bearings. Figure 1 presents the construction and main dimensions of the machine. The diameter and length of the rotor are 71 $\mathrm{mm}$ and $200 \mathrm{~mm}$, respectively. The inner diameter of the stator core is $75 \mathrm{~mm}$, and thus the radial air gap height is $2 \mathrm{~mm}$.

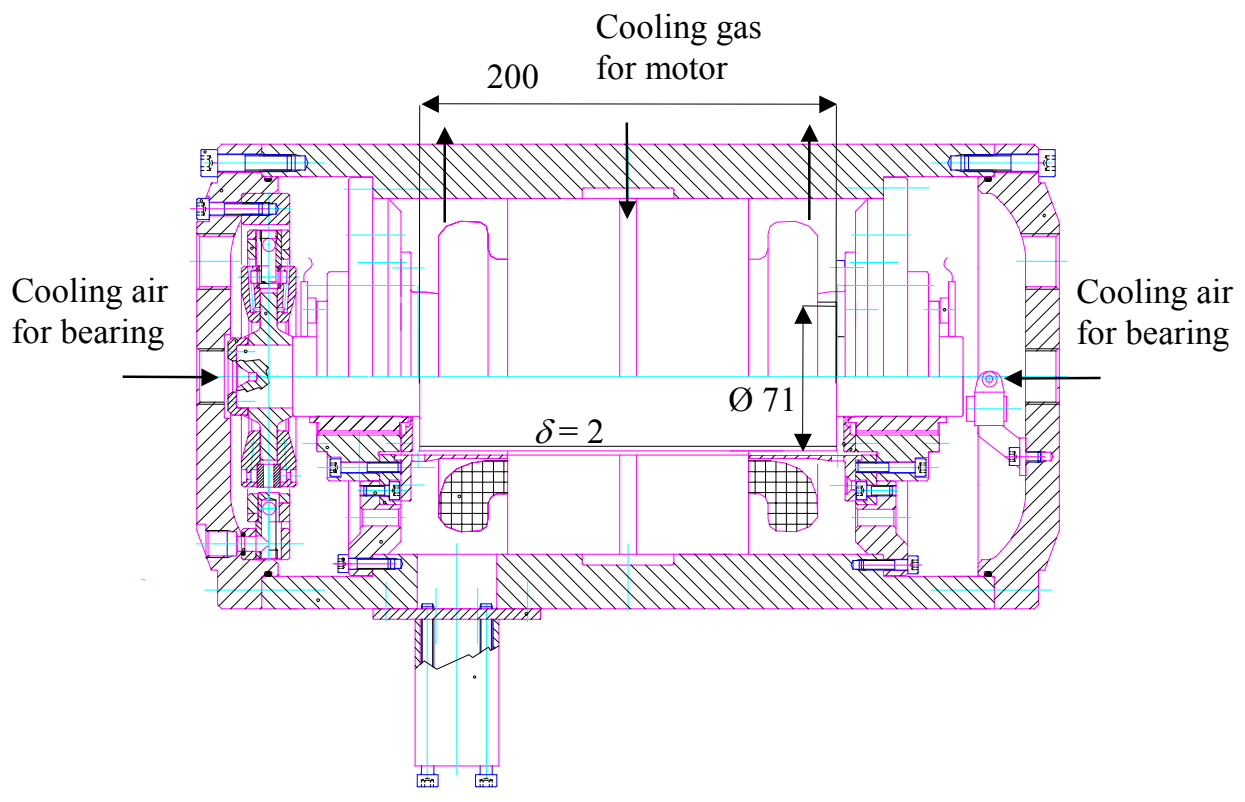

Figure 1. Constructional drawing of the test machine. The solid-rotor induction motor is equipped with gas bearings. (Saari 1998)

The test machine cooling is illustrated in figure 2a. The cooling gas is blown into the motor through a cooling duct in the middle of the stator core. After passing the air gap, the hot gas is taken out from the end winding space. In the experiments, the motor is cooled by air. The cooling through the air gap is provided with a blower. The cooling of the gas bearings is also done by air. The outlets for the cooling air are at the ends of the machine. The solid-rotor 
induction motor is equipped with gas bearings. The vertical rotor is supported with an axial gas bearing. It is maintained by a pressurized air network.

The purpose of the grooved stator slots is to increase the turbulence level and heat transfer in the air gap. The term "Open stator slots" refers to the original construction, in which there were 36 axial grooves on the stator surface. The width and depth of the grooves are shown in figure $2 \mathrm{~b}$. The variation in the depth is due to the windings in the slots. In the current tests the axial grooves were filled with industrial cement. In this study a smooth stator construction was used, and it is referred to as "closed stator slots".

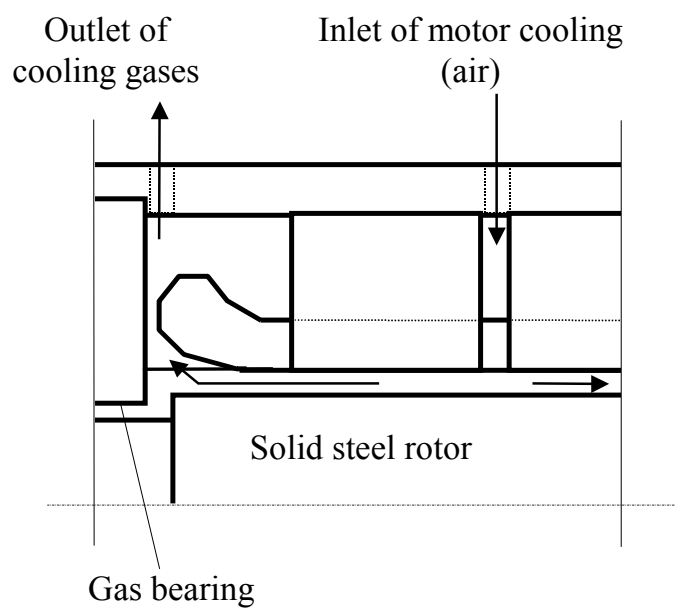

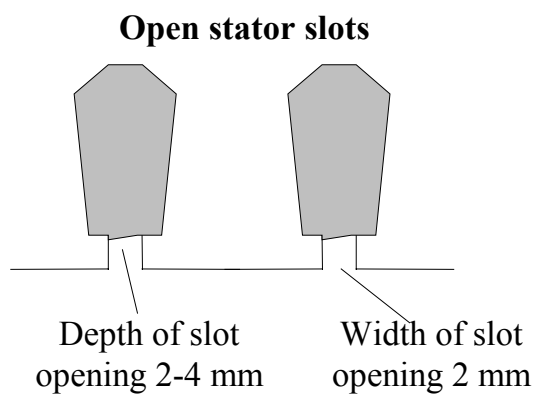

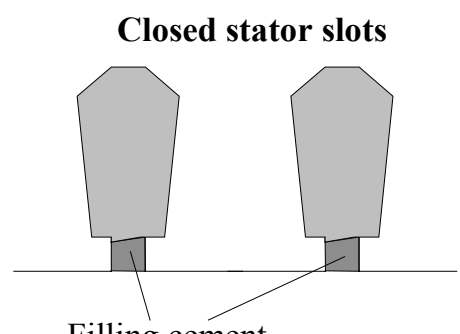

Filling cement a)

Figure 2. a) Schematic drawing of the test machine. The cooling of the electric motor is provided by a gas flow (air) through the cooling duct and air gap. b) Open and closed stator slots. (Saari 1998) 


\section{ESTIMATION OF FLOW MODE, FRICTION AND HEAT TRANSFER}

\subsection{Introduction}

A literature study is included to introduce the basic concepts of the cooling fluid in the air gap of an electric machine. Analytic and semi-empiric equations are defined to be able to compare the numeric and measured results to existing data.

First the flow components are discussed. The flow field is complex due to the interaction of inertia, buoyancy and centrifugal effects. These determine the flow pattern and heat transfer mechanism.

Frictional losses are considered between two co-centric cylinders. Determination of the friction coefficient and velocity factor for open and closed stator slots is discussed. The results of Saari (1998) are reviewed as an introduction to the study of high-speed electric machines at LUT.

The heat generation in electric motors is a direct result of the conversion from electrical and mechanical losses to heat. The heat transfer mechanisms are heat conduction, heat convection and heat radiation. Classically the problem of determining the convective heat transfer coefficient is solved by using a proper semi-empiric equation. Until recently such equations were used at LUT as well.

There is lack of scientific research papers concerning heat transfer in high-speed electric machines. Therefore attention is paid to basic parametric study of semi-empiric characteristics, non-dimensional groups and the modes of heat transfer to understand the nature of the phenomenon.

According to the literature, some research groups have developed codes to solve the flow field in test machines on lower rotation speeds. Mostly they are based on simplified Navier-Stokes equations. Because there are many uncertainties in modelling convective heat transfer by semi-empiric equations, a numeric method, Finflo flow solver, has been selected to model the air gap flow in the present study. 


\subsection{Electrical and mechanical losses in a high-speed machine}

The most dominant electric losses in conventional induction machines are the resistive losses of copper $\left(P_{\mathrm{K} 1}, P_{\mathrm{K} 2}\right)$ and magnetic flux losses of iron $\left(P_{\mathrm{r}}\right)$ (Aura, Tonteri 1986). A sankey diagram for the electrical and mechanical losses of an induction machine is presented in figure 3, where $P_{\mathrm{el}}$ is input power and $P_{\mathrm{e}}$ is output power. $P_{\mu}$ characterizes mechanical losses, $\delta$ is the height of the air gap and $P_{\delta}$ power passing the air gap. $P_{l}$ means other losses. All the mechanic losses and part of the electric losses are transferred to the helical cooling airflow between the rotor and the stator.

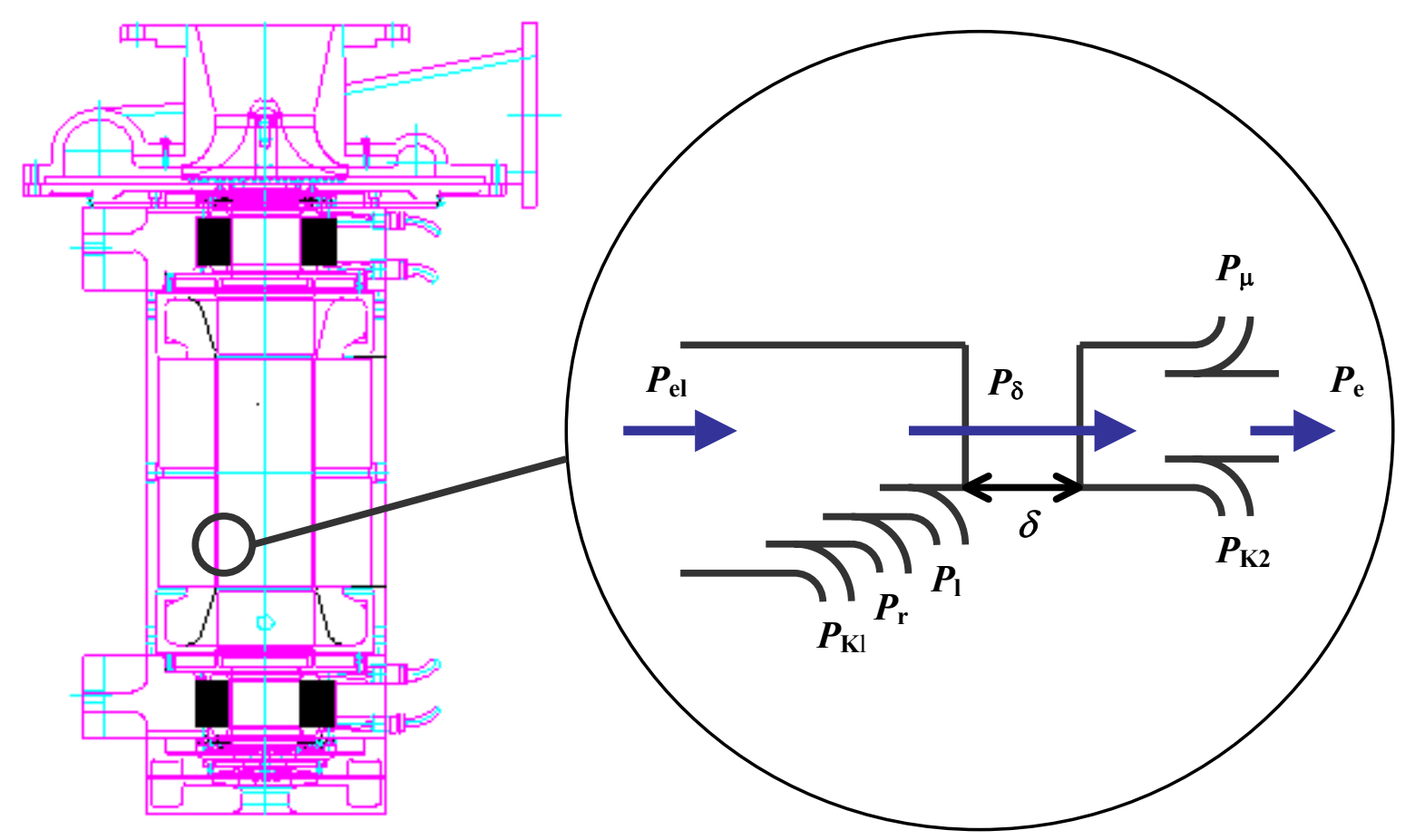

Figure 3. Electrical and mechanical losses in an induction machine.

In high-speed electric machinery the friction losses can be $40 \%$ of the total losses (Tommila 2001, private conversation). The resistive losses of copper and the magnetic flux losses of iron are design parameters when designing a new construction. The heat generation in electrical motors is a direct result of the conversion from electrical and mechanical losses to heat. In general there exists a heat flow from the inner to the outer parts of the machine. Heat transfer mechanisms are heat conduction, heat convection and heat radiation. The total heat flow into the air gap of a high-speed machine is the sum of the electric losses, friction losses and acceleration power. Related to these losses the heat transfer coefficient, the friction coefficient and the velocity factor are solved in this thesis. 


\subsection{Flow components}

The friction losses and heat transfer are set by the velocity field and gas properties. The theoretic velocity distribution in the air gap of electric machines is a result of the following flow components (Saari 1998):

- Tangential flow due to rotor rotation

- Cooling gas axial flow through the air gap

- Taylor vortices due to centrifugal forces

The importance of each flow depends on the peripheral speed of the rotor, the flow rate of the cooling gas, gas properties and air gap geometry. Typical peripheral speeds of rotors are 100$500 \mathrm{~m} / \mathrm{s}$ and the axial velocity of the cooling gas is $20-60 \mathrm{~m} / \mathrm{s}$. In the study the peripheral speed is subsonic $\left(u_{\max }=297 \mathrm{~m} / \mathrm{s}\right)$. At a lower supersonic speed no effects on the friction coefficient or the heat transfer are detected (Larjola 2002, private conversation). The force needed to blow the cooling gas through the air gap is maintained by a ventilator. The ventilator is supplied by an external power source or it is driven by an electric motor. The tangential and axial flow velocity profiles of laminar and turbulent air gap flows are presented in figure 4.

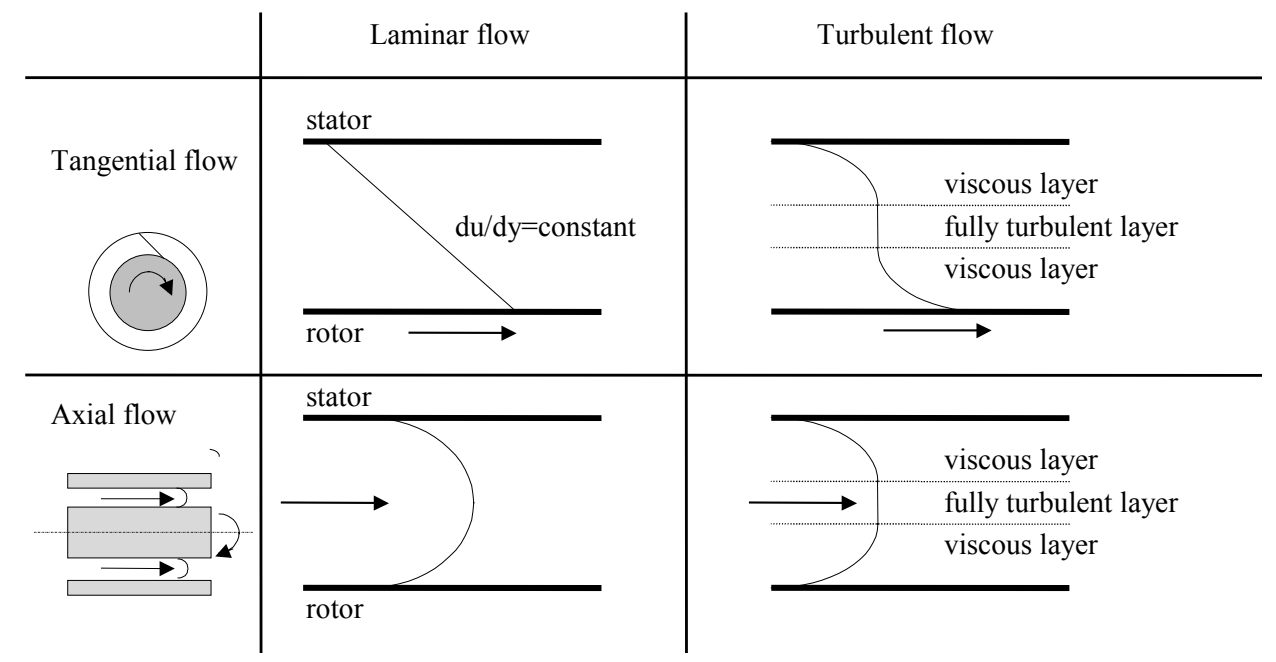

Figure 4. Tangential and axial velocity profiles of laminar and turbulent air gap flows. (Saari 1998)

The type of fluid motion is determined by the dimensionless Reynolds number. It is a ratio of inertia and viscous forces. The tangential flow is the result of the rotating rotor. Turbulence is described by the Couette Reynolds number. 


$$
\operatorname{Re}_{\delta}=\frac{\rho u_{1} \delta}{\mu}
$$

The quantity $u_{1}$ is the peripheral speed of the rotor. Axial flow through an annulus is called the Hagen-Poisseuille flow (Streeter 1985). For axial flow through the air gap the Reynolds number is

$$
\operatorname{Re}_{a}=\frac{\rho v_{m} 2 \delta}{\mu}
$$

where $v_{m}$ is the mean axial fluid velocity. It is calculated by the volume flow rate and the cross section of the air gap.

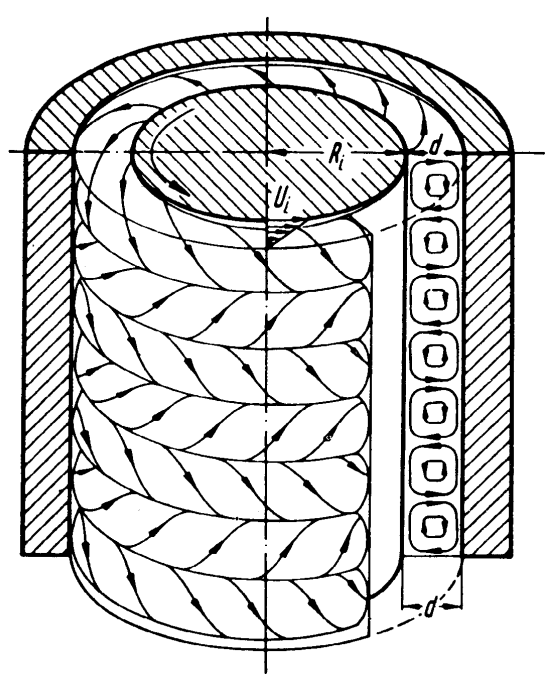

Figure 5. Taylor vortices between two concentric cylinders. Inner cylinder rotating, outer cylinder at rest. (Schlichting 1979)

Taylor vortices are circular velocity fluctuations appearing in the air gap (figure 5). They are due to the centrifugal force affecting the fluid particles. At low rotational speeds the flow is laminar, because the creation of vortices is damped by frictional force. In addition to the Couette Reynolds number, the creation of vortices depends on the radial air gap height. These parameters are included in the Taylor number (Saari 1998)

$$
T a=\operatorname{Re}_{\delta}^{2} \frac{\delta}{r_{1}}=\frac{\rho^{2} \omega^{2} r_{1} \delta^{3}}{\mu^{2}}
$$


where $\omega$ is the angular velocity and $r_{1}$ is the rotor radius. In typical applications the axial flow Reynolds number $\operatorname{Re}_{\mathrm{a}}$ is between $4457-13370\left(v_{\mathrm{m}}=20-60 \mathrm{~m} / \mathrm{s}\right)$ and the Taylor number $\mathrm{Ta}^{1 / 2}$ between $5914-13223\left(u_{1}=100-500 \mathrm{~m} / \mathrm{s}\right)$. The ratio $\delta / r_{1}$ is $0.0563(0.002 \mathrm{~m} / 0.0355 \mathrm{~m})$ in the test machine at LUT.

A very systematic and comprehensive study on Taylor-Couette flows was performed by Kaye and Elgar in 1958. Their field of application was the cooling of electric machines. The study included flow visualisations, time-dependant velocity measurements using a hot-wire anemometer, and heat transfer measurements. They identified the basic flow regimes comprising laminar flow, laminar flow with vortices, turbulent flow and turbulent flow with vortices (figure 6).

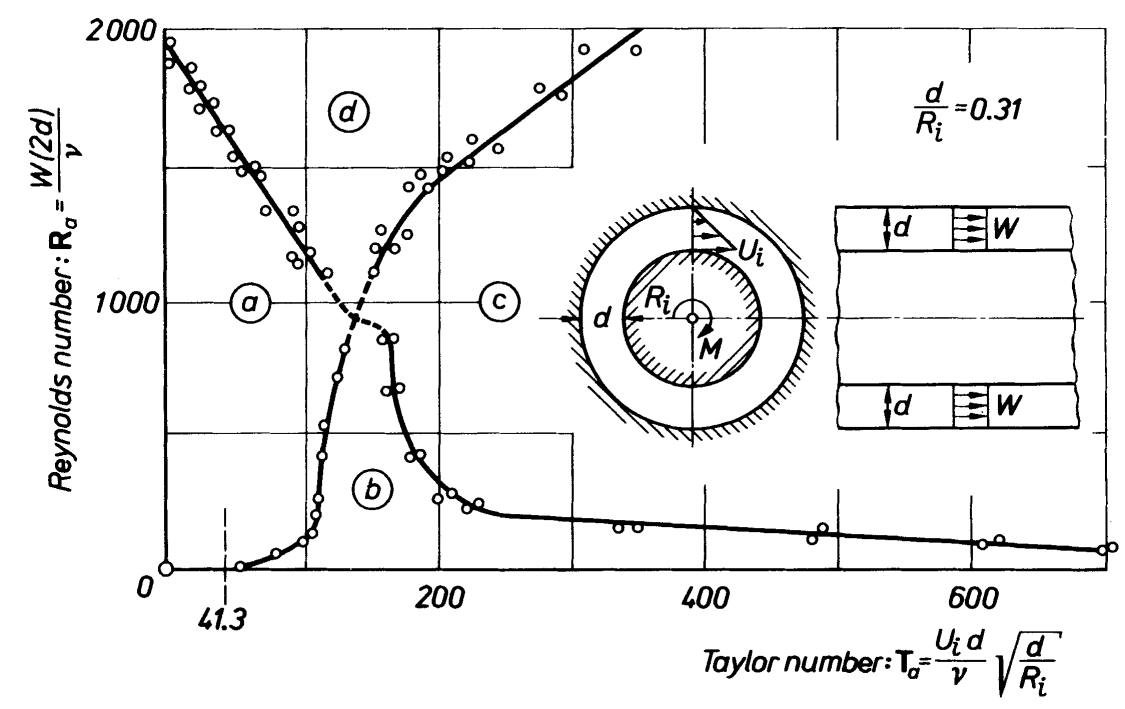

Figure 6. Ranges of laminar and turbulent flow in the annulus between two concentric cylinders. Measurements by Kaye and Elgar 1958 (Schlichting 1979): a) laminar flow, b) laminar flow with Taylor vortices, c) turbulent flow with vortices and d) turbulent flow.

\subsection{Friction losses}

The tangential force per area is described as shear stress. When we consider laminar flow between two co-centric cylinders, the shear stress has the equation (Saari 1998)

$$
\tau=\rho v r\left(\frac{u}{r}\right)
$$


where $v$ is the molecular viscosity, $r$ is the radius and $u$ is the tangential fluid velocity. In fully turbulent flows, the shear stress is set by the chaotic motion of fluid particles, and the fluidviscosity is a minor factor. The shear stress for turbulent flow is written into the form

$$
\tau=\rho\left(v+\varepsilon_{M}\right) r\left(\frac{u}{r}\right)
$$

where $\varepsilon_{\mathrm{M}}$ is the eddy diffusivity of momentum. It is increased when the distance from the wall increases. In order to calculate equation 5 one should know the velocity distribution and eddy diffusivity in the flow. There are no complete models for turbulence, and these factors are therefore based on measured data (Saari 1998).

The frictional drag is usually defined by an unitless friction coefficient. It is an empirical coefficient depending on many factors, such as the nature of flow and the surface quality. For a rotating cylinder, the friction coefficient is (Saari 1998)

$$
C_{f}=\frac{\tau_{1}}{\frac{1}{2} \rho u_{1}^{2}}
$$

where $\tau_{1}$ is the shear stress on the rotor surface. By using equation 6 and the definition of the torque, we can write

$$
T=C_{f} \rho \pi \omega^{2} r_{1}^{4} l
$$

to friction torque where $l$ is the axial air gap length. Equation 7 gives the torque acting on the rotor.

\section{Friction coefficient of rotating cylinder}

One of the earliest studies dealing with the friction torque of rotating cylinders was published by Wendt (1933). Three different cylinders were tested at Couette Reynolds numbers up to $10^{5}$. Pure water and water-glycerol mixtures were used in the experiments. Wendt's measured data fit well with the following equations (Saari 1998): 


$$
\begin{gathered}
C_{f}=\frac{0.46\left(\frac{\left(r_{2}-r_{1}\right) r_{2}}{r_{1}^{2}}\right)^{0.25}}{\operatorname{Re}_{\delta}^{0.5}} \quad \quad\left(400<\mathrm{Re}_{\delta}<10^{4}\right) \\
C_{f}=\frac{0.073\left(\frac{\left(r_{2}-r_{1}\right) r_{2}}{r_{1}^{2}}\right)^{0.25}}{\operatorname{Re}_{\delta}^{0.3}} \quad\left(10^{4}<\operatorname{Re}_{\delta}<10^{5}\right)
\end{gathered}
$$

where $r_{2}$ is the inner radius of the outer cylinder.

Bilgen and Boulos (1973) have measured the friction torque of enclosed smooth cylinders having Couette Reynolds numbers between $2 \times 10^{4}$ and $2 \times 10^{6}$. On the basis of their own measurements and experiments by some other authors, they developed equations for friction coefficient. In the turbulent region, the friction coefficients are (Saari 1998)

$$
\begin{array}{ll}
C_{f}=0.515 \frac{\left(\frac{\delta}{r_{1}}\right)^{0.3}}{\operatorname{Re}_{\delta}^{0.5}} & \left(500<\mathrm{Re}_{\delta}<10^{4}\right) \\
C_{f}=0.0325 \frac{\left(\frac{\delta}{r_{1}}\right)^{0.3}}{\operatorname{Re}_{\delta}^{0.2}} & \left(10^{4}<\operatorname{Re}_{\delta}\right)
\end{array}
$$

The friction and gas-flow losses have been studied experimentally by Saari (1998). The analysis focused on the motor air gap where a large part of these losses are located. The friction coefficient in the air gap was calculated using equations 8-9.

The gas flow losses were analysed according to equation 10 (Polkowski 1984) by Saari (1998).

$$
T=\frac{2}{3} \pi \rho\left(r_{2}^{3}-r_{1}^{3}\right) v_{m} u_{m}
$$

where $v_{\mathrm{m}}$ and $u_{\mathrm{m}}$ are the mean axial and tangential fluid velocities, respectively. Equation 10 
assumes that the cooling fluid has only an axial velocity component before entering the air gap. The mean tangential velocity is usually expected to be half of the surface speed of the rotor. The friction loss in the air gap follows equation 11 (Saari 1998)

$$
P=k_{1} C_{f} \rho \pi \omega^{3} r_{1}^{4} l
$$

where the friction coefficient $C_{\mathrm{f}}$ is defined by equation $6 . C_{\mathrm{f}}$ is also calculated by the Finflo program via sector torques (equations 7 and 11) on various rotational speeds. $k_{1}$ is the roughness coefficient, which is 1.0 for smooth surfaces. The friction losses of the air-cooled test motor measured by Saari in 1998 are presented in figure 7.

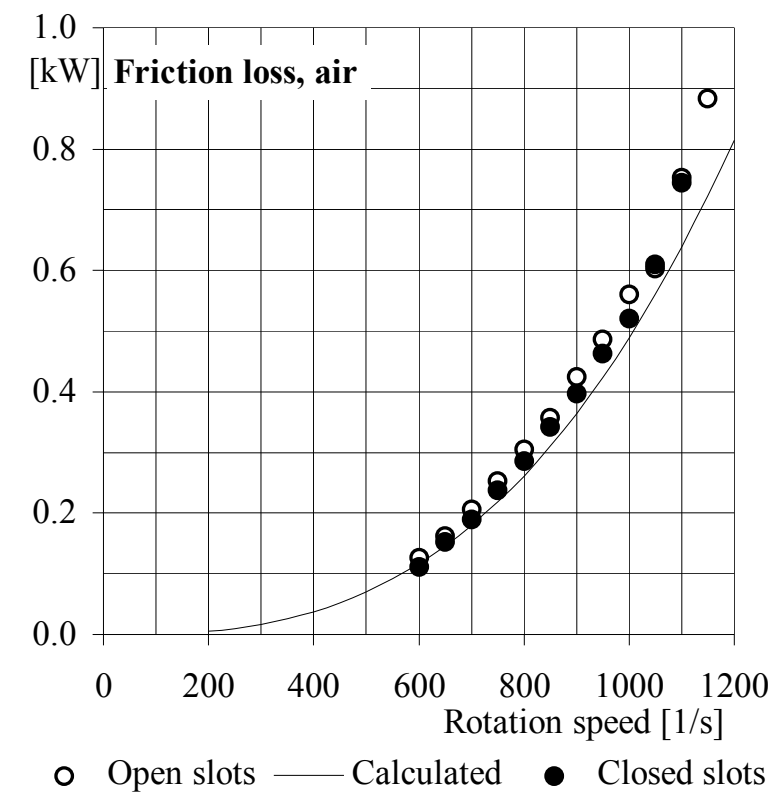

Figure 7. Friction losses in the air gap of the air-cooled test motor. The coolant flow is zero. The roughness coefficient is 1.0 in the calculated friction-loss curve. The curve corresponds to the temperature of $50^{\circ} \mathrm{C}$ and pressure of 1.013 bar in the air gap. (Saari 1998)

Large losses may be associated with the coolant flow through the air gap of a high-speed motor. Based on equation 10, we can express the gas flow losses by the equation

$$
P=\frac{2}{3} \pi \rho\left(r_{2}^{3}-r_{1}^{3}\right) v_{m} u_{m} \omega
$$


Equation 12 assumes that the coolant flow does not have a tangential velocity component before entering the air gap. The final tangential velocity is related to the peripheral speed of the rotor.

$$
u_{m}=k_{2} u_{1}
$$

where $k_{2}$ is the velocity factor (Saari 1998). If we assume that both air gap surfaces are smooth, we obtain the value 0.48 for the velocity factor (Polkowski 1984, Dorfman 1963). This is, however, a purely theoretical value. The real value is much lower, as can be seen in the figures below. By assuming that the air gap is very small, $\left(r_{1} \rightarrow r_{2}\right)$, equation 12 can be written into a more practical form (Saari 1998)

$$
P=k_{2} q_{m}\left(\omega r_{1}\right)^{2}
$$

where $q_{\mathrm{m}}$ is the mass flow rate of the air gap gas. This is one definition of acceleration power. It is also related to the axial losses through the air gap. The aim of the experiments by Saari (1998) was to measure the roughness coefficient $k_{1}$ and velocity factor $k_{2}$ in the air gap of the LUT high-speed electric motor, see figures $8 \mathrm{a}$ and $8 \mathrm{~b}$.

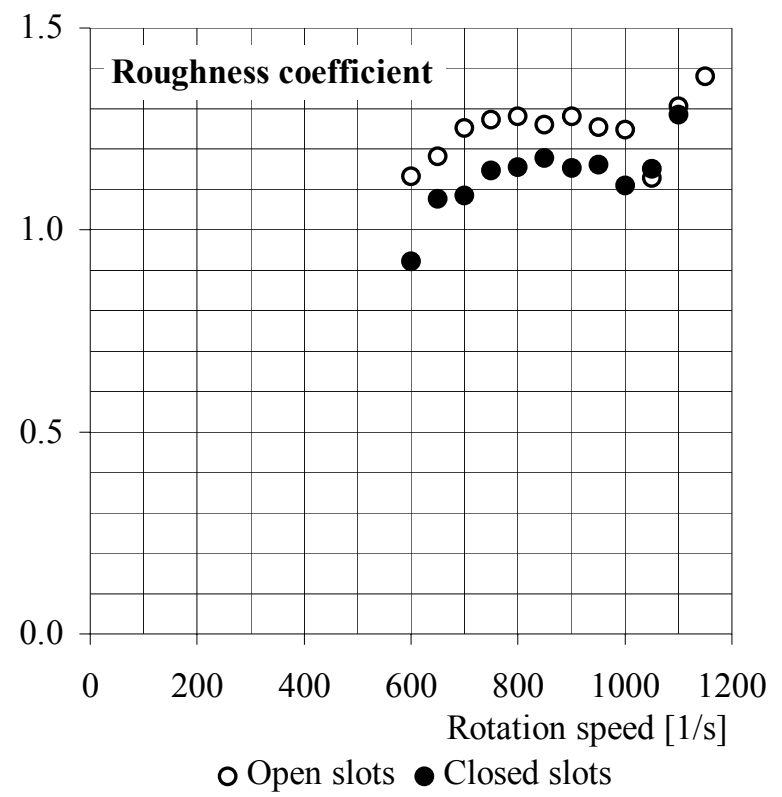

a)

Figure 8. a) Roughness coefficient $k_{1}$ of air and b) velocity factor $k_{2}$ of R134a in the air gap. The curves correspond to a temperature of $50^{\circ}$ and pressure of 1.013 bar. The mean velocity factor is 0.15 when the stator slots are open and 0.18 when they are closed. (Saari 1998) 


\subsection{Heat transfer in an annular channel with rotating inner cylinder}

\section{Introduction to the problem}

Motor temperature is linked to the life and performance of the $\mathrm{AC}$ induction machine. The winding temperature of the stator directly impacts the durability of the insulation system. The temperature distribution developed through the motor housing as part of the waste heat rejection path can also affect bearing temperatures and lead to reduced load capacity or fatigue life. Since the electrical resistance of most common motor winding materials is highly temperature dependent, the final operating temperature of the machine affects motor losses and efficiency. The task of motor designers is to maximize the performance of the motor while minimizing cost (Liao et al. 1999). In the study of Liao et al. (1999) the average stator temperature was decreased by $8{ }^{\circ} \mathrm{C}$ by increasing the thermal conductivity on the stator winding.

In spite of its technological importance, little work has been directed toward the study of heat transfer within rotating cylindrical annuli (Ball et al. 1989). The flow fields in such systems are complex due to the interaction of the inertia, buoyancy and the centrifugal effects. In a heated rotating system the buoyancy and the centrifugal forces are of major importance. The resulting combination of these determines the flow pattern and the heat transfer mechanism (Yang and Farouk 1992). In the internal air systems of gas turbine engines or generators, a large variety of different types of annular channels with rotating cylinders are found. Even though the geometry is very simple, the flow field in such channels can be completely threedimensional and also unsteady. From the literature it is well known that the basic twodimensional flow field breaks up into a pattern of counter rotating vortices as soon as the critical speed of the inner cylinder is exceeded (figures 5 and 6). The presence of a superimposed axial flow leads to a helical shape of the vortex pairs moving through the channel (Jakoby et al. 1998).

In such a problem as the flow in the air gap, we are interested in modeling the total system of the conduction in the solid wall and convection in the fluid. This kind of problem is known as a conjugate heat transfer problem (Shaw 1992). In this work the conduction through walls is, however, considered using constant temperatures at walls. According to previous findings there exist different flow modes, forces and heat transfer forms in the cooling fluid flow. 


\section{Heat transfer by convection and conduction}

Heat convection occurs at the surface between a solid and a fluid and can be expressed by Newton's cooling law (Incropera, DeWitt 1996, Kaltenbacher, Saari 1992):

$$
\Phi^{\prime \prime}=h\left(T_{S}-T_{f}\right)
$$

where $\Phi^{\prime \prime}$ is the heat flow normalized to the cross section, $h$ the heat transfer coefficient, $T_{\mathrm{S}}$ the temperature of solid and $T_{\mathrm{f}}$ the temperature of fluid.

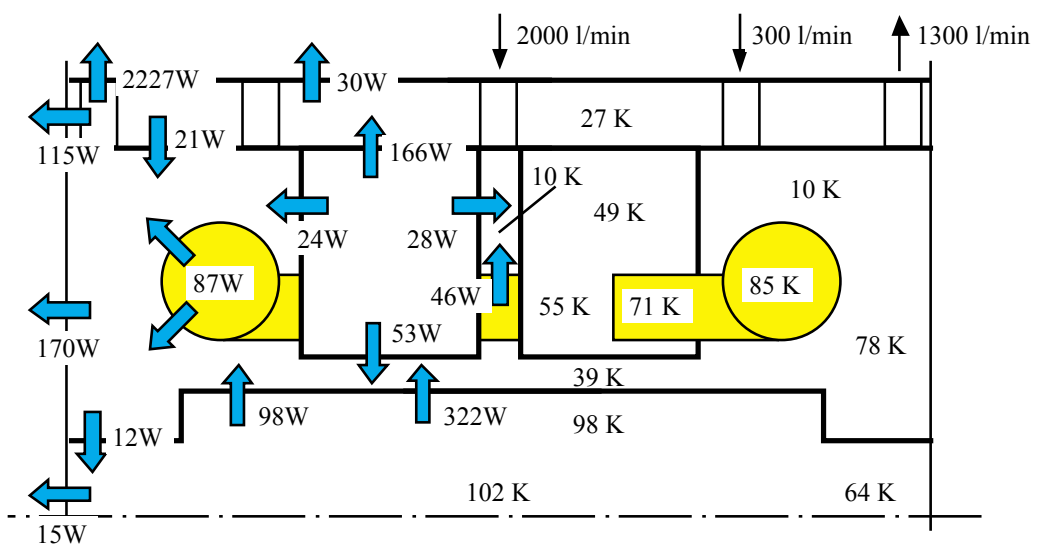

Figure 9. Temperature rises and the heat and volume flows of a high-speed electric motor. The input power of the machine is $50.5 \mathrm{~kW}$ and the rotational speed $99850 \mathrm{RPM}$. The total volume flow of the coolant is $2600 \mathrm{1} / \mathrm{min}$, of which $2000 \mathrm{1} / \mathrm{min}$ goes through the air gap. (Saari 1995)

The local temperature rise and the heat and volume flows in the cooling of a typical highspeed electric motor are presented in figure 9. The rate of heat transfer is dependent on the following variables and effects (Becker and Kaye 1962)

1. Speed of the rotor (inner cylinder)

2. Axial velocity of air in the annulus

3. Temperature gradients at the walls of the annulus

4. Entrance effects or degree of development of thermal and velocity boundary layers

5. Surface roughness 
There are several non-dimensional groups that are useful when considering heat transfer problems. These are

- the Prandtl number, which is defined as

$$
\operatorname{Pr}=\frac{\mu c_{p}}{k}
$$

and can be seen to be the ratio of viscous diffusion of momentum to thermal diffusion through conduction. Typical values of $\operatorname{Pr}$ for gases are 0.65 to 1 , with air having the value about 0.7 . By comparison water has the value of about 6.0 at room temperature (Shaw 1992).

- the Nusselt number, which is defined as

$$
N u=\frac{h d}{k}
$$

where $d$ is a typical length and $h$ is the heat transfer coefficient defined as the surface flux of heat $\dot{q}$ divided by some temperature difference, i.e.

$$
h=\frac{\dot{q}}{T_{s}-T_{f}}
$$

where $T_{\mathrm{s}}$ is the temperature of the surface and $T_{\mathrm{f}}$ is a reference temperature, say of the fluid surrounding the surface. The Nusselt number is a non-dimensional measure of heat transfer through a surface (Shaw 1992).

- the Grashof number, which is defined as

$$
G r=\frac{g d^{3} \beta \Delta T}{v^{2}}
$$


where $g$ is the acceleration due to gravity, $d$ is a typical length, $\beta$ is the coefficient of volume expansion, $\Delta T$ is the temperature difference and $v$ is the kinematic viscosity. This parameter is used to characterize natural convection problems (Shaw 1992).

Another non-dimensional heat transfer coefficient, the Stanton number, can be formed from $\mathrm{Nu}, \mathrm{Re}$, and $\mathrm{Pr}$ :

$$
\begin{aligned}
& S t=\frac{N u}{\operatorname{Re} \operatorname{Pr}} \\
& S t=\frac{1}{2} C_{f}
\end{aligned}
$$

Equation 21 is the formal statement of Reynolds' analogy for fluids of $\operatorname{Pr} \approx 1$.

Many of the fundamental relations correlating convective heat transfer are based on the simple statement made by Osborne Reynolds that the heat transfer coefficient in certain classes of fluid flow is a simple multiple of the skin friction coefficient. It can be derived by modelling the velocity and temperature profiles in an 'attached' boundary layer — in other words, in an unseparated flow (Wilson 1985).

According to Welty et al. (1976), we have obtained the following possible forms for convection data through dimensional-analysis considerations.

Forced convection

$$
N u=f_{1}(\mathrm{Re}, \operatorname{Pr})
$$

or

$$
S t=f_{2}(\operatorname{Re}, \operatorname{Pr})
$$

Natural convection

$$
N u=f_{3}(G r, \operatorname{Pr})
$$

The similarity between equations $22 \mathrm{a}$ and $22 \mathrm{~b}$ is apparent. In equation $22 \mathrm{~b} G r$ has replaced $\mathrm{Re}$ in the equation indicated by equation 22a. It should be noted that the Stanton number can be used only in correlating forced convection data (Welty et al. 1976). 
For compressible flow, there is dissipation of kinetic energy into thermal energy by viscous shear within the boundary layer. This is characterized by an increase in the static temperature $t_{\mathrm{g}}$ near the wall, as shown in figure 10. The Prandtl number is the ratio of the viscosity (responsible for energy dissipation) to the thermal diffusivity (mechanism allowing heat to escape from the boundary layer). This would suggest that for a given free-stream kinetic energy, a high Prandtl number should lead to a high adiabatic wall temperature, and vice versa. This dissipation of kinetic energy is related to the recovery factor $r$ defined by the following equation:

$$
T_{g, e}=T_{w, a}=t_{g}+r \frac{u_{g}^{2}}{2 c_{p}}
$$

where $T_{\mathrm{g}, \mathrm{e}}$ is the effective gas temperature or adiabatic wall temperature, and $T_{\mathrm{w}}$, a, is the temperature the wall would reach if it were uncooled and is, therefore, a measure of the viscous heating in the boundary layer (Glassman 1975).

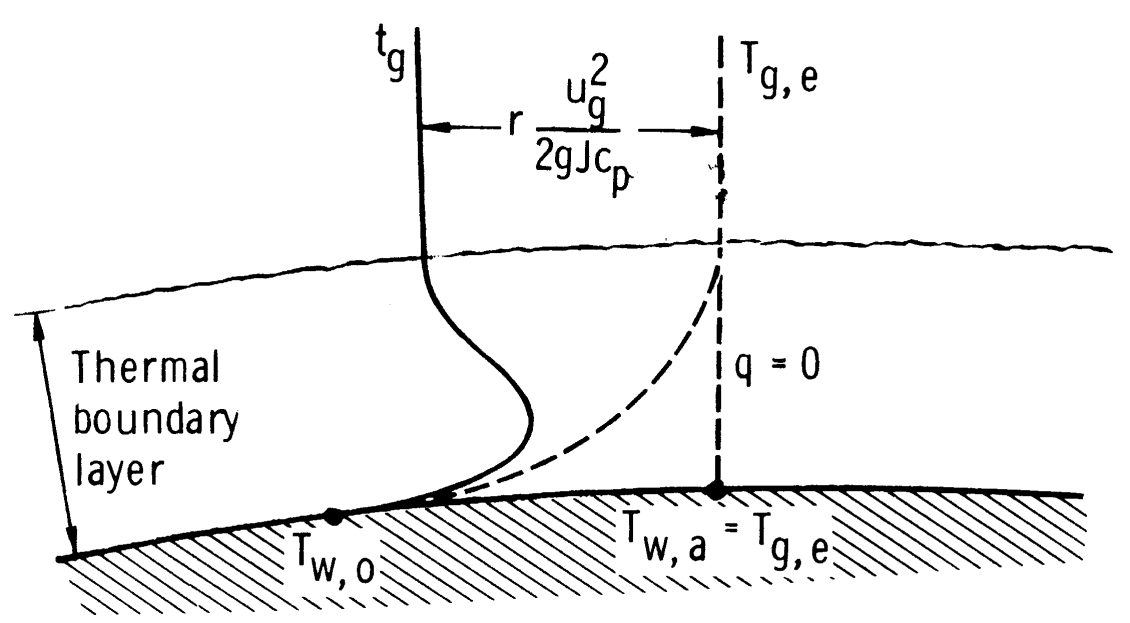

Figure 10. Temperature distribution in a high-velocity boundary layer (Glassman 1975).

The problem in determining the heat flux from the main parts of the high-speed electric machine to the cooling air flow is to find a suitable expression for the heat transfer coefficient $h$. Classically this is done by using semi-empirical equations. A number of schemes can be used, but in general 


$$
h=C \operatorname{Re}_{L}^{m} \operatorname{Pr}^{n}
$$

where $C$ is the constant dependent on coolant-passage geometry, and $\operatorname{Re}_{\mathrm{L}}$ is the Reynolds number based on characteristic length $L$ (Glassman 1975). The laminar contribution to molecular diffusivity of heat and momentum is straightforward, but our limited understanding of turbulent flow requires the use of various assumptions in describing the turbulent counterpart (Glassman 1975).

Until recently the following equation was used at LUT to calculate convective heat transfer in the air gap of a high-speed electric machine (VDI-Wärmeatlas 1988, Larjola et al. 1990).

$$
\begin{aligned}
& N u=0.0214\left(\operatorname{Re}^{0.8}-100\right) \operatorname{Pr}^{0.4}\left[1+\left(\frac{d_{h}}{L}\right)^{0.66}\right] \\
& N u=\frac{h d_{h}}{k} \quad \operatorname{Re}=\frac{\rho w_{r e d} d_{h}}{\mu} \\
& d_{h}=\tau \sqrt{\frac{8}{3}} \quad w_{\text {red }}=\sqrt{\left(\frac{\omega R}{2}\right)^{2}+w_{a x}^{2}}
\end{aligned}
$$

where $d_{h}$ is hydraulic diameter, $L$ and $\tau$ air gap length and height. $w_{\text {red }}$ is the reduced velocity in the helical direction $\left(10^{4}<\operatorname{Re}<10^{6}, 0.7<\operatorname{Pr}<1.0\right.$, Larjola et al. 1990) in the air gap. The coverage of equation 26 when solved as rotation speed depends on the height of the air gap, the density of the gas, the viscosity and the axial velocity $(3361 / \mathrm{s}<\mathrm{N}<491721 / \mathrm{s}, 75 \mathrm{~m} / \mathrm{s}<$ $\left.u_{1}<10968 \mathrm{~m} / \mathrm{s}\right)$. The high rotational flow increases the turbulence level of the flow and the equation is valid on lower speeds as well (Larjola 2002, private conversation). The $N u$ equation is for the heat transfer in turbulent flow through pipes (VDI-Wärmeatlas 1988). The equation of the hydraulic diameter is based on the LUT assumption that heat transfer takes place into the middle flow of the air gap and the assumption of the hydraulic diameter as area / perimeter (Larjola et al. 1990). The equation of reduced velocity is based on trigonometry and the assumption that the velocity of the gas is the one half of the peripheral speed of the rotor. As an example, using equation 26 yields magnitudes $260-1080 \mathrm{~W} /\left(\mathrm{m}^{2} \mathrm{~K}\right)$ for the mean 
heat transfer coefficients for the studied rotation speeds between 10 000-80 000 RPM (167$1333 \mathrm{1} / \mathrm{s}$ ). The axial velocity $w_{\mathrm{ax}}=40 \mathrm{~m} / \mathrm{s}$ is used in the example. These empirical values as a function of rotation speed and air gap heights $\tau$ of $1 \mathrm{~mm}, 2 \mathrm{~mm}$ and $4 \mathrm{~mm}$ are shown in figure 11. The medium properties for air in this example are calculated at $760 \mathrm{mmHg}, 50{ }^{\circ} \mathrm{C}$ using the incompressible flow assumption according to Pfitzer and Beer (1992). On these speeds the Couette Reynolds number $\operatorname{Re}_{\delta}$ is varied between 4500-33500 (9946 $<\operatorname{Re}<54654, \tau=2 \mathrm{~mm}$ ).

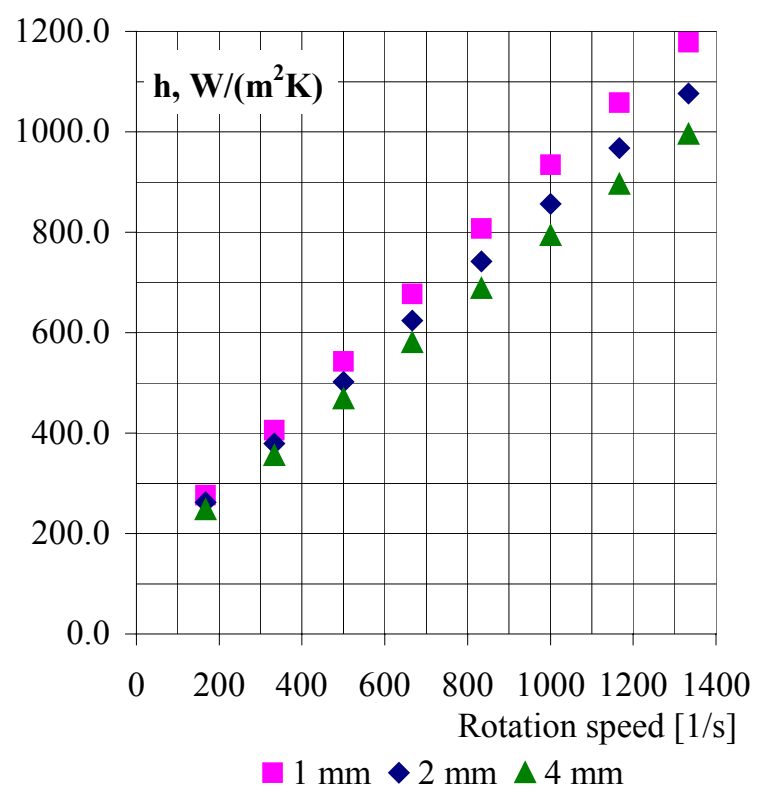

Figure 11. Semi-empiric heat transfer coefficients as a function of rotation speed. The rotation speed is varied between $10000-80000 \mathrm{RPM}(167-1333 \mathrm{~Hz})$. The air gap heights are $1 \mathrm{~mm}, 2 \mathrm{~mm}$ and $4 \mathrm{~mm}$.

The heat flux from the rotor or the stator is proportional to the temperature gradient (either effective or static gas temperature) at the wall:

$$
q=-\left.k_{g} \frac{\partial t}{\partial y}\right|_{y=0}=-\left.k_{g} \frac{\partial T_{g, e}}{\partial y}\right|_{y=0}=h_{g, x}\left(T_{g, e}-T_{w, 0}\right)
$$

where $k_{\mathrm{g}}$ is the effective thermal conductivity of the gas (Glassman 1975).

\section{Heat transfer by radiation}

According to Incropera et al. (1996) the radiative heat transfer between the long concentric cylinders is: 


$$
q_{12}=\frac{\sigma A_{1}\left(T_{1}^{4}-T_{2}^{4}\right)}{\frac{1}{\varepsilon_{1}}+\frac{1-\varepsilon_{2}}{\varepsilon_{2}}\left(\frac{r_{1}}{r_{2}}\right)}
$$

where the lower indexes correspond to respective surfaces. A surface radiative property known as emissivity $\varepsilon$ may be defined as the ratio of the radiation emitted by the surface to the radiation emitted by a blackbody at the same temperature. In the conditions of the highspeed electric machine $\left(T_{1}=150{ }^{\circ} \mathrm{C}, T_{2}=100{ }^{\circ} \mathrm{C}, r_{1}=0.0355 \mathrm{~m}, r_{2}=0.0375 \mathrm{~m}, A_{1}=\right.$ $0.022305 \mathrm{~m}^{2}$ ) equation 28 gives the value $q_{12}=9.72 \mathrm{~W}$ when $\varepsilon_{1}=\varepsilon_{2}=0.75$. The radiation heat transfer coefficient $h_{\mathrm{r}}=q_{12} / A_{1}\left(T_{1}-T_{2}\right)$ is $8.71 \mathrm{~W} /\left(\mathrm{m}^{2} \mathrm{~K}\right)$ (Holman 1989). Also very small heat transfer between the rotor and the stator by radiation is expected. In accordance with Sissom et al. (1972) many common gases and mixtures have a non-polar symmetrical molecular structure and so do not emit or absorb radiant energy within temperature limits of interest. Included among these are oxygen, nitrogen, hydrogen, and mixtures of them, such as dry air.

\section{Comparing the importance of the different ways of heat transfer}

Within a given situation, all three modes of heat transfer might occur. For example, the heat might flow through a solid by conduction and then be transferred into a fluid where it is convected away with the fluid, and if, say, flames are present they will radiate heat energy all around. However, in the context of fluid flow, it is convection that is most important and so we will concentrate on this mode of heat transfer (Shaw 1992). Numerical examples are given for equations 26 and 28. In many instances the convection heat transfer coefficient is not strongly dependent on temperature. Obviously, the radiation coefficient is a very strong function of temperature (Holman 1989). This information is useful in the experimental part of the present work. Measuring the convective heat transfer is not strongly dependent on temperatures at walls with varying inlet cooling fluid temperatures. The heat transfer is confined to the boundary layer region very near the surface, where large velocity and temperature gradients are present (Glassman 1975). Because there are many uncertainties in modelling the convective heat transfer by semi-empirical equations, the Finflo flow solver has been selected to model the air gap flow. 


\section{NUMERICAL FLOW SIMULATION}

\subsection{Introduction}

Thermal modelling of $\mathrm{AC}$ induction motors using computational fluid dynamics has been done by Liao et al. (1999). They applied the commercially available CFD tool, the Fluent code, to the modelling of the whole motor. The conjugate solution included the temperature distribution and fluid flow solution. The results were compared to test data and found to be in good agreement. Thermal analysis of a large permanent magnet synchronous motor has been performed using the TMG Thermal Analysis ${ }^{\mathrm{TM}}-3 \mathrm{D}$ heat transfer module by Negrea and Rosu (2001). Using finite difference control volume technology, TMG makes it easy to model nonlinear and transient heat transfer processes including conduction, radiation, free and forced convection, fluid flow and phase angle. In the work of Negrea and Rosu (2001) the convective heat transfer coefficients based on the semi-empiric equations found from the literature were given as input data.

The numerical part of this work consists of the results of the Finflo software calculations based on the Reynolds-averaged Navier-Stokes equations applied to air gap simulation. The main goal is to solve the heat transfer coefficients in the air gap. The effects of turbulence are evaluated by the algebraic Baldwin-Lomax turbulence model, the low-Reynold's number $k-$ $\varepsilon$ model proposed by Chien, and using the $k-\omega$ SST turbulence model by Menter. The three chosen turbulence models are not designed for highly rotational flows. In such flows the eddy viscosities in the streamwise and cross-flow directions can differ significantly.

The main dimensions of the test machine air gap are presented, the computational domain is selected and a sector grid is done for a simple geometry of the annulus. Due to the symmetry of the electric motor geometry only one half of the annulus is discretized. Boundary conditions are set to model for the flow between the cooling air and the two main parts of the machine. A grid with 3.6 million cells and 8-processor parallel computing is first tested. To simplify the geometry, using a sector mesh and small cell number give more reasonable results. The velocity and temperature profiles, the turbulence values viscosity and kinetic energy, the friction coefficient and the velocity factor and local and mean heat transfer coefficients are calculated by the numeric method. The friction coefficient and velocity factor 
are compared to the semi-empirical equations and the results of Saari (1998). Also the local heat transfer coefficients of the air gap with a combination of the grooved stator and smooth rotor are presented in the thesis.

\subsection{Finflo flow solver}

The development of flow solvers based on the Navier-Stokes equations was started in the Laboratory of Aerodynamics at Helsinki University of Technology in 1987. The goal was to develop computer codes for the simulation of subsonic, transsonic and supersonic flows. The commercial codes available at that time were mainly intended for incompressible flows and were ineffective in aerodynamic applications, so the only way to get an advanced computer code was to write one. The results of calculations with this computer code Finflo applied to the annulus flow inside the high-speed electric machine are presented in this work.

Finflo is a Navier-Stokes solver capable of handling incompressible and compressible flow, i.e. subsonic, transsonic and supersonic flows (Siikonen et al. 2001). The Reynolds-averaged thin-layer Navier-Stokes equations are solved by a Finite-Volume method. The solution is based on approximately factorised time-integration with local time stepping. The code utilizes either Roe's flux-difference splitting (Roe 1981) or van Leer's flux-vector splitting (Van Leer 1982). The effects of turbulence are simulated in the thesis with the algebraic turbulence model of Baldwin and Lomax (1978), the low-Reynold's number $k-\varepsilon$ model proposed by Chien (1982), and using the $k-\omega$ SST turbulence model by Menter (1993).

\subsection{Flow equations}

The Reynolds-averaged Navier-Stokes equations, the equations for the kinetic energy $k$ and dissipation $\varepsilon$ of turbulence can be written in the following form (Siikonen and Ala-Juusela 2001)

$$
\frac{\partial U}{\partial t}+\frac{\partial\left(F-F_{v}\right)}{\partial x}+\frac{\partial\left(G-G_{v}\right)}{\partial y}+\frac{\partial\left(H-H_{v}\right)}{\partial z}=Q
$$


where the unknowns are $U=(\rho, \rho u, \rho v, \rho w, E, \rho k, \rho \varepsilon)^{\mathrm{T}}$. In the equation $\varepsilon$ can be replaced by that of $\omega$. The inviscid fluxes are

$F=\left(\begin{array}{l}\rho u \\ \rho u^{2}+p+\frac{2}{3} \rho k \\ \rho v u \\ \rho w u \\ \left(E+p+\frac{2}{3} \rho k\right) u \\ \rho u k \\ \rho u \varepsilon\end{array}\right)$

$G=\left(\begin{array}{l}\rho v \\ \rho u v \\ \rho v^{2}+p+\frac{2}{3} \rho k \\ \rho w v \\ \left(E+p+\frac{2}{3} \rho k\right) v \\ \rho v k \\ \rho v \varepsilon\end{array}\right)$

$H=\left(\begin{array}{l}\rho w \\ \rho u w \\ \rho v w \\ \rho w^{2}+p+\frac{2}{3} \rho k \\ \left(E+p+\frac{2}{3} \rho k\right) w \\ \rho w k \\ \rho w \varepsilon\end{array}\right)(30)$

where $\rho$ is the density, the velocity vector by using Cartesian components is $\vec{V}=u \vec{i}+v \vec{j}+w \vec{k}, p$ is the pressure, $k$ is the turbulent kinetic energy and $\varepsilon$ its dissipation. The total internal energy $E$ is defined as

$$
E=\rho e+\frac{\rho \vec{V} \cdot \vec{V}}{2}+\rho k
$$

where $e$ is the specific internal energy. The viscous fluxes are

$$
F_{v}=\left(\begin{array}{l}
0 \\
\tau_{x x}+\frac{2}{3} \rho k \\
\tau_{x y} \\
\tau_{x z} \\
u\left(\tau_{x x}+\frac{2}{3} \rho k\right)+v \tau_{x y} \\
+w \tau_{x z}-q_{x} \\
\mu_{k}(\partial k / \partial x) \\
\mu_{\varepsilon}(\partial \varepsilon / \partial x)
\end{array}\right) G_{v}=\left(\begin{array}{l}
0 \\
\tau_{x y} \\
\tau_{y y}+\frac{2}{3} \rho k \\
\tau_{y z} \\
u \tau_{x y}+v\left(\tau_{y y}+\frac{2}{3} \rho k\right) \\
+w \tau_{y z}-q_{y} \\
\mu_{k}(\partial k / \partial y) \\
\mu_{\varepsilon}(\partial \varepsilon / \partial y)
\end{array}\right) H_{v}=\left(\begin{array}{l}
0 \\
\tau_{x z} \\
\tau_{y z} \\
\tau_{z z}+\frac{2}{3} \rho k \\
u \tau_{x z}+v \tau_{y z} \\
+w\left(\tau_{z z}+\frac{2}{3} \rho k\right)-q_{z} \\
\mu_{k}(\partial k / \partial z) \\
\mu_{\varepsilon}(\partial \varepsilon / \partial z)
\end{array}\right)
$$

Here the stress tensor $\tau_{\mathrm{ij}}$ includes laminar and turbulent components. The fluid is assumed to be Newtonian and, therefore, the laminar stresses are modelled by using the Stokes hypothesis. The Reynolds stresses $\overline{\rho u_{i}^{\prime \prime} u_{j}^{\prime \prime}}$ are included in the stress tensor $\tau_{\mathrm{ij}}$. 


$$
\tau_{i j}=\mu\left[\frac{\partial u_{j}}{\partial x_{i}}+\frac{\partial u_{i}}{\partial x_{j}}-\frac{2}{3}(\nabla \cdot \vec{V}) \delta_{i j}\right]-\overline{\rho u_{i}^{\prime \prime} u_{j}^{\prime \prime}}+\delta_{i j} \frac{2}{3} \rho k
$$

For the Reynolds stresses the Boussinesq approximation

$$
-\overline{\rho u_{i}^{\prime \prime} u_{j}^{\prime \prime}}=\mu_{T}\left[\frac{\partial u_{j}}{\partial x_{i}}+\frac{\partial u_{i}}{\partial x_{j}}-\frac{2}{3}(\nabla \cdot \vec{V}) \delta_{i j}\right]-\frac{2}{3} \rho k \delta_{i j}
$$

is utilized. Here $\mu_{\mathrm{T}}$ is a turbulent viscosity coefficient, which is calculated by using a turbulence model, and $\delta_{\mathrm{ij}}$ is the Kronecker delta. In the momentum and energy equations, the kinetic energy contribution $2 / 3 \rho k \delta_{\mathrm{ij}}$ has been connected with pressure and appears in the convective fluxes, whereas the diffusive part is connected with the viscous fluxes. The viscous stresses contain a laminar and turbulent part. Respectively, the heat flux is written as

$$
\vec{q}=-\left(\lambda+\lambda_{T}\right) \nabla T=-\left(\mu \frac{c_{p}}{\operatorname{Pr}}+\mu_{T} \frac{c_{p}}{\operatorname{Pr}_{T}}\right) \nabla T
$$

where $\lambda$ is a molecular and $\lambda_{\mathrm{T}}$ a turbulent thermal conductivity coefficient. Pr is a laminar and $\operatorname{Pr}_{\mathrm{T}}$ a turbulent Prandtl number, respectively, and $c_{\mathrm{p}}$ is specific heat at constant pressure. The diffusion of turbulence variables is modelled as

$$
\begin{aligned}
& \mu_{k} \nabla k=\left(\mu+\frac{\mu_{T}}{\sigma_{k}}\right) \nabla k \\
& \mu_{\varepsilon} \nabla \varepsilon=\left(\mu+\frac{\mu_{T}}{\sigma_{\varepsilon}}\right) \nabla \varepsilon
\end{aligned}
$$

where $\sigma_{k}$ and $\sigma_{\varepsilon}$ are the turbulent Schmidt's number of $k$ and $\varepsilon$, respectively. The pressure is calculated from an equation of state $p=p(\rho, e)$, which, with a perfect gas assumption utilized in this study, is written as 


$$
p=(\gamma-1)\left(E-\rho \frac{u^{2}+v^{2}+w^{2}}{2}-\rho k\right)=(\gamma-1) \rho e
$$

where $\gamma$ is the ratio of specific heats $c_{\mathrm{p}} / c_{\mathrm{v}}$. Since this case is essentially incompressible, pressure differences are solved instead of pressure.

The components of the source term $Q$ are non-zero in buoyance terms and in turbulence model equations. The buoyance terms are

$$
Q=\left(\begin{array}{l}
-\left(\rho-\rho_{0}\right) g_{i} \\
-\left(\rho-\rho_{0}\right) g_{j} \\
-\left(\rho-\rho_{0}\right) g_{k} \\
-\left(\rho-\rho_{0}\right)\left(g_{i} u+g_{j} v+g_{k} w\right)
\end{array}\right)
$$

where $\rho_{0}$ is the reference density and $\vec{g}$ is gravitational acceleration.

In the present study an artificial compressibility approach is used to determine the pressure. The flux calculation is a simplified version of the approximate Riemann-solver utilized for compressible flows (Siikonen 1995). It should be noted that in this approach the artificial sound speed affects the solution, but the effect is of a second order and is not visible when the grid is refined. The solution method is described in Rahman et al. (1997).

\subsection{Turbulence models}

\section{Isotropic turbulence in the rotating channel flow}

One- and two-equation turbulence models (e.g. B $-\mathrm{L}, k-\varepsilon, k-\omega$ ) give an isotropic turbulence, which is turbulence constant in all directions. In the real situation the turbulence is said to be anisotropic (Shaw 1992).

The rotation causes changes in the turbulence. In the case of the one- and two-equation models the Reynolds stresses are modelled by the Boussinesq eddy-viscosity approximation. Applications (Wilcox 2000) where such models fail are: 
- $\quad$ flows with sudden changes in mean strain rate

- $\quad$ flow over curved surfaces

- $\quad$ flow in duct with secondary motions

- $\quad$ flow in rotating fluids

- $\quad$ three-dimensional flows

- $\quad$ flows with boundary-layer separation

All these features are typical for the cooling air flow in the air gap of an electric machine. These can be taken into consideration by curvature corrections (to take the effect of the coriolis force into account) or by using anisotropic turbulence models (Siikonen 2002, private conversation).

The two equation models require ad hoc corrections for the rotating channel flow to make realistic predictions (Wilcox 2000). Surface curvature, like system rotation, has a significant effect on the structural features of the turbulent boundary layer. The curvature has a trivial effect on the turbulence kinetic energy equation. The coriolis acceleration yields additional inertial terms in the Reynolds-stress equation. These curvature terms greatly improve the accuracy for flow over curved walls. They are ad hoc modifications that cannot be generalized for arbitrary flows. The corrections mostly improve the turbulence values compared to for instance the standard $k-\varepsilon$ model (Siikonen 1997).

Another means is to use anisotropic turbulence models. The rotating channel flows are an interesting application of stress-transport models. The stress-transport models hold promise of more accurate predictions for three-dimensional flows (Wilcox 2000).

The primary reason why two-equation models are inaccurate for three-dimensional boundary layers, for example, lies in their use of isotropic eddy viscosity (Wilcox 2000). However, the eddy viscosities in the streamwise and cross flow directions of a typical three-dimensional boundary layer can differ significantly.

Figure 12 compares computed and measured skin frictions on the boundary layer of a segmented cylinder, part of which rotates about its axis. The experiment was performed by Higuchi and Rubesin (Wilcox 2000). 


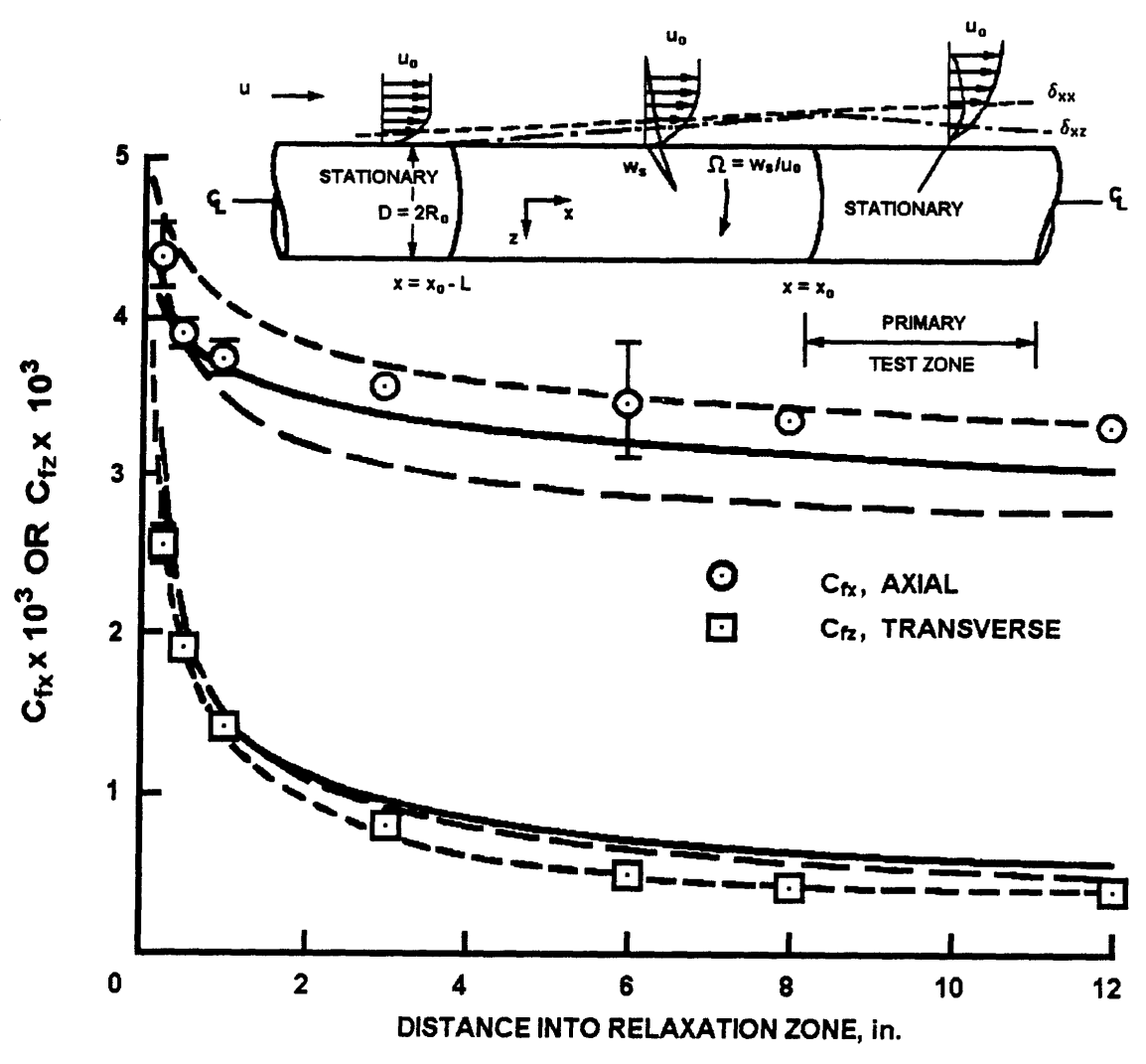

Figure 12. Skin friction on a segmented spinning cylinder; - Cebeci-Smith model; - - WilcoxRubesin k- $\omega^{2}$ model, - - - Wilcox-Rubesin stress-transport model; o $\square$ Higuchi and Rubesin. (Wilcox 2000)

As shown, the Wilcox-Rubesin stress-transport model describes most accurately both the axial $\left(c_{\mathrm{fx}}\right)$ and transverse $\left(c_{\mathrm{fz}}\right)$ skin friction components in the relaxation zone, i.e. the region downstream of the spinning segment. The Cebeci-Smith algebraic model and the WilcoxRubesin two-equation model yield skin friction components that differ from measured values by as much as $20 \%$ and $10 \%$, respectively (Wilcox 2000 ).

\section{Baldwin - Lomax Turbulence Model}

At present, there are two algebraic turbulence models implemented in Finflo: the BaldwinLomax 1978 model and the Cebeci-Smith model (Stock and Haase 1989). They are based on similar expressions for turbulent viscosity. Both models need non-dimensional distance from the surface $y^{+}$(Finflo User Guide version 3.0, 1998) 


$$
y^{+}=y_{n} \frac{\rho u_{T}}{\mu}=y_{n} \sqrt{\frac{\rho}{\mu}\left(\frac{\partial \rho}{\partial y}\right)}
$$

The algebraic models express the turbulent viscosity functionally as $\mu_{\mathrm{T}}=\rho \nu_{\mathrm{T}} . v_{\mathrm{T}}$ is calculated from

$$
v_{T}=\min \left(v_{T i}, v_{T 0}\right) \quad v_{T i}=l^{2}\left|\frac{\partial V_{T}}{\partial y_{n}}\right| \quad l=k y_{n}\left(1-e^{-y^{+} / A^{+}}\right)
$$

\section{$k-\varepsilon$ Turbulence Model}

As mentioned above, turbulent stresses resulting from the Reynolds averaging of the momentum equation are modelled by using the Boussinesq approximation (34). The turbulent viscosity coefficient $\mu_{\mathrm{T}}$ is determined by using Chien's (Chien 1982) low Reynolds number $k$ - $\varepsilon$ model from the formula (Siikonen and Ala-Juusela 2001)

$$
\mu_{T}=c_{\mu} \frac{\rho k^{2}}{\varepsilon}
$$

where $c_{\mu}$ is a empirical coefficient. The source term of Chien's model is

$$
Q=\left(\begin{array}{c}
P-\rho \varepsilon-2 \mu \frac{k}{y_{n}^{2}} \\
c_{1} \frac{\varepsilon}{k} P-c_{2} \frac{\rho \varepsilon^{2}}{k}-2 \mu \frac{\varepsilon}{y_{n}^{2}} e^{-y^{+} / 2}
\end{array}\right)
$$

where $y_{\mathrm{n}}$ is the normal distance from the wall, and the dimensionless distance $y^{+}$is defined by

$$
y^{+}=y_{n} \frac{\rho u_{\tau}}{\mu}=y_{n} \frac{\sqrt{\rho \tau_{w}}}{\mu} \approx y_{n}\left[\frac{\rho|\nabla \times \vec{V}|}{\mu}\right]_{w}^{1 / 2}
$$


Here $u_{\mathrm{T}}$ is friction velocity and $\tau_{\mathrm{w}}$ is friction on the wall, and the connection between them is $u_{\tau}=\sqrt{\tau_{w} / \rho}$. The unknown production of the turbulent kinetic energy is modelled using the Boussinesq approximation (34)

$$
P=-\overline{\rho u_{i}^{\prime \prime} u_{j}^{\prime \prime}} \frac{\partial u_{i}}{\partial x_{j}}=\left[\mu_{T}\left(\frac{\partial u_{i}}{\partial x_{j}}+\frac{\partial u_{j}}{\partial x_{i}}-\frac{2}{3} \delta_{i j} \frac{\partial u_{k}}{\partial x_{k}}\right)-\frac{2}{3} \delta_{i j} \rho k\right] \frac{\partial u_{i}}{\partial x_{j}}
$$

The turbulence model presented above contains empirical coefficients. These are given by (Finflo User Manual version 2.2, 1997)

$$
\begin{array}{llrl}
c_{1} & =1.44 & & \\
c_{2} & =1.92\left(1-0.22 e^{-\mathrm{Re}_{T} / 36}\right) & \sigma_{k} & =1.0 \\
c_{\mu} & =0.09\left(1-e^{-0.0115 y^{+}}\right) & \sigma_{\varepsilon}=1.3
\end{array}
$$

where the turbulence Reynolds number is defined as

$$
\operatorname{Re}_{T}=\frac{\rho k^{2}}{\mu \varepsilon}
$$

Chien's model is very robust, but it has several shortcomings. It usually overestimates the turbulence level and does not perform well in the case of an increasing pressure gradient.

\section{k - $\omega$ Turbulence Model}

To improve the near-wall behaviour of the $k-\varepsilon$ model, a mixture of the $k-\varepsilon$ and $k-\omega$ models, known as Menter's $k-\omega$ SST model (Menter 1993, Menter 1994, Lellsten and Laine 1998), has gained increasing popularity in recent years. Menter's $k-\omega$ SST model is a twoequation turbulence model where the $k-\omega$ model is utilized in a boundary layer, and outside of that the turbulence is modelled with the $k-\varepsilon$ model. However, the $\varepsilon$-equation is transferred into the $\omega$-equation in order to allow a smooth change between the models. In the SST-model the turbulent stress is limited in a boundary layer in order to avoid unrealistic strain-rates, 
which are typical for the Boussinesq eddy viscosity models. The equations for $k$ and $\omega$ are (Siikonen and Ala-Juusela 2001)

$$
\begin{aligned}
& \rho \frac{\partial k}{\partial t}+\rho u_{j} \frac{\partial k}{\partial x_{j}}=P-\beta^{*} \rho k \omega+\frac{\partial}{\partial x_{j}}\left[\left(\mu+\frac{\mu_{T}}{\sigma_{k}}\right) \frac{\partial k}{\partial x_{j}}\right] \\
& \rho \frac{\partial \omega}{\partial t}+\rho u_{j} \frac{\partial \omega}{\partial x_{j}}=\frac{\gamma \rho}{\mu_{T}} P+\frac{\partial}{\partial x_{j}}\left[\left(\mu+\frac{\mu_{T}}{\sigma_{\omega}}\right) \frac{\partial \omega}{\partial x_{j}}\right]+2 \rho \frac{1-F_{1}}{\sigma_{\omega 2} \omega} \frac{\partial k}{\partial x_{j}} \frac{\partial \omega}{\partial x_{j}}
\end{aligned}
$$

The model coefficients in equations 48 and 49 are obtained from

$$
\left(\sigma_{k} \sigma_{\omega} \beta\right)^{T}=F_{1}\left(\sigma_{k} \sigma_{\omega} \beta\right)_{1}^{T}+\left(1-F_{1}\right)\left(\sigma_{k} \sigma_{\omega} \beta\right)_{2}^{T}
$$

with the following values

$$
\begin{array}{lll}
\sigma_{k 1}=1.176 & \sigma_{\omega 1}=2.0 & \beta_{1}=0.075 \\
\sigma_{k 2}=1.0 & \sigma_{\omega 2}=1.168 & \beta_{2}=0.0828
\end{array}
$$

The coefficients $\kappa$ and $\beta^{*}$ have constant values of 0.41 and 0.09 . Coefficient $\gamma$ is calculated from

$$
\gamma=\frac{\beta}{\beta^{*}}-\frac{\kappa^{2}}{\sigma_{\omega} \sqrt{\beta^{*}}}
$$

The term $P$ in equations 48 and 49 is a production of the turbulent kinetic energy and it is calculated from equation 45 . The last term in the $\omega$ equation originates from the transformed $\varepsilon$ equation and it is called a cross-diffusion term. The switching function which governs the choice between the $\omega$ and $\varepsilon$ equations is

$$
F_{1}=\tanh \left(\Gamma^{4}\right)
$$


where

$$
\Gamma=\min \left(\max \left(\frac{\sqrt{k}}{\beta^{*} \omega d} ; \frac{500 v}{\omega d^{2}}\right) ; \frac{4 \rho \sigma_{\omega 2} k}{C D_{k \omega} d^{2}}\right)
$$

The first term is the turbulent length scale divided with the distance from the walls. This ratio is around 2.5 in a logarithmic layer and approaches zero in an outer layer. The second term has a value of $\geq 1$ only in a viscous sublayer. The meaning of the third term is to ensure stable behaviour of $F_{1}$ when the value of $\omega$ in the free stream is small. $C D_{\mathrm{k} \omega}$ is the positive part of the cross diffusion term

$$
C D_{k \omega}=\max \left(\frac{2 \rho}{\sigma_{\omega 2} \omega} \frac{\partial k}{\partial x_{j}} \frac{\partial \omega}{\partial x_{j}} ; C D_{k \omega \min }\right)
$$

where $C D_{\text {komin }}$ is the lower limit of the cross diffusion term. In the original SST model the eddy viscosity $\mu_{\mathrm{T}}$ is defined as

$$
\mu_{T}=\frac{a_{1} \rho k}{\max \left(a_{1} \omega ;\left|\Omega_{i j}\right| F_{2} F_{3}\right)}
$$

where $a_{1}=0.31$ and $\left|\Omega_{\mathrm{ij}}\right|=\sqrt{2 \Omega_{i j} \Omega_{i j}}$, with $\Omega_{\mathrm{ij}}$ being the vorticity tensor.

$$
\Omega_{i j}=\frac{1}{2}\left(\frac{\partial u_{i}}{\partial x_{j}}-\frac{\partial u_{j}}{\partial x_{i}}\right)
$$

The above term $F_{2}$ is a switching function that disables the SST limitation outside the boundary layers. Function $F_{2}$ works like function $F_{1}$ except that its value remains as one farther in the outer boundary layer. It is defined as

$$
F_{2}=\tanh \left(\Gamma_{2}^{2}\right)
$$

where 


$$
\Gamma_{2}=\max \left(\frac{2 \sqrt{k}}{\beta^{*} \omega d} ; \frac{500 v}{\omega d^{2}}\right)
$$

In equation 56 the lower limit of the nominator is based on Bradshaw's assumption, in which the turbulent shear stress in the boundary layer depends on $k$ as follows:

$$
\left|\rho \overline{u^{\prime \prime} v^{\prime \prime}}\right|=a_{1} \rho k
$$

Thus the traditional Kolmogorov-Prandtl-expression $\mu_{T}=\rho k / \omega$ is used to the limit

$$
\mu_{T}=\frac{\left|\rho \overline{u^{\prime \prime} v^{\prime \prime}}\right|}{\left|\Omega_{i j}\right|}=\frac{a_{1} \rho k}{\left|\Omega_{i j}\right|}
$$

This is called the SST limitation for $\mu_{\mathrm{T}}$. The SST limitation improves significantly the behaviour of the model in boundary layers that have an unfavourable pressure gradient, in which cases the traditional model clearly overestimates the turbulent viscosity.

The meaning of function $F_{3}$ is to prevent activation of the SST limitation near the rough walls (Helsten and Laine 1998, Helsten and Laine 1997). Function $F_{3}$ is defined as

$$
F_{3}=1-\tanh \left[\left(\frac{150 v}{\omega d^{2}}\right)^{4}\right]
$$

where $d$ is the distance from the walls. 


\subsection{Main dimensions, computational grid and boundary conditions}

Regardless of the simplicity in annular geometry, solving this three-dimensional problem numerically accurately (by trial and error) is quite a demanding task. To make a mesh can be considered as a discretization of the space in which the flow takes place (Shaw 1992).

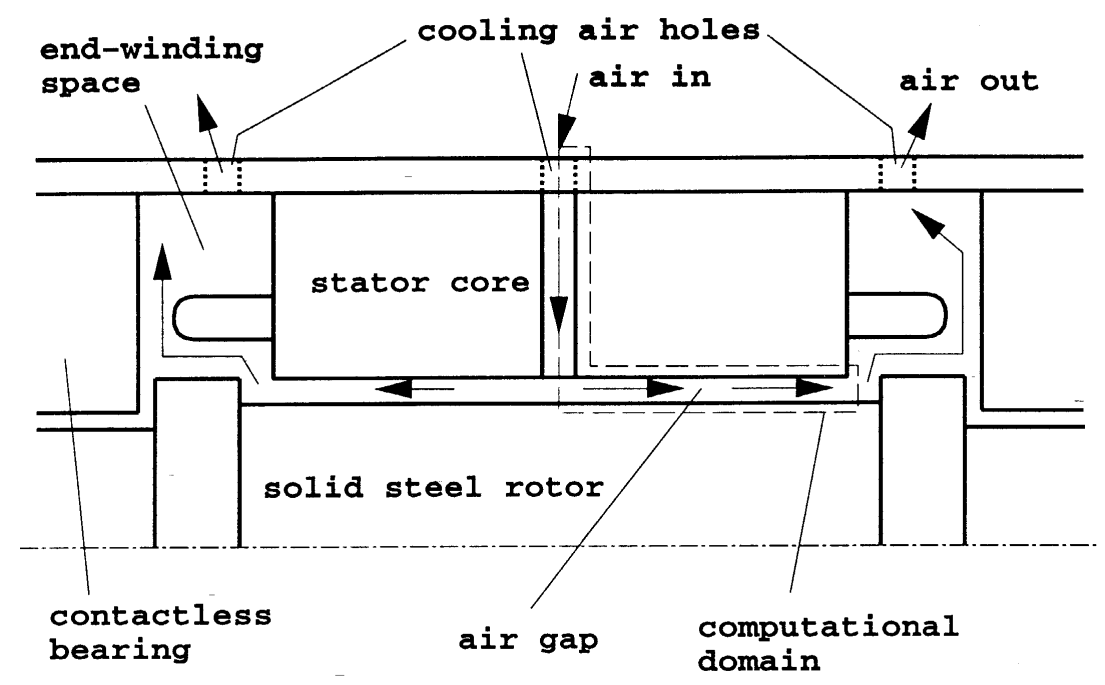

Figure 13. High-speed electric motor with flow paths and a computational domain.

One half of the annulus is modelled. Calculations are done using a sector grid of $11.25^{\circ}$. The grid has smooth surfaces. It is divided into five blocks. A high-speed electric motor with coolant flow paths: stator slot, an air gap and a computational domain are shown in figure 13. The main dimensions of the example can be seen in table 1 and the number of cells in the I, J and $\mathrm{K}$ directions of the five blocks in table 2.

Table 1. Main dimensions of the example.

\begin{tabular}{|l|l|}
\hline Diameter of the rotor & $0.071 \mathrm{~m}$ \\
\hline Air gap height & $0.002 \mathrm{~m}$ \\
\hline Length of one half of the annular channel & $0.1 \mathrm{~m}$ \\
\hline
\end{tabular}

The grid is partly simplified close the flow entrance where the incoming stator slot flow turns to the air gap. The first two blocks are made to discretize the flow from the stator slot to the air gap entry (see figure 19). Turning grid lines from the stator slot to the annulus are used to reduce the cell number. The air gap is discretized using the third block. 
Table 2. Number of cells in the five blocks of the grid in I, J and $\mathrm{K}$ directions.

\begin{tabular}{llllll}
\hline Block & I & J & K & $\Sigma$ & Location \\
\hline 1 & 48 & 32 & 8 & 12288 & Stator slot \\
2 & 16 & 32 & 8 & 4096 & Rotor entry \\
3 & 48 & 64 & 8 & 24576 & Air gap \\
4 & 2 & 32 & 8 & 512 & Inlet \\
5 & 2 & 64 & 8 & 1024 & Outlet \\
\hline Total & & & & 42496 &
\end{tabular}

A grid in the middle of the flow paths has been copied to the whole frame in figure 14. The height of the first row of cells is everywhere $6 \cdot 10^{-6} \mathrm{~m}$. As a non-dimensional distance this is on the average for the rotor between $y^{+} \approx 2.39-1.54$ and for the stator $y^{+} \approx 0.73-1.19$ in the axial direction.

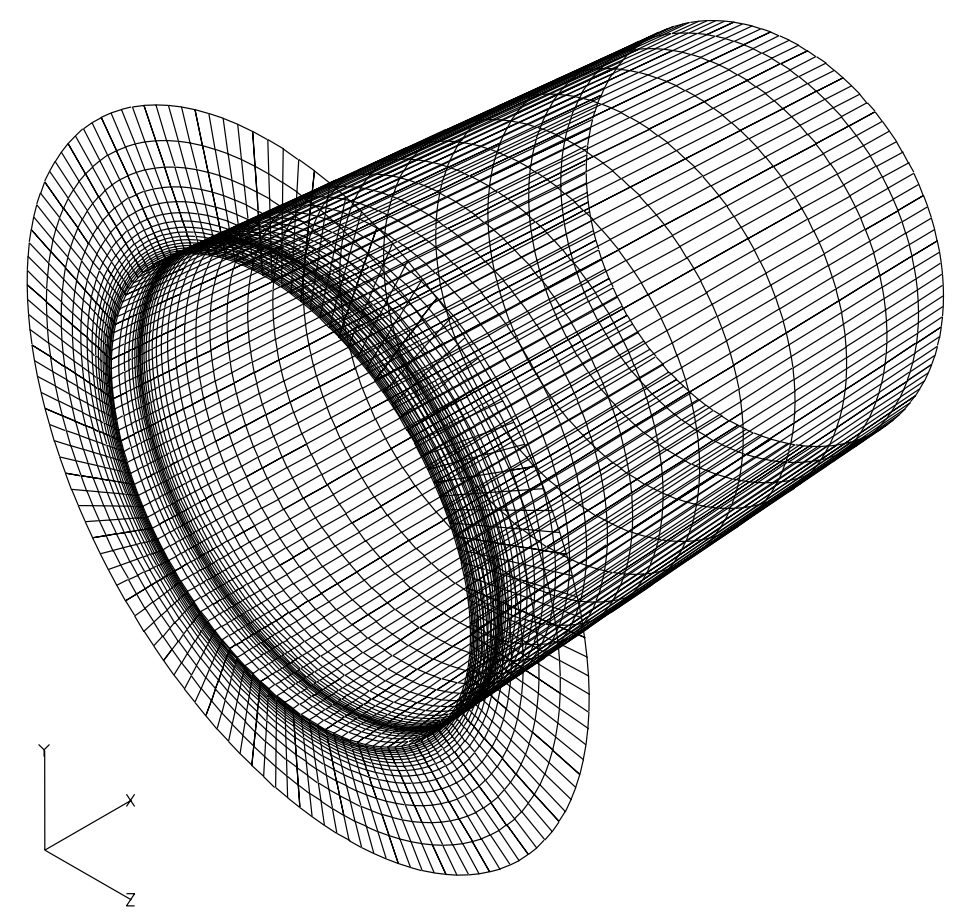

Figure 14. Sector grid in the middle of flow paths copied to the whole frame.

Inlet boundary conditions are defined at the beginning of the middlemost inlet cooling air hole (at stator slot) of the computational domain (figure 13). There the homogeneous velocity field 
is fixed. This is done in order to get a developed boundary layer to the entry of the electric motor annulus. The mean axial velocity of $40 \mathrm{~m} / \mathrm{s}$ through an annulus is selected. It is between the typical values of $20-60 \mathrm{~m} / \mathrm{s}$. The constant coolant flow rate $0.02 \mathrm{~kg} / \mathrm{s}$ is chosen for one half. It is based on the desirable axial mean flow velocity: $q_{\mathrm{m}}=\rho v A$, where $\rho$ is the density and $v$ the axial velocity of the fluid and $A$ the area of the annular channel. The inlet air temperature is $20{ }^{\circ} \mathrm{C}$ and the absolute pressure 1 bar. The total enthalpy, the static pressure and the mass flow rate are given as inlet and outlet conditions of the annulus. The stator slot is divided by a mirror boundary condition. It is set in the middle at the stator slot and in the beginning of the annular channel. A pair of cyclic boundaries is specified at the intersections between the axial symmetry planes and mesh walls of the sector. The rotor peripheral speed is varied between 112-297 m/s. Variable angular velocities as input parameters are set to the rotating rotor surfaces. Heat transfer from the hot stator and rotor surfaces to the cooling airflow is modelled by giving constant surface temperatures $T_{\text {stator }}=100{ }^{\circ} \mathrm{C}$ and $T_{\text {rotor }}=150$ ${ }^{\circ} \mathrm{C}$ as boundary conditions. These temperatures are due to the losses and depend on the rotation speed and the loading of the machine. A grid sensitivity study was done for 50000 RPM peripheral speed simulation using the Baldwin-Lomax turbulence model. At the three coarseness levels of the grid the mean heat transfer coefficients for the rotor were 344 $\mathrm{W} /\left(\mathrm{m}^{2} \mathrm{~K}\right)$ for the finest grid (level 1), $323 \mathrm{~W} /\left(\mathrm{m}^{2} \mathrm{~K}\right)$ for the level 2 and $282 \mathrm{~W} /\left(\mathrm{m}^{2} \mathrm{~K}\right)$ (level 3$)$. The stator values were 304,298 and $248 \mathrm{~W} /\left(\mathrm{m}^{2} \mathrm{~K}\right)$. In the study the simulations are done on the second coarseness level.

\subsection{The simulation process}

In the simulation process three annular air gap cases were calculated: a 3D grid with 3.6 million cells, a sector grid (42496 cells) and a grid with a grooved stator (113280 cells). The calculation started with the $3 \mathrm{D}$ grid of 3.6 million cells and non-heated walls. The convergence took 12000 cycles. One processor batch processing proceeded 500 cycles a day. The heavy-duty calculation collapsed easily. The friction coefficient $C_{\mathrm{f}}=0.0013$ was then attained for 30000 RPM rotation speed. The next step was 8-processor parallel computing to calculate the heat transfer coefficients. The mean values of these were small: $h_{\text {stator }}=166$ $\mathrm{W} /\left(\mathrm{m}^{2} \mathrm{~K}\right), h_{\text {rotor }}=135 \mathrm{~W} /\left(\mathrm{m}^{2} \mathrm{~K}\right)$ compared to the sector grid (figure 36$)$ results. The flow rate $20 \mathrm{~g} / \mathrm{s}$ was the smallest that converged well. The simulation of acceleration power (velocity factor) with $30000 \mathrm{RPM} k_{2}=0.102$ corresponded well to the previous measurements by 
Saari (1998). The 3D simulation results with 3.6 million cells and 8-processor parallel computing are presented in figures 15 and 16. The Finplo post-processing program has been used to visualize the grid and flow quantity temperature, static pressure and total velocity. Next the annular channel was discretized as a sector mesh of $11.25^{\circ}$. These results are presented in sections 3.7 to 3.13 and 3.15. The main advantage came from using small cell numbers. Many cases could be calculated during a short simulation time. The values of the heat transfer coefficients were bigger. A case with six rotation speeds $(100-300 \mathrm{~m} / \mathrm{s})$ and three turbulence models was simulated. The average axial flow velocity $40 \mathrm{~m} / \mathrm{s}$ (typical values 20 $60 \mathrm{~m} / \mathrm{s}$ ) of a high-speed electric motor was selected to model the air gap fluid dynamics and heat transfer. The following results were attained for the test machine air gap dimensions:

- $\quad$ Velocity and temperature profiles and turbulence quantities

- $\quad$ Local and mean heat transfer coefficients between cooling air and heated walls

- $\quad$ Friction coefficient and velocity factor on six rotational speeds

The next challenge was to establish the results for smooth and grooved rotor-stator combinations. Some of these results are reviewed in section 3.14.

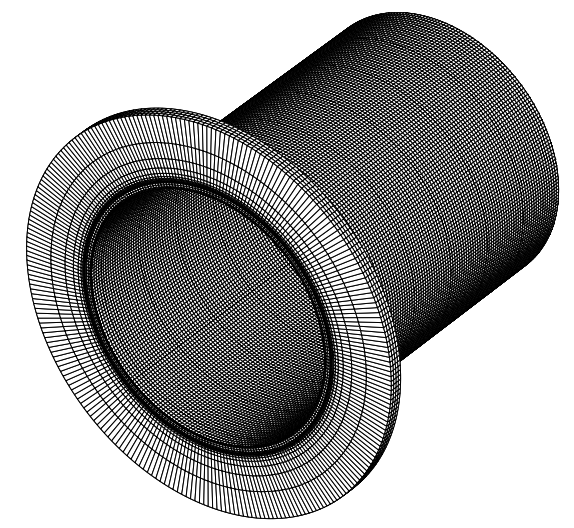

a)

Figure 15. a) 3D grid, 3.6 million cells, b) temperature field (K). 


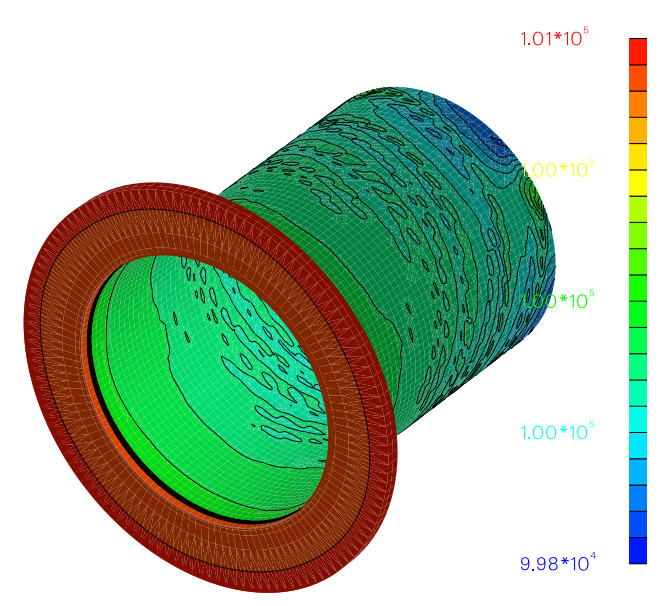

a)

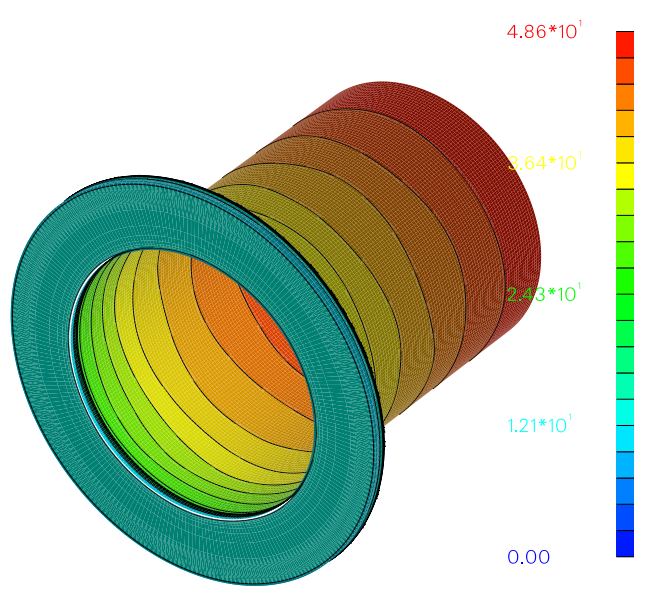

b)

Figure 16. a) Static pressure $(\mathrm{Pa})$, b) total velocity $(\mathrm{m} / \mathrm{s})$.

\subsection{Convergence}

Common convergence criteria for turbulence models are the $L_{2}$-norm of density residual $\|\Delta \rho\|_{2}$, volume averaged temperature residual, and $L_{2}$-norms of the main variables $\| \Delta(\rho, \rho u$, $\rho E) \|_{2}$. The fourth criterion is the rolling moment coefficient $C_{l}^{*}$ for the Baldwin-Lomax (B L) model, turbulent kinetic energy for the $k-\omega$ and $L_{2}$ norms of $k$, and $\varepsilon\|\Delta(\rho \mathrm{k}, \rho \varepsilon)\|$ for the $k$ $-\varepsilon$ turbulence model. Output file IBDIAG contains the convergence history of various flow quantities (Siikonen et al. 2001). Figure 17 contains typical convergence histories for B $-\mathrm{L}, k$ $-\omega$ and $k-\varepsilon$. The convergence of sector calculations takes generally 25000 iteration cycles with the Baldwin-Lomax turbulence model (30 000-80 000 RPM), 10000 cycles with the $k-$ $\omega$ SST turbulence model and 50000 iteration cycles with the low-Reynold's number model proposed by Chien $(k-\varepsilon$ turbulence model). All the models exhibit satisfactory convergence behaviour. The computation is performed with the SGI Origin 2000 (Cedar) owned by CSC Scientific Computing Ltd as batch processing. The CPU-time/cycle required is about 0.2 seconds per cycle with all the turbulence models and on all RPM. The total computing times for the three turbulence models are 1.4 hours, 0.6 hours and 2.8 hours, respectively. 

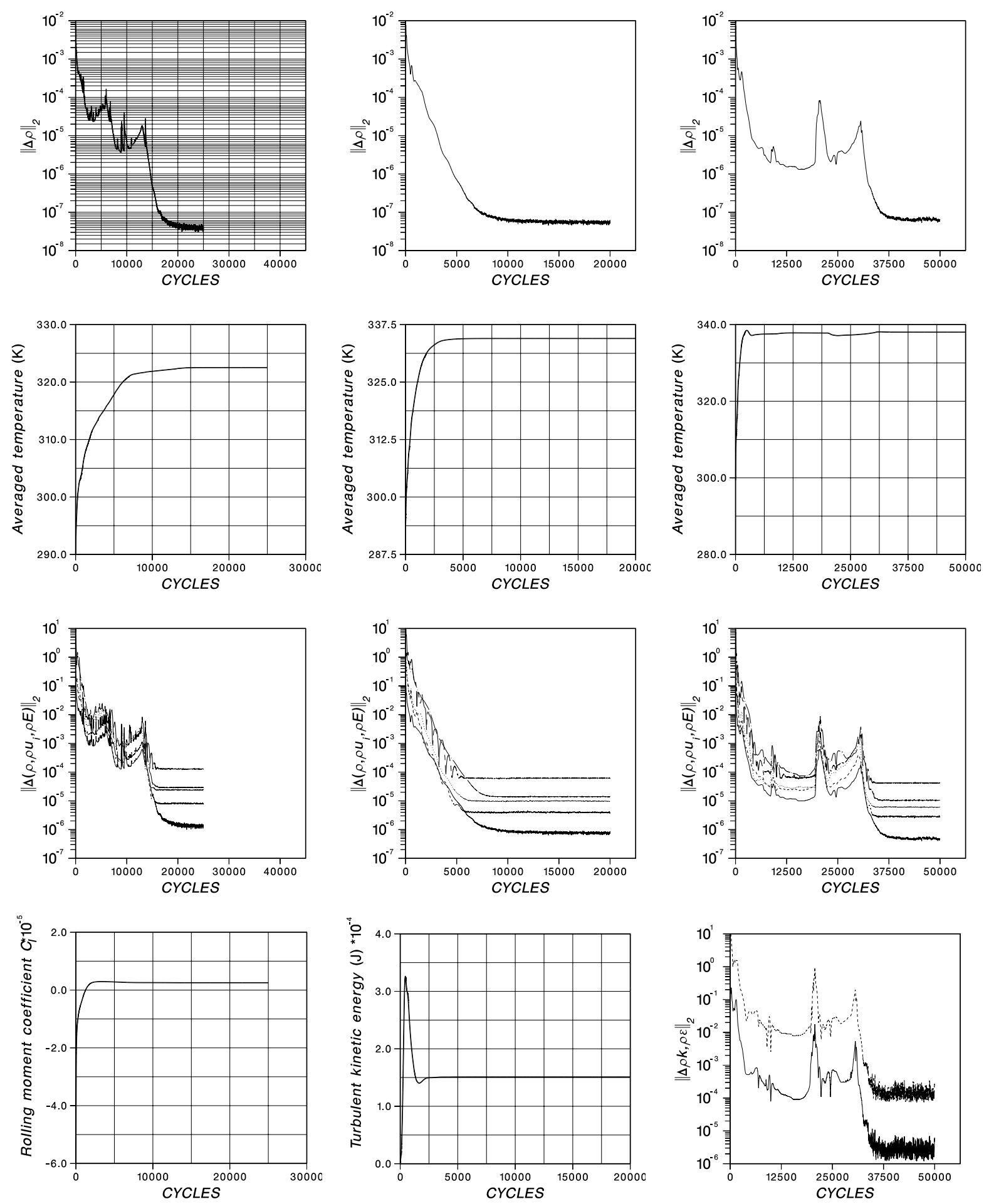

a)

b)

c)

Figure 17. Convergence criteria for three turbulence models: a) Baldwin-Lomax, 30000 RPM, b) $k-$ $\omega, 60000$ RPM and c) $k-\varepsilon, 80000$ RPM: $L_{2}$ norm of density residual, averaged temperature, $L_{2}$ norms of main variables, rolling moment coefficient $C_{1}^{*}$ for the $\mathrm{B}-\mathrm{L}$ model, turbulent kinetic energy for $k-$ $\omega$ and $L_{2}$ norms of $k$, and $\varepsilon\|\Delta(\rho \mathrm{k}, \rho \varepsilon)\|$ for the $k-\varepsilon$ turbulence model. 


\subsection{Velocity field}

Axial and peripheral velocity distributions at 80000 RPM speed are reviewed for the $k-\varepsilon$ model. The streamlines and the pressure field are shown at the speed of 30000 RPM. These boundary speeds are emphasized when presenting the studied flow quantities. The velocity field in the annular channel by the numeric method is realistic (figures 21 and 22). The streamlines are in the mean flow helical direction. Figure 18 shows the flow phenomenon from the stator slot to the air gap for the smooth stator-rotor combination. There exist two

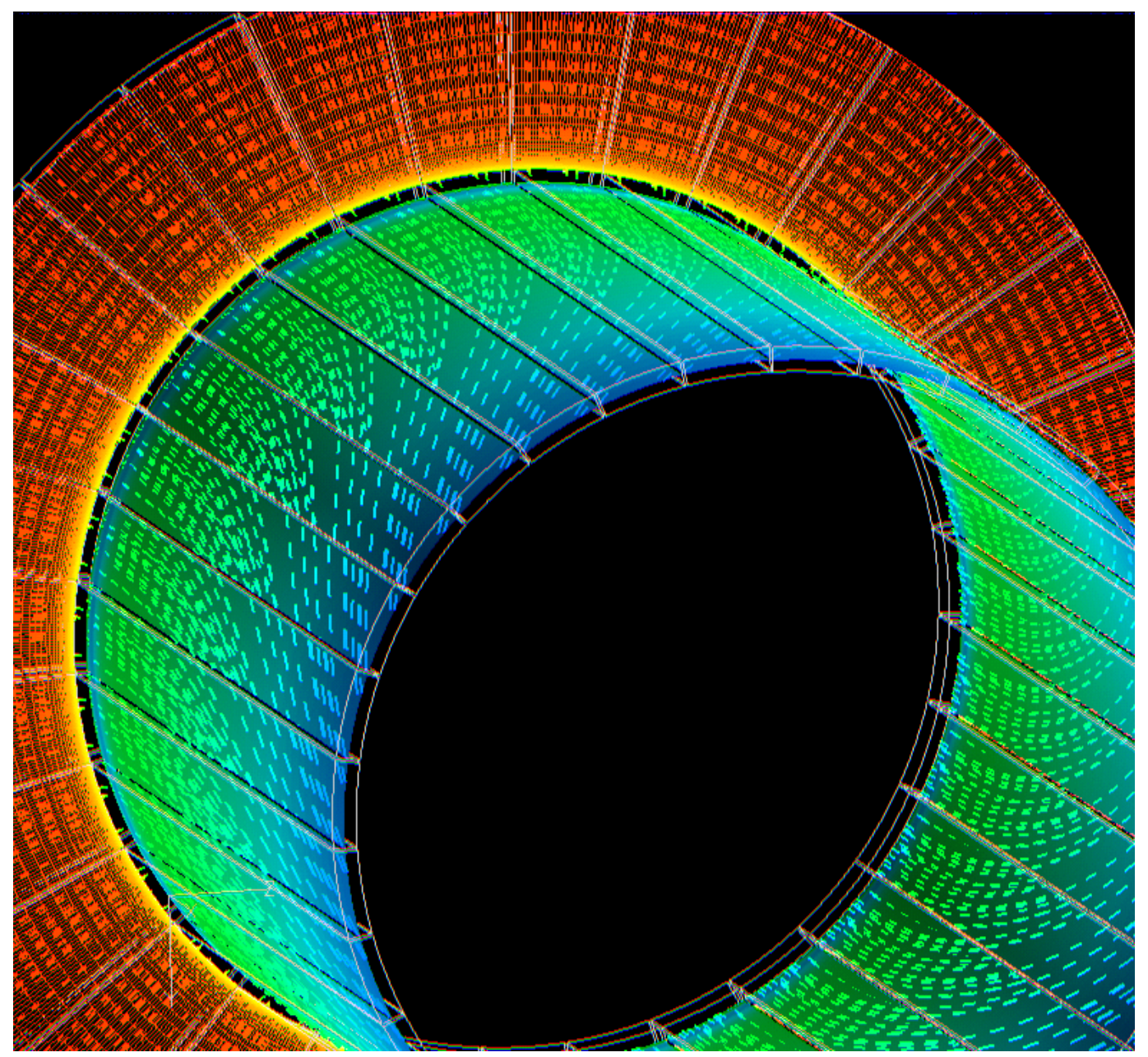

Figure 18. Streamlines and pressure field from the stator slot to the air gap. The rotation speed of the rotor is $30000 \mathrm{RPM}$ and the $k-\varepsilon$ turbulence model is used.

swirls in the flow field from the stator slot to the air gap. The first of them is situated close the wall in the stator slot. The second is close to the stator at the annular entry (figures 19 and 20). The absence of Taylor vortices in the air gap is surprising since there exists large centrifugal forces. The significance of buoyancy effects is small in the forced flow field. 


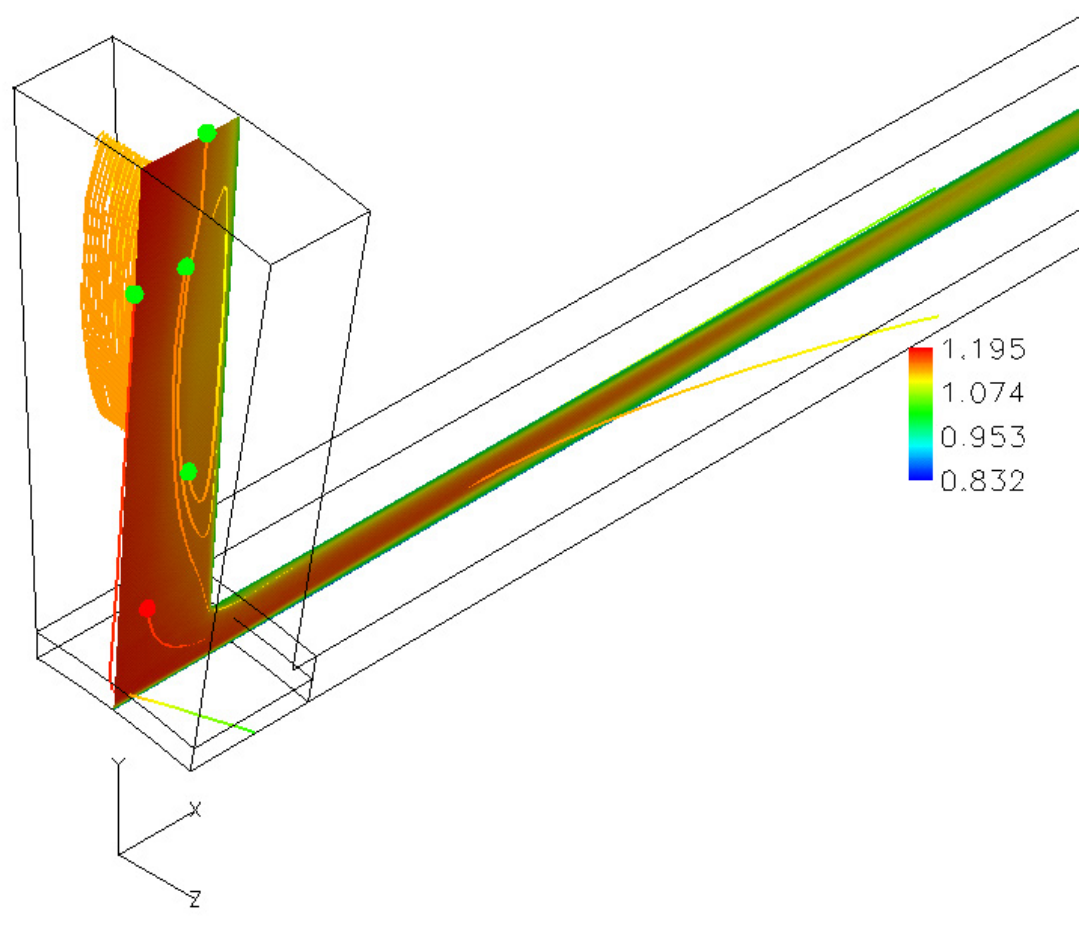

Figure 19. The first whirl is situated in the stator slot. The streamlines are in the density field $\left(\mathrm{kg} / \mathrm{m}^{3}\right)$.

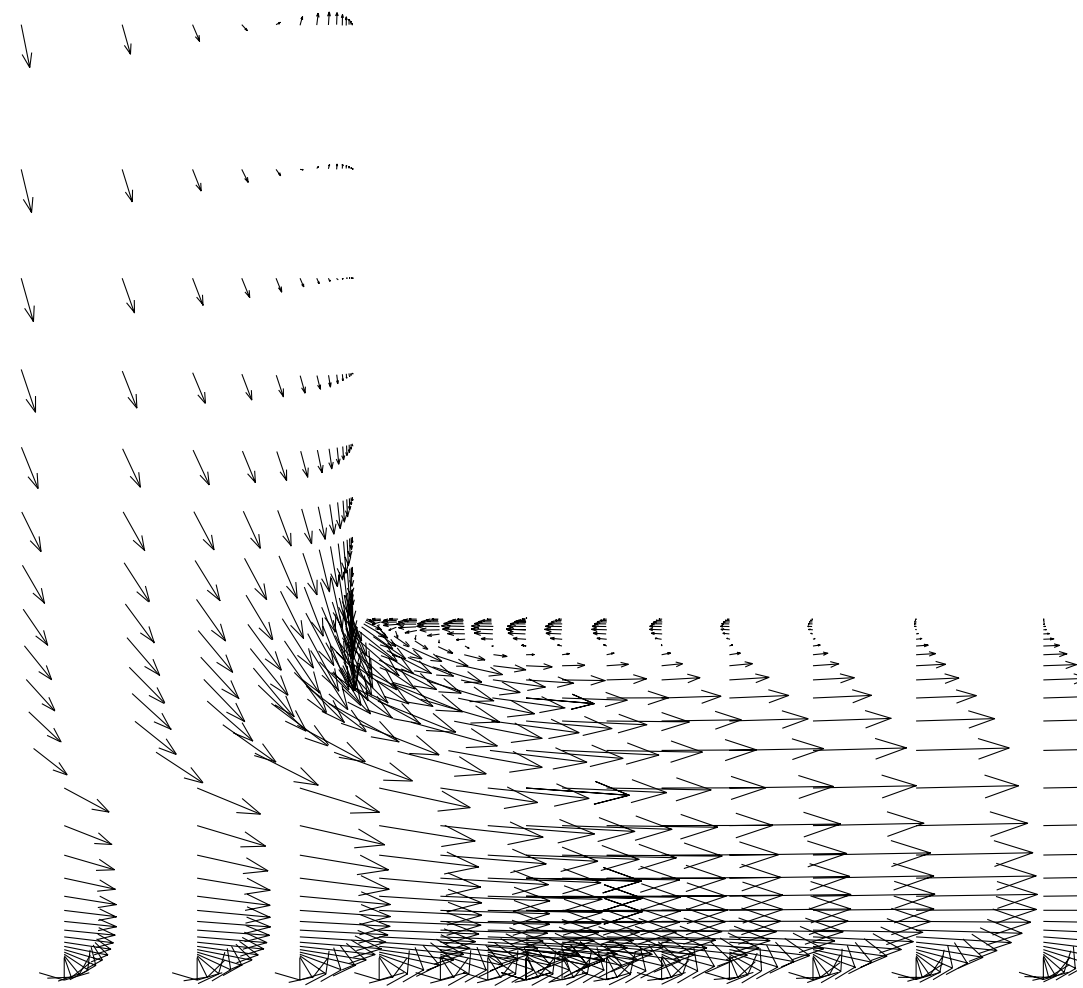

Figure 20. Velocity vectors of the second whirl are situated close to the stator at the annular entry. 
Local velocity distributions at $80000 \mathrm{RPM}(297 \mathrm{~m} / \mathrm{s})$ are shown in figures 21 and 22 . Axial and tangential velocity profiles are presented on sequenced stations as a function of the channel axial position to the total length ratio $x / L: 0<x<L$, where the channel length $L$ is $100 \mathrm{~mm}$, and the air gap height. The air gap height is defined as a dimensionless height of the air gap $y / y_{\max }: 0<y<y_{\max }$, where $y_{\max }$ is $2 \mathrm{~mm}$ (rotor: $y / y_{\max }=0$, stator: $y / y_{\max }=1$ ).

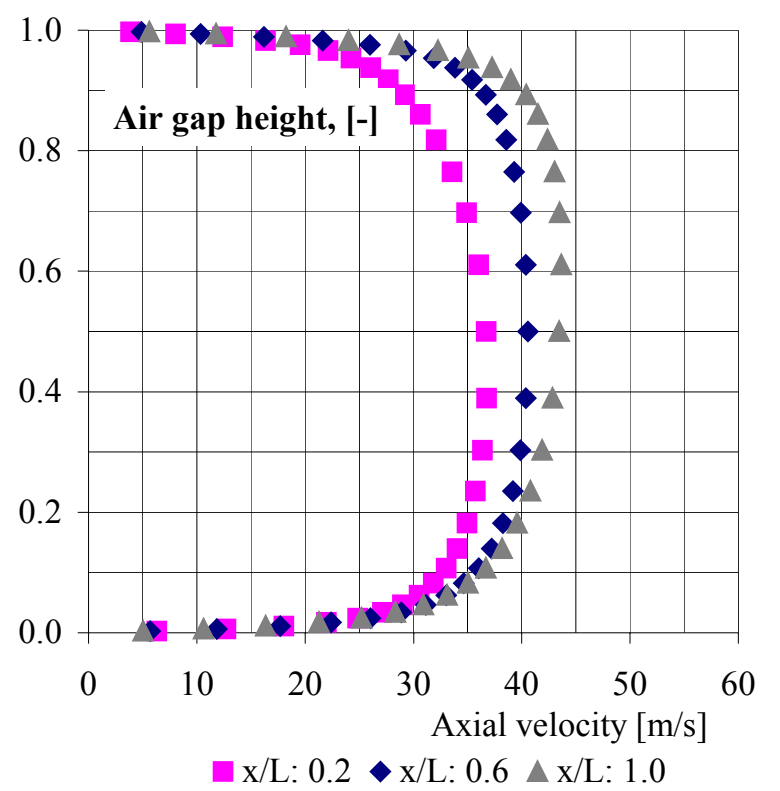

Figure 21. Calculated axial velocity in the annulus at rotor speed $80000 \mathrm{RPM}$ and radius $r=0.0355$ $\mathrm{m}$ (table 1). The $k-\varepsilon$ turbulence model is used.

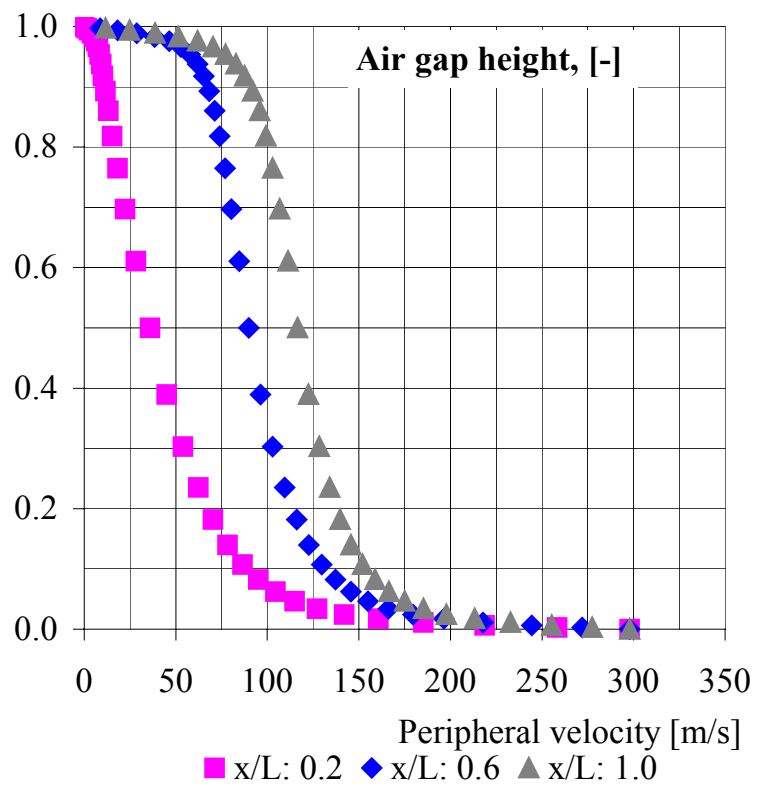

Figure 22. Calculated peripheral velocity in the annulus, 80000 RPM, $k-\varepsilon$. 


\subsection{Temperature field}

The temperature distribution in the axial and radial direction of the air gap is shown in figures 23 and 24 . The rotor peripheral speed is $112 \mathrm{~m} / \mathrm{s}$ (30 $000 \mathrm{RPM})$ and the $k-\omega$ model is used.

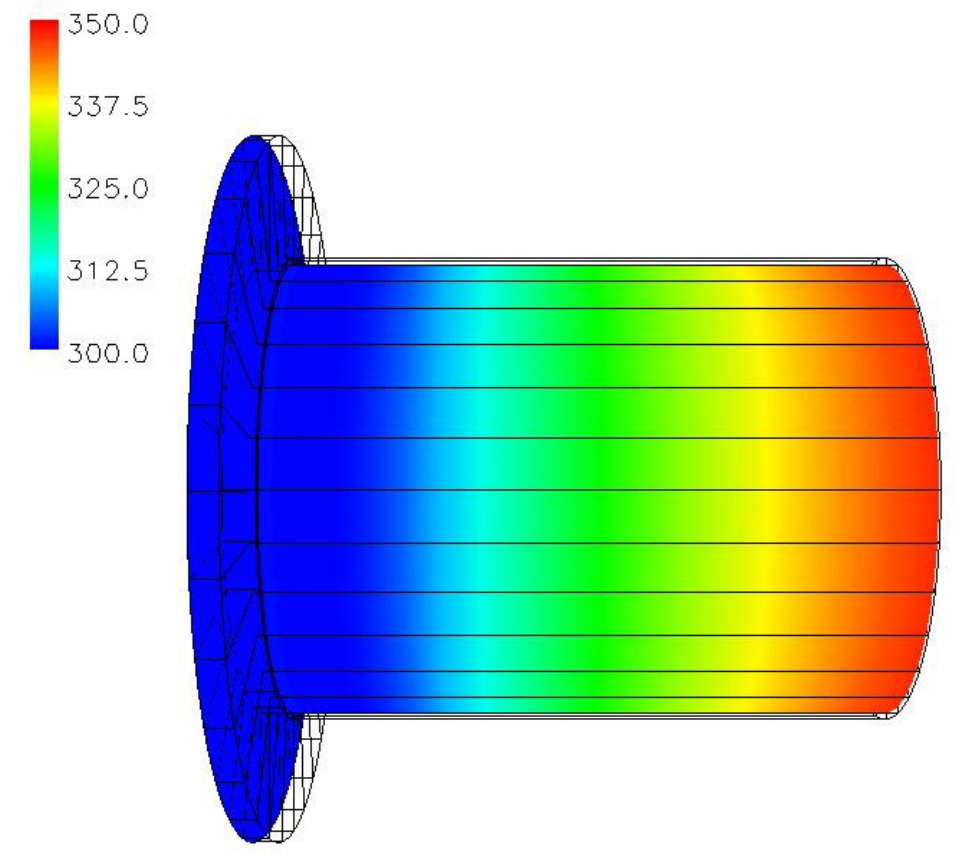

Figure 23. Temperature field in the axial direction of the annular channel (degree Kelvin).

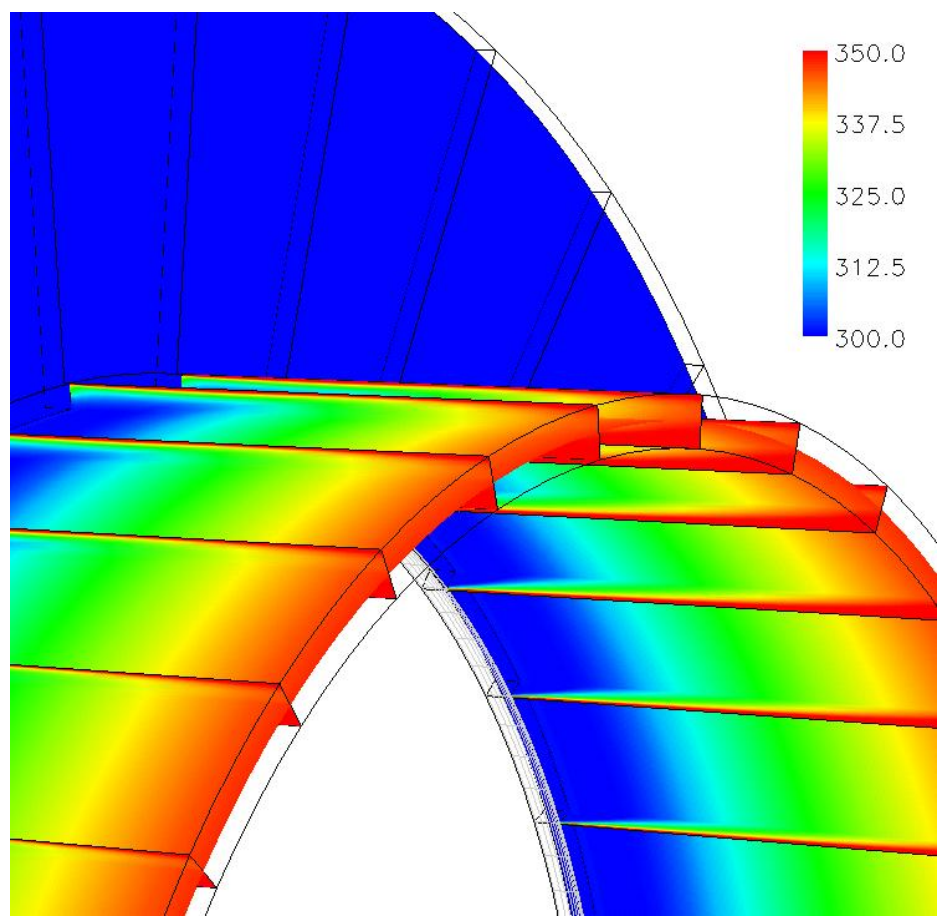

Figure 24. Temperature distribution in the radial direction in the air gap (table 1). 


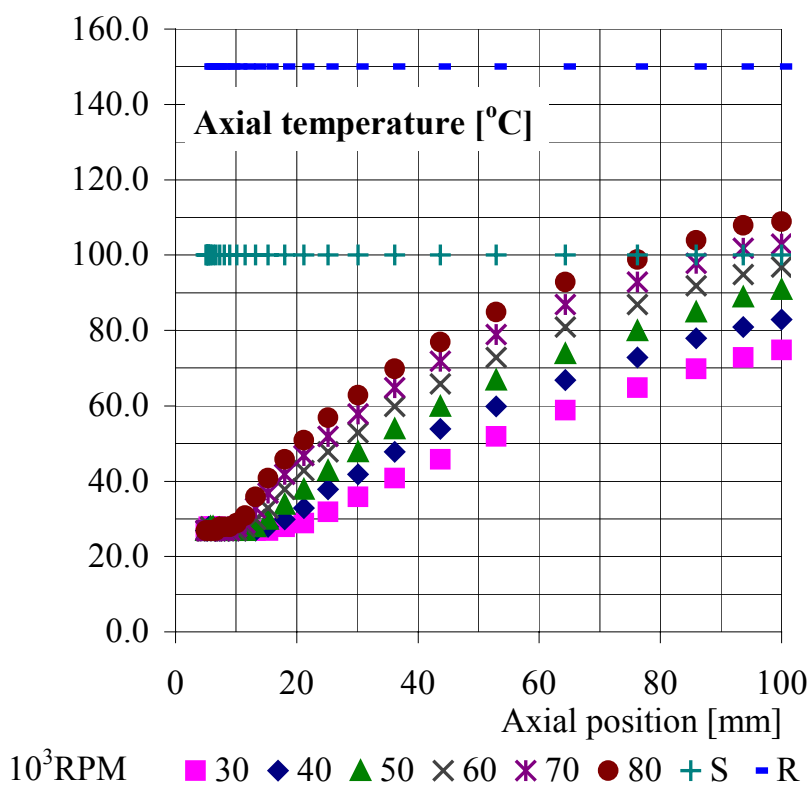

Figure 25. Local air flow temperatures on sequenced axial positions in the air gap and stator and rotor surface temperatures. The rotation speed is between $30-8010^{3} \mathrm{RPM}$. The $k-\varepsilon$ turbulence model is used.

Rotor and stator surface temperatures and local air flow temperatures in the channel height of $\frac{1}{2} y_{\max }$ on various rotational speeds on geometric axial positions of the computational domain are shown in figure 25. The temperature profiles on the sequenced axial position $x / L$ are given in figure 26 for $80000 \mathrm{RPM}(297 \mathrm{~m} / \mathrm{s})$. The dimensions of the example are in table 1 .

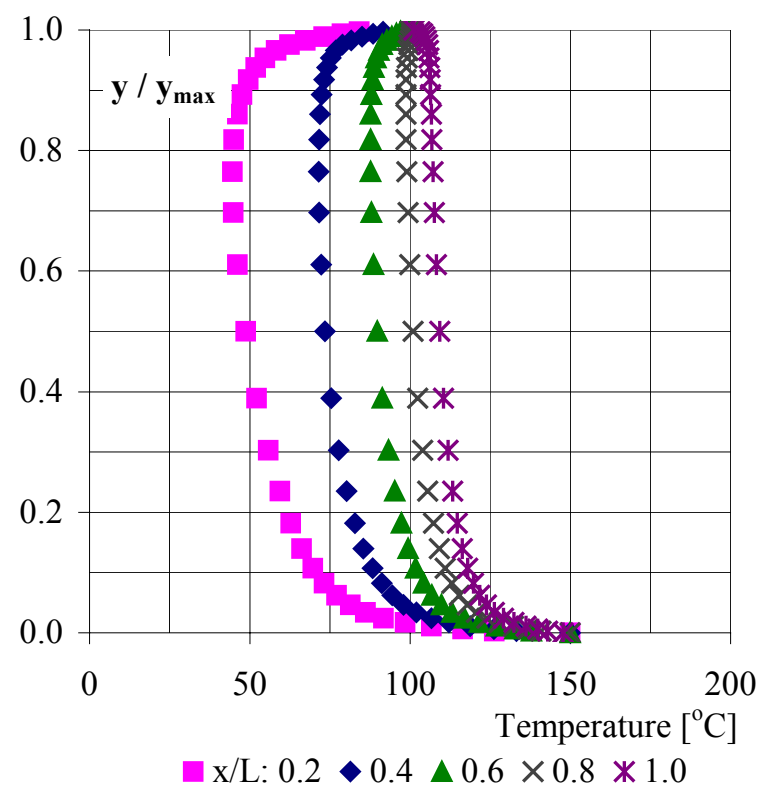

Figure 26. Temperature profiles at axial positions $x / L: 0.2,0.4,0.6,0.8$ and 1.0 , the rotation speed of the rotor is $80000 \mathrm{RPM}$. The $k-\varepsilon$ turbulence model is used. 


\subsection{Turbulence values}

The distribution of turbulent viscosity and turbulent kinetic energy on 30000 and 80000 RPM speed with the $k-\varepsilon$ model and 30000 RPM using the $k-\omega$ model are depicted in figures 2730.
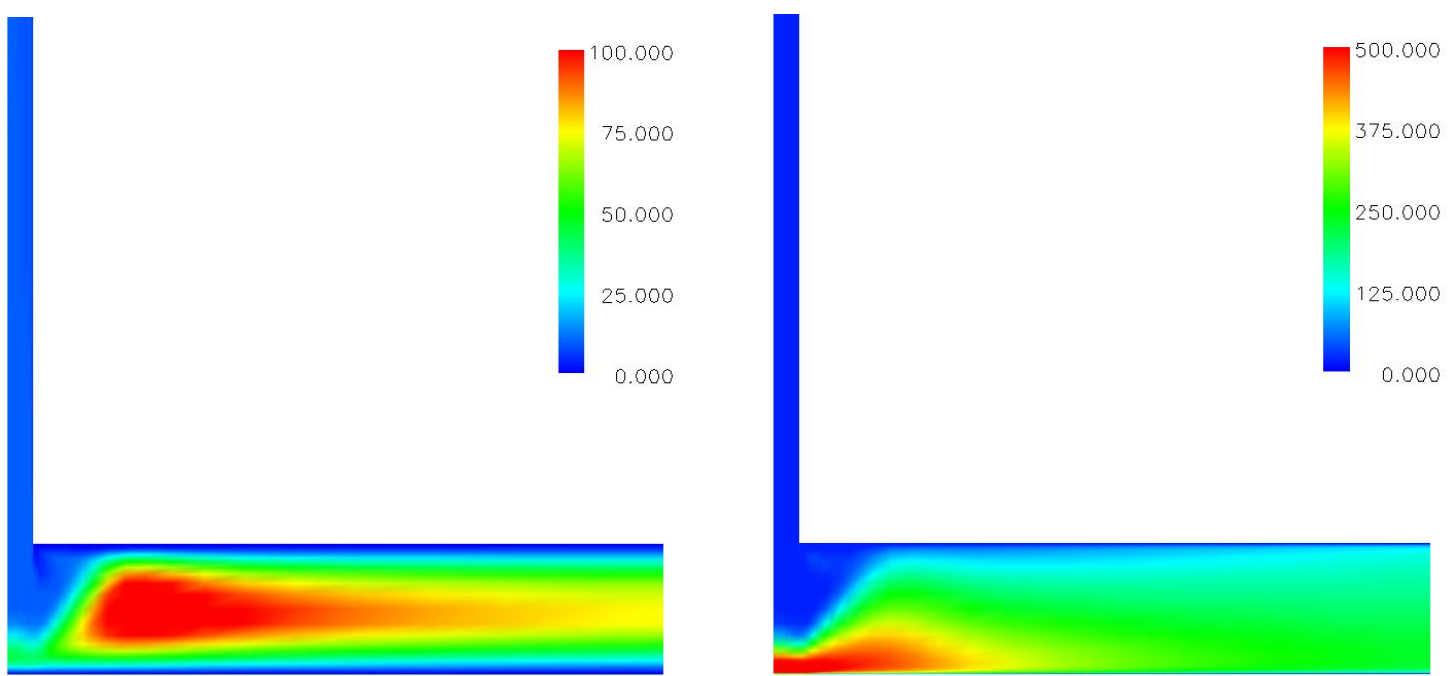

a)

b)

Figure 27. Turbulence values a) $\mu_{\mathrm{T}} / \mu$ and b) $\rho k$ for the $k-\varepsilon$ turbulence model at rotor peripheral speed $297 \mathrm{~m} / \mathrm{s}$.

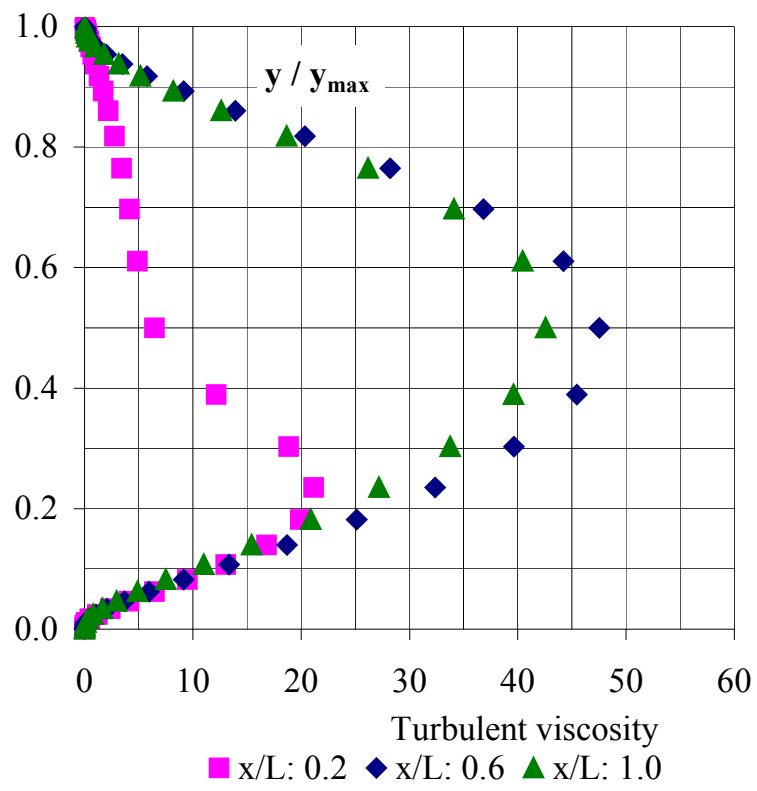

a)

Figure 28. a) Turbulent viscosity, b) kinetic energy of turbulence, 30000 RPM (112 m/s). The $k-\varepsilon$ turbulence model is used.

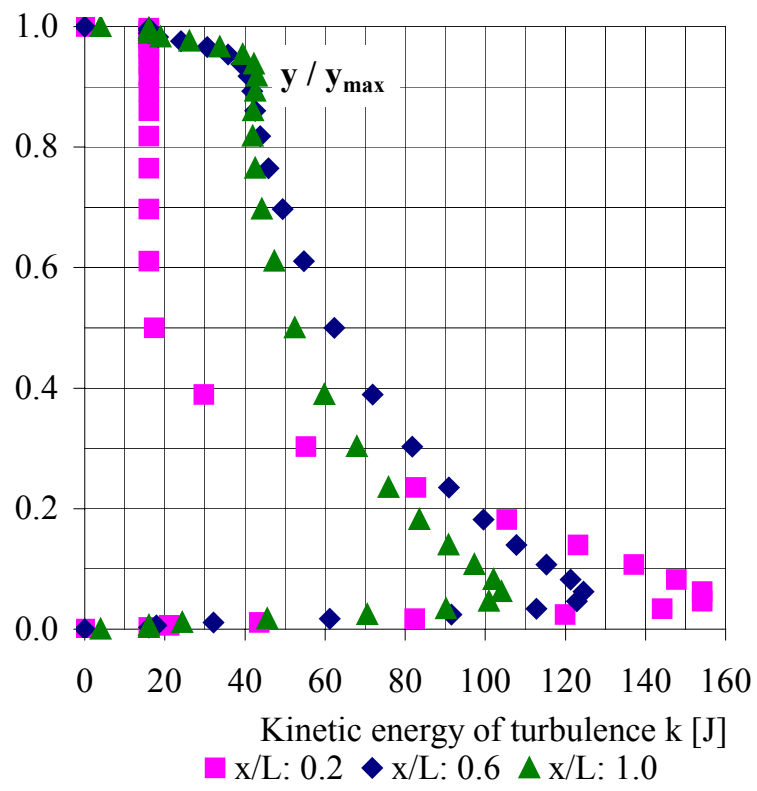

b) 


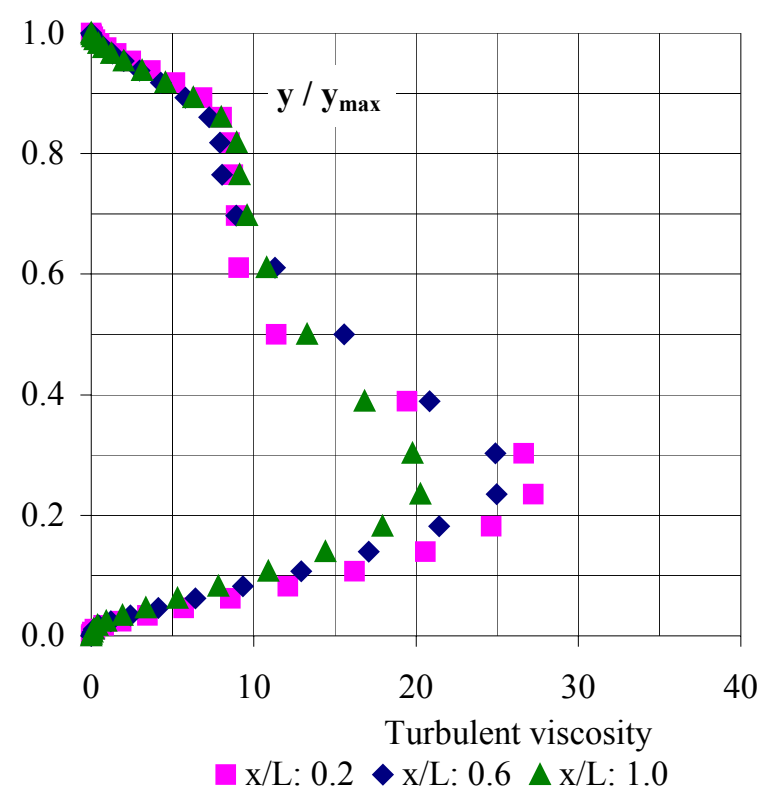

a) Figure 29. a) Turbulent viscosity, b) kinetic energy of turbulence, 30000 RPM; the $k-\omega$ turbulence model.

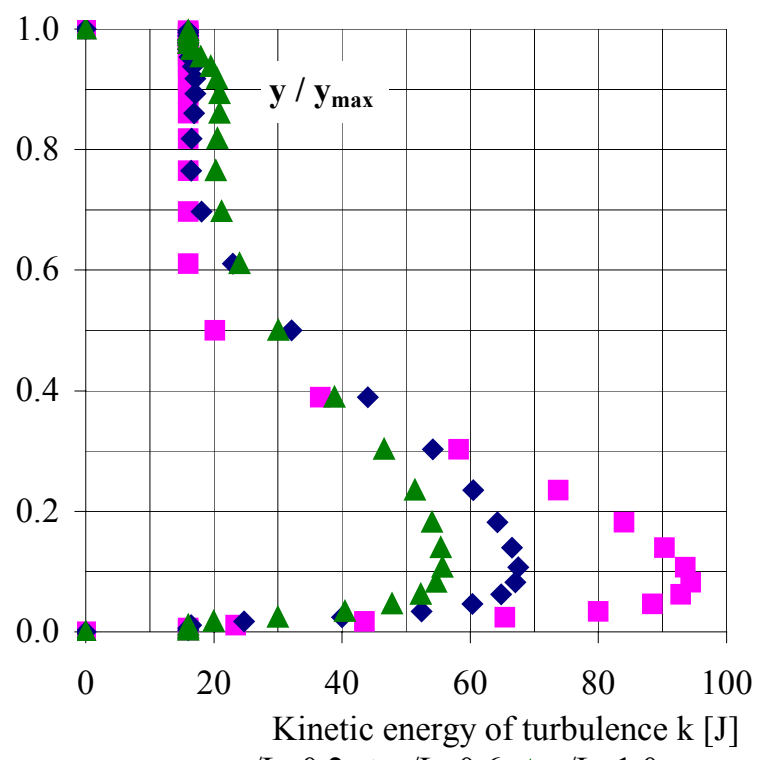

口 $/ \mathrm{L}: 0.2 \diamond \mathrm{x} / \mathrm{L}: 0.6 \Delta \mathrm{x} / \mathrm{L}: 1.0$

b) $\mathrm{x} / \mathrm{L}: 0.2 \diamond \mathrm{x} / \mathrm{L}: 0.6 \Delta \mathrm{x} / \mathrm{L}: 1.0$

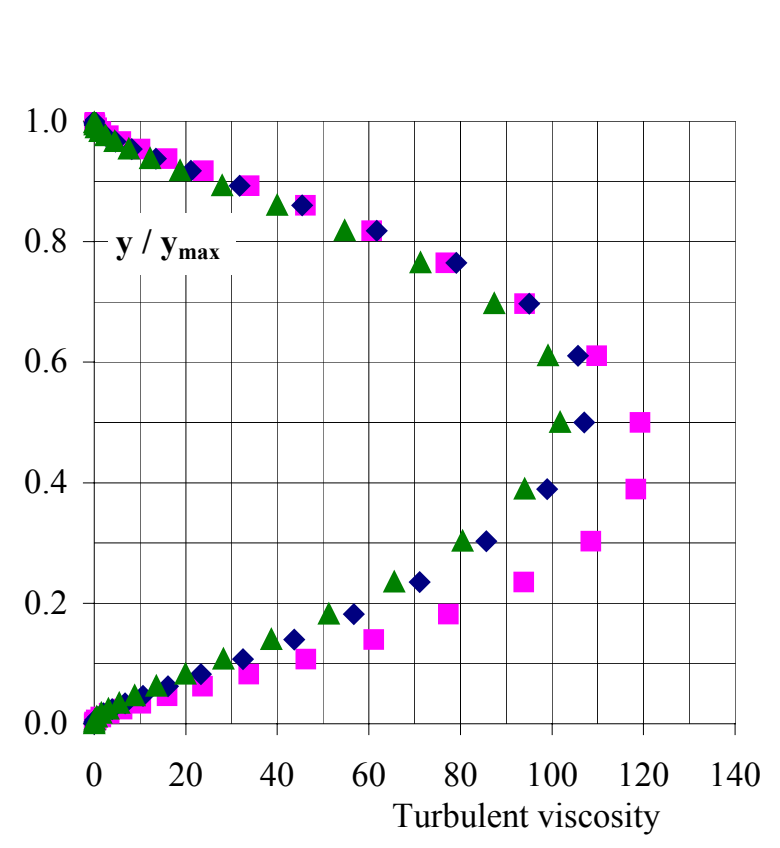

a)

Figure 30. a) Turbulent viscosity, b) kinetic energy of turbulence, 80000 RPM; the $k-\varepsilon$ model.

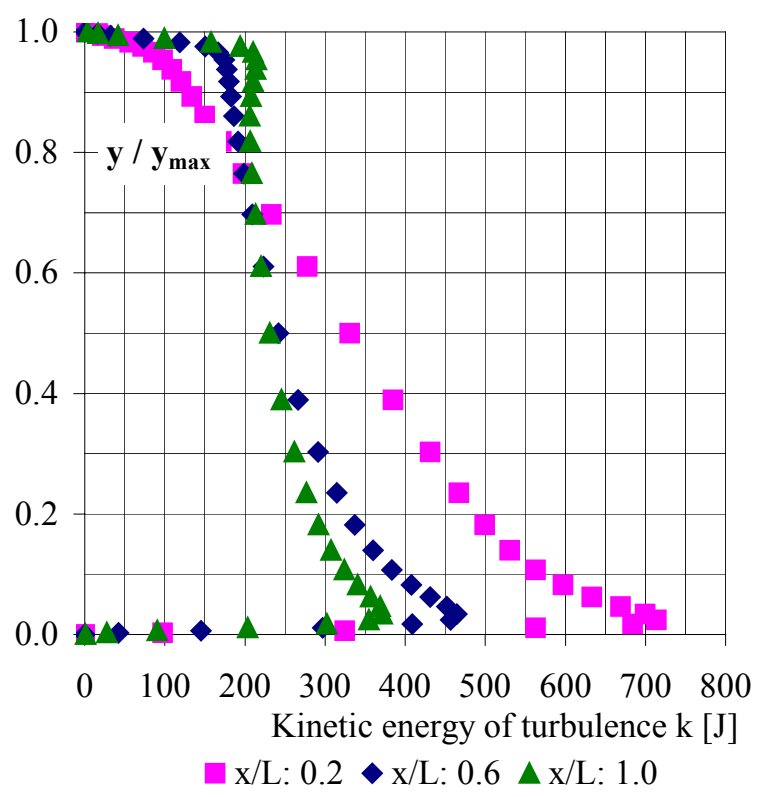

b)

For the $k-\varepsilon$ and $k-\omega$ models the degree of turbulence $k=1 / 3 u_{i}^{2} / U^{2}=0.2$ and a nondimensional turbulence coefficient $\mu_{T} / \mu=10$ are given at inlet and outlet boundaries. There the kinetic energy of turbulence and the dissipation of turbulence are calculated using these values. 


\subsection{Summary of the velocity and temperature fields and the turbulence values}

The streamlines of the air gap flow are in the mean flow helical direction. In the forced convection flow the buoyancy effects are small. Centrifugal effects (Taylor vortices) are not detected. There exist two swirls in the flow field from the stator slot to the air gap. The first of them is situated close to the wall in the stator slot, the second is close to the stator at the annular entry. The velocity profiles are roundest by the $k-\varepsilon$ model. The axial velocity increases a bit along the axial direction. The profiles in peripheral direction are not well developed until the end of the channel. The temperature rise at $1 / 2$ height in the air gap by the numerical method is between $50-85{ }^{\circ} \mathrm{C}$ for rotor peripheral speeds between $112-297 \mathrm{~m} / \mathrm{s}$. At 70 000-80 000 RPM the cooling air temperature exceeds the stator temperature (figure 25). The turbulent viscosity and kinetic energy of the turbulence values of the $k-\varepsilon$ model are bigger than the values of the $k-\omega$. The kinetic energy of turbulence attains the highest values close to the rotor surface in the beginning of the air gap. The turbulent viscosity values are highest in the first part at $1 / 2$ height of the channel. The turbulent viscosity does not change a lot in the axial direction. These values of the $k-\omega$ model (30 000 RPM) are situated more close the rotor surface $\left(y / y_{\max }=0\right)$. The turbulence values at 80000 RPM with $k-\omega$ are not logical. The turbulent viscosity is between 5-8.5, and the values of kinetic energy are constants on the whole height of $y / y_{\max }$ in the air gap.

\subsection{Friction coefficient and velocity factor}

Friction coefficients are modelled using the $k-\varepsilon$ and the $k-\omega$ turbulence model. The Finflo simulation is compared to the friction coefficients calculated from equations 8, 9 and Saari's (1998) results. The rotation speed is $500-1333 \mathrm{~Hz}$ (figure 31a) (30 $000-80000 \mathrm{RPM}$ ). Equations 8 and 9 are valid between the range of $403 \mathrm{~Hz}-4021 \mathrm{~Hz}$. The prediction of the friction coefficient by the $k-\omega$ model compares well to the results presented by Wendt (1993) and Bilgen \& Boulos (1973) and the result by Saari (figure 31a). It fits best, however, in the middle of the studied rotation speed range. The values of the $k-\varepsilon$ are smaller. The friction coefficient by the $k-\omega$ model deviates from the other results at the high and low end of rotation speed (Compare 0.0028 to 0.002 at $500 \mathrm{~s}^{-1}$, a $40 \%$ difference). 
The velocity factors are modelled by using the $k-\omega$ model at various rotational speeds. The values are compared to the measurements of Saari (1998) in figure 31b. The velocity factor (on the average 0.083 ) for air by the solver is lower than $k_{2}$ for R134a (Saari 1998) and lower than the average value 0.48 predicted by Polkowski (1984) and Dorfman (1963), but it fits well within the values of air measured by Saari (1998) (figure 31b). The Finflo software with the $k-\omega$ model is used successfully to solve the friction coefficient and velocity factor for the smooth stator-rotor combination.

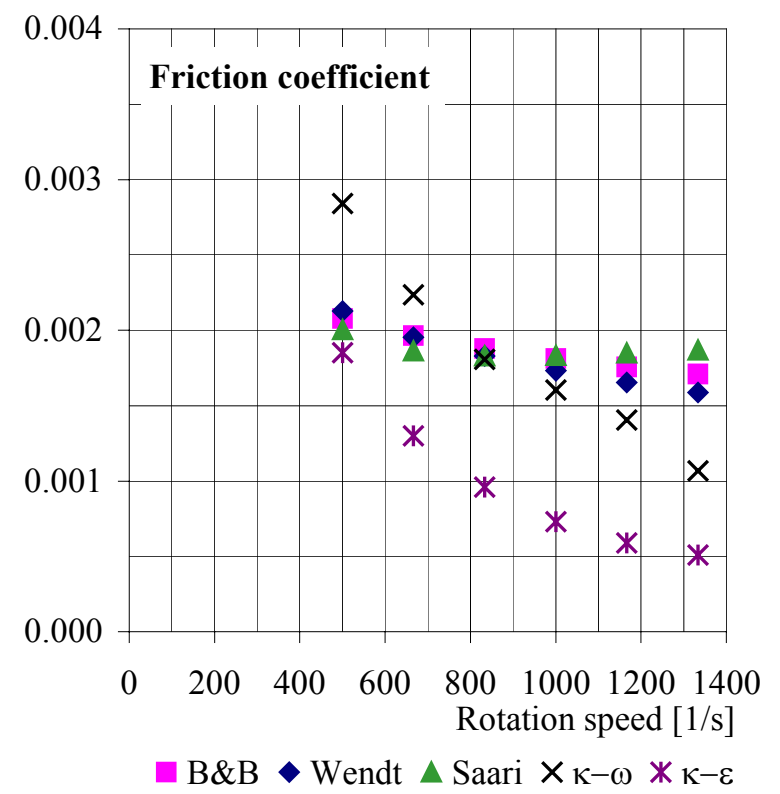
a)

Figure 31. a) Friction coefficient $C_{\mathrm{f}}$ and b) velocity factor $k_{2}$ presented at various rotation speeds.

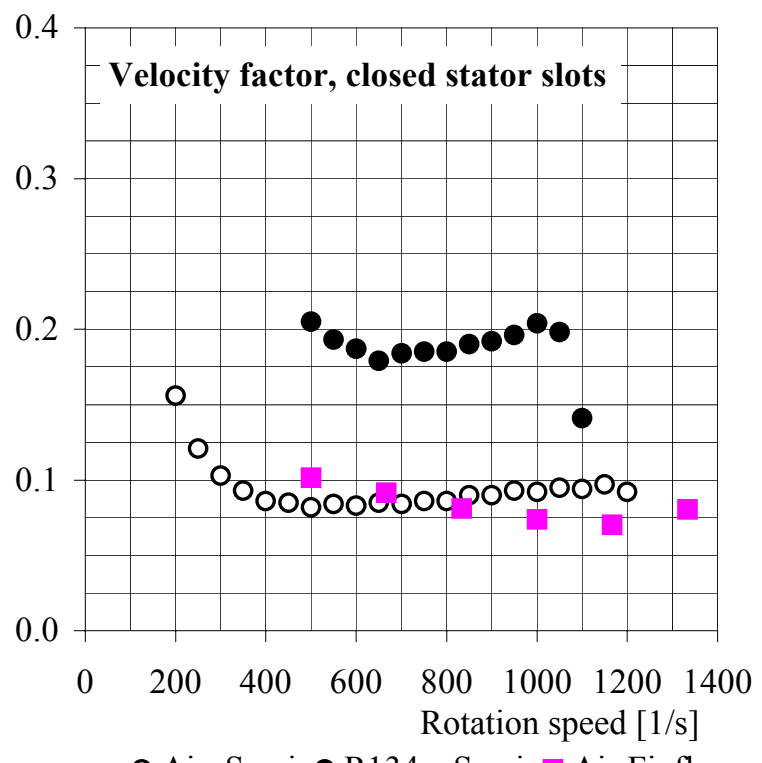

o Air: Saari • R134a: Saari $\square$ Air:Finflo

b)

The friction coefficient and the velocity factor are solved as follows. The friction torque $T$ is calculated by the torque coefficient $C_{\mathrm{M}}$ from equation 63 (Haapanen 1984)

$$
T=C_{M} \frac{1}{2} \rho u^{2} A_{r e f} l_{r e f}
$$

where $A_{\text {ref }}$ is the reference area (sector friction surface) and $l_{\text {ref }}$ the reference length (axial length of the sector). $u$ is the rotor peripheral speed. $C_{\mathrm{M}}$ is solved by Finflo. The friction loss $P$ is calculated as

$$
P=T \omega
$$


where $\omega$ is the angular velocity of the rotor. The respective friction coefficient $C_{\mathrm{f}}$ is solved from equation 11. The acceleration power (velocity factor) is calculated using two cooling air mass flow rates, $q_{\mathrm{m} 1}=0.02 \mathrm{~kg} / \mathrm{s}$ and $q_{\mathrm{m} 2}=0.06 \mathrm{~kg} / \mathrm{s}$. The simulated friction torque (equation 63 ) of the test machine as a function of the mass flow rate is graphically presented in figure 32. The rotational speed is $60000 \mathrm{RPM}$.

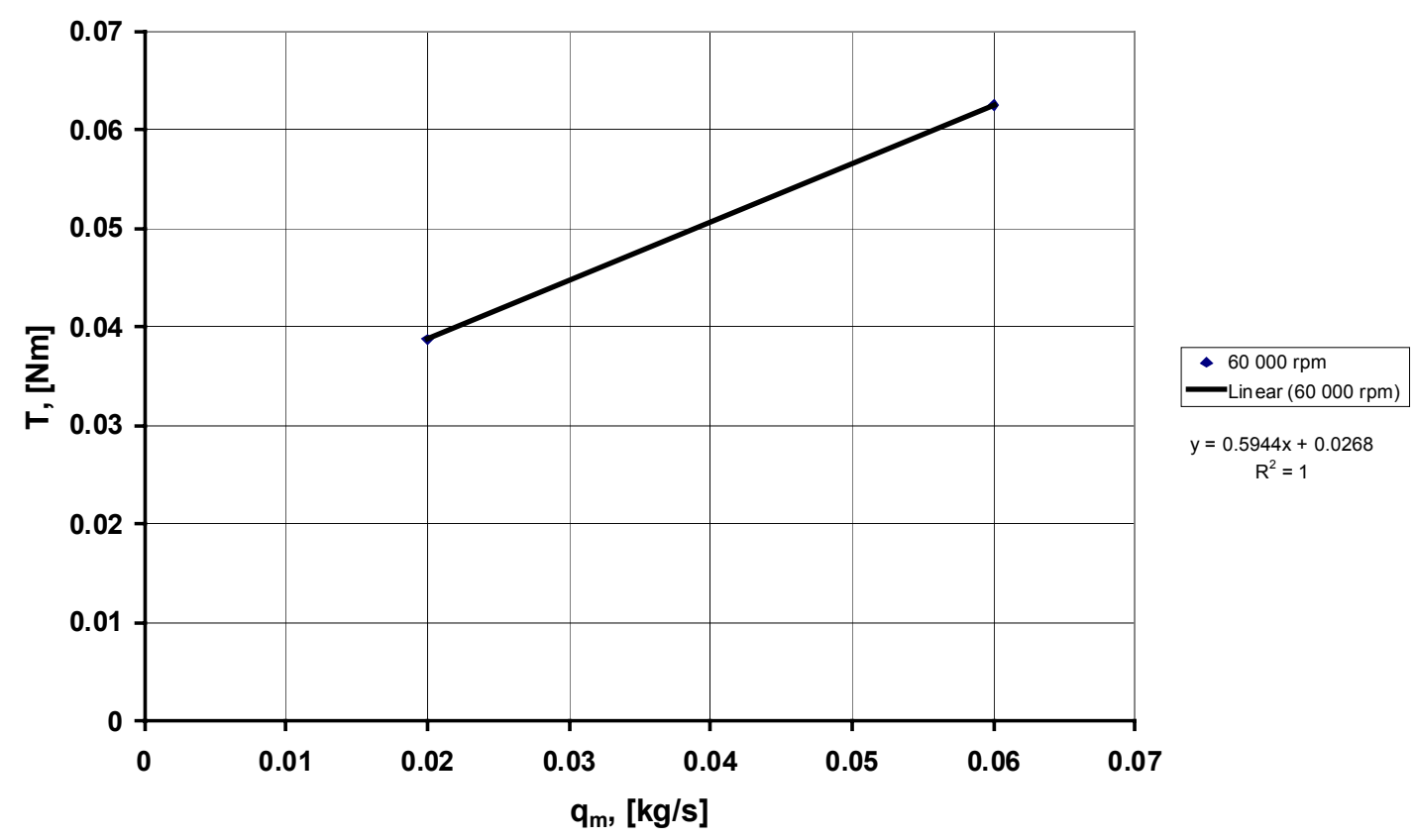

Figure 32. Friction torque presented as a function of the mass flow rate.

The slope of the linear fit gives zero mass flow rate torque. The velocity factor $k_{2}$ for the mass flow rate $0.02 \mathrm{~kg} / \mathrm{s}$ is calculated as

$$
k_{2}=\frac{P}{q_{m} u^{2}}
$$

where

$$
\begin{aligned}
& q_{m}=\Delta q_{m}=q_{m 2}-q_{m 1}=0.02 \mathrm{~kg} / \mathrm{s}-0 \mathrm{~kg} / \mathrm{s}=0.02 \mathrm{~kg} / \mathrm{s} \\
& T=\Delta T=T_{2}-T_{1}=0.0387 \mathrm{Nm}-0.0268 \mathrm{Nm}=0.0119 \mathrm{Nm} \\
& P=\Delta T \omega=0.0119 \mathrm{Nm} \cdot 6283 \mathrm{rad} / \mathrm{s}=74.7677 \mathrm{~W} \\
& u=223 \mathrm{~m} / \mathrm{s}
\end{aligned}
$$


$k_{2}=0.0752$ is solved from equation 65. The numerical flow simulation is done using the sector of $1 / 32$ of the total peripheral length. Hence the torque in figure 32 is received by multiplying it by 32 .

\subsection{Local and mean heat transfer coefficients}

Heat is transferred from the hotter rotor and stator surfaces to the cooler air gap flow. Principally heat is not transferred between the rotor and stator surfaces. Thus heat transfer is conveniently calculated along the axial direction of the machine. The heat transfer coefficients are calculated on six rotational speeds with rotor peripheral speed between 112-297 m/s (30 000-80 000 RPM). The results of the three turbulence models can be compared. The local heat transfer coefficients are shown in figures 33-35 as a function of the axial position of the air gap. The mean heat transfer coefficients are presented in figure 36 as a function of rotation speed. The dimensions of the example are shown in table 1. The local heat transfer coefficients are calculated from the axial heat flux distribution normal to the walls, from constant wall temperatures, and by axially rising the gas bulk temperatures as follows

$$
h=\frac{\Phi^{\prime \prime}}{T_{w}-T_{f}}
$$

where $\Phi^{\prime \prime}$ is the local heat flux, $T_{\mathrm{w}}$ the wall temperature of the stator or the rotor and $T_{\mathrm{f}}$ the local bulk temperature of the fluid.

The mean heat transfer coefficients are achieved by averaging the local heat transfer coefficients. There exists a stator whirl close to the stator at the annular entry. The probable effect of the stator whirl there is a lower stator heat transfer on lower speeds. This is visible in figure 33a for the $k-\varepsilon$ turbulence model. At 70 000-80 000 RPM the cooling air temperature (figure 25) exceeds the stator temperature. Thus in the end of the annulus the heat transfer from the stator to the cooling air flow decreases and the direction of the heat flux is converted towards the stator surface. On the constant mass flow rate the rotor heat transfer coefficient attains a saturation point at a higher rotational speed (figures 33b, 34b, 35b and 36b) close 70 000 RPM $(1166 \mathrm{~Hz})$. The heat transfer coefficient of the stator grows uniformly. 
Themagnitudes of the mean heat transfer coefficients are almost constant with the different turbulence models.

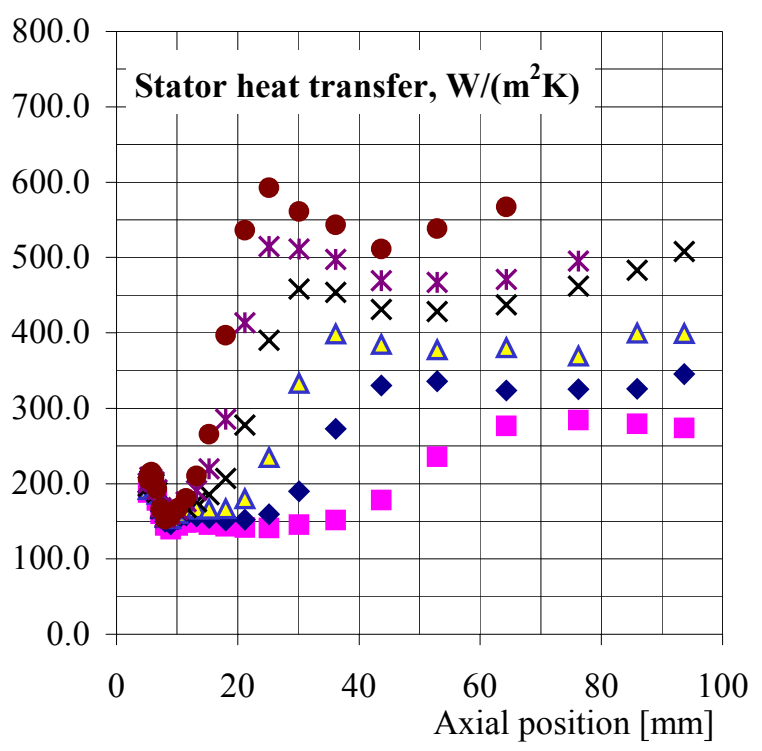

$10^{3} \mathrm{RPM}: \quad \square \quad 30 \bullet 40 \Delta 50 \times 60 * 70 \bullet 80$

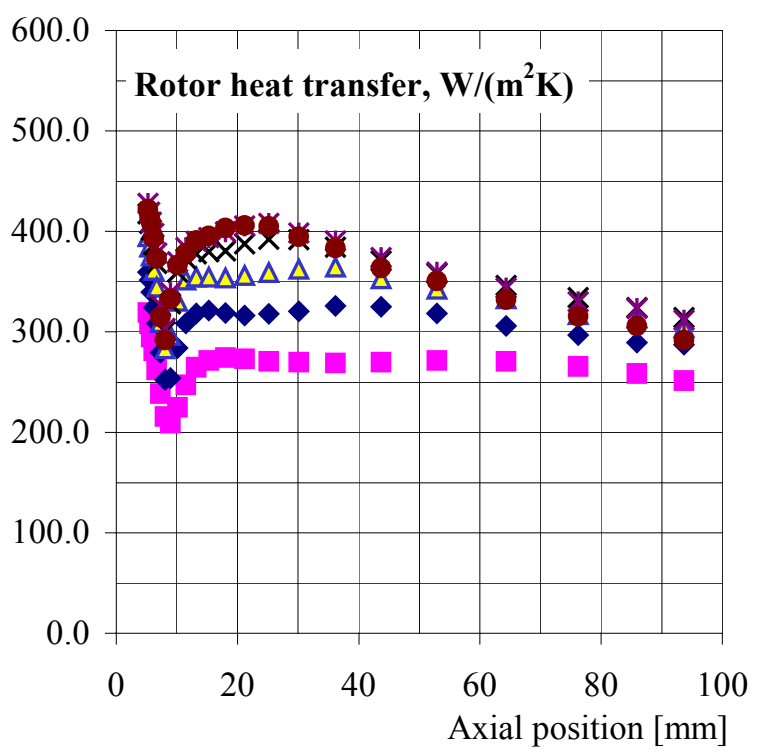

$10^{3} \mathrm{RPM}: \quad \square \quad 30 \bullet 40 \Delta 50 \times 60 * 70 \bullet 80$

a)

b)

Figure 33. Local a) stator, b) rotor heat transfer coefficients in the axial direction of the annulus, the rotational speed is between $30000 \ldots 80000 \mathrm{RPM}$. The $k-\varepsilon$ turbulence model is used.

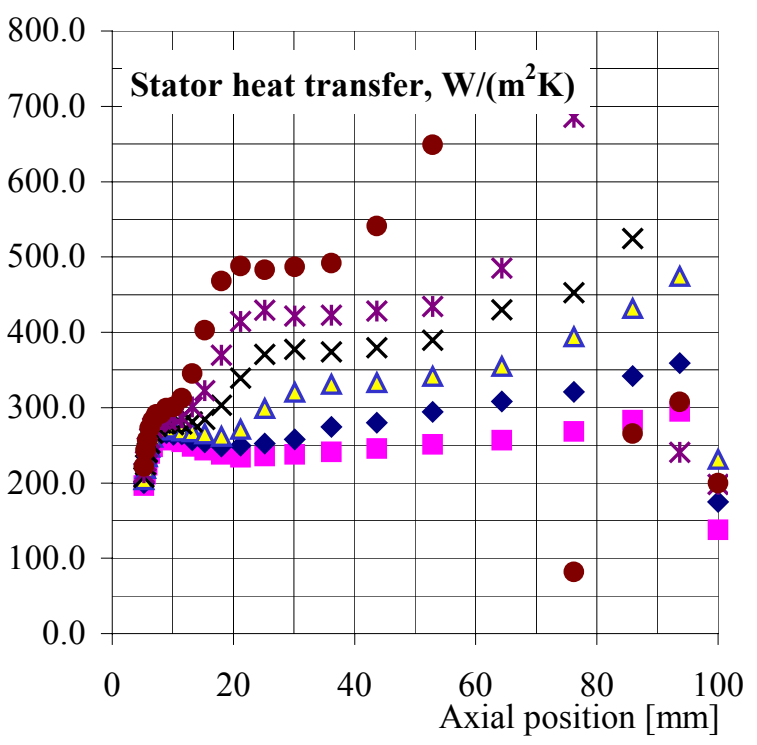

$10^{3} \mathrm{RPM}: \quad \square 30 \bullet 40 \Delta 50 \times 60 * 70 \bullet 80$

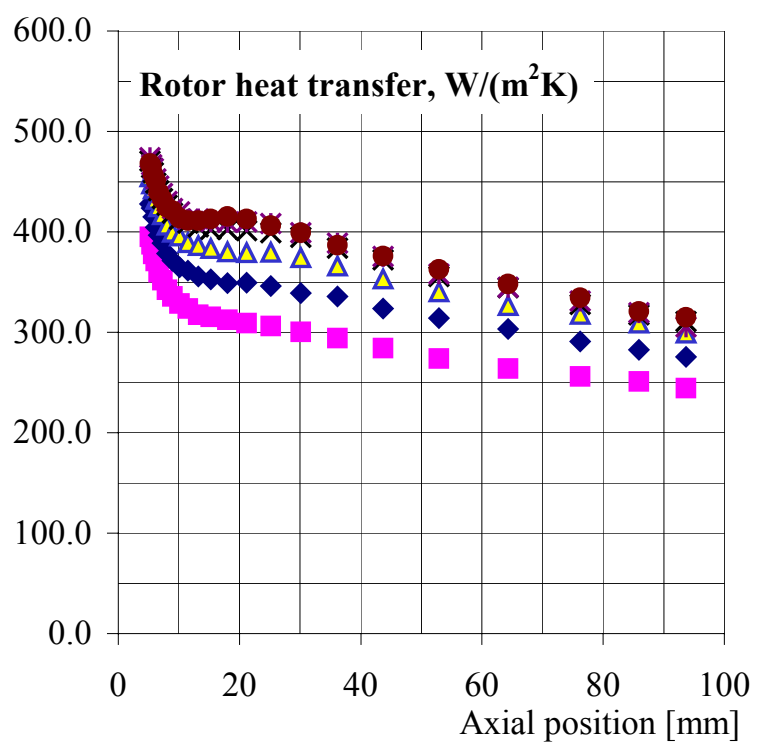

$10^{3} \mathrm{RPM}: \quad \square 30 \bullet 40 \Delta 50 \times 60 * 70 \bullet 80$

a)

b)

Figure 34. Local a) stator, b) rotor heat transfer coefficients in the axial direction of the annulus, the rotational speed is between $30000 \ldots 80000 \mathrm{RPM}$. The $k-\omega$ turbulence model is used. 


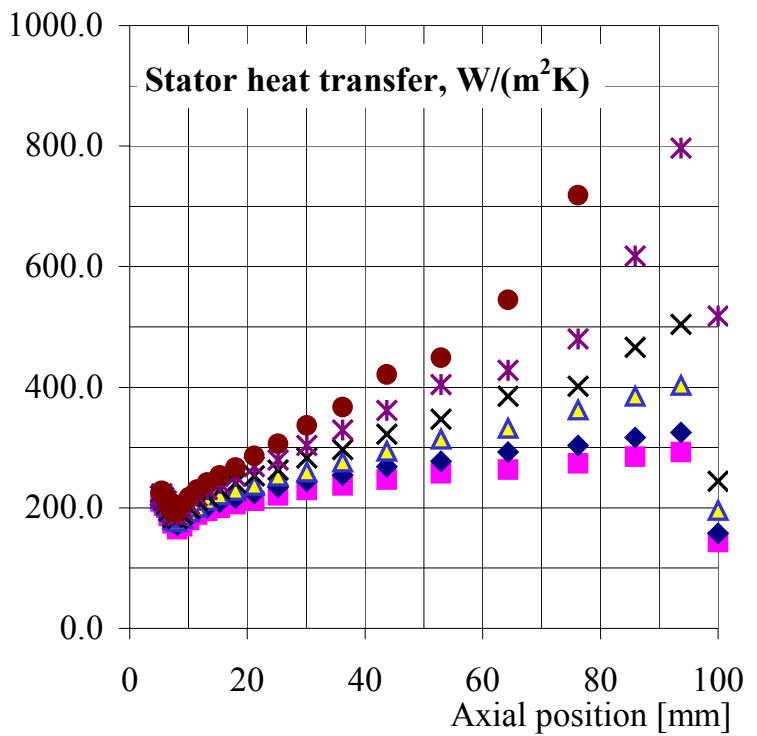

$10^{3} \mathrm{RPM}: \quad \square \quad 30 \bullet 40 \Delta 50 \times 60 * 70 \bullet 80$

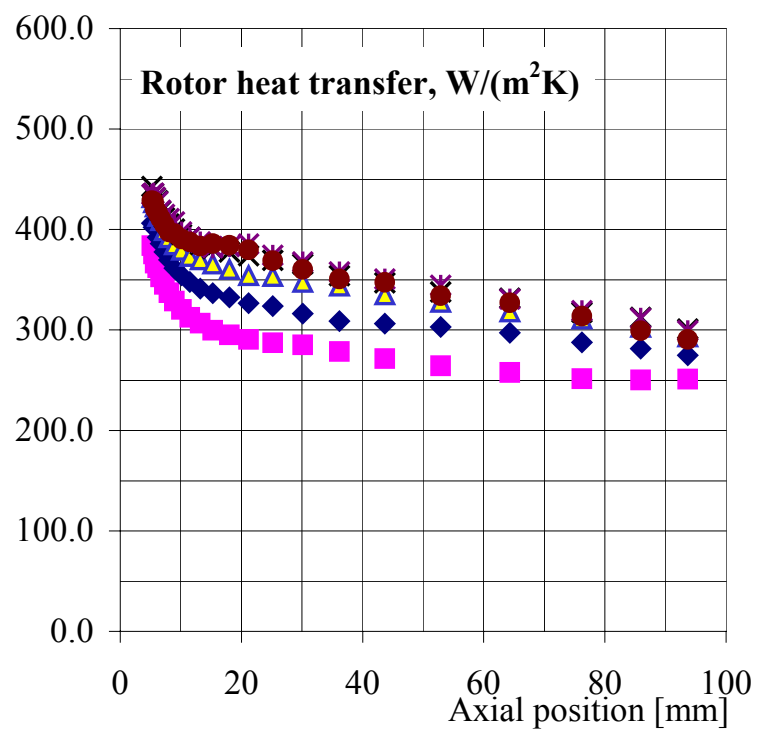

$10^{3} \mathrm{RPM}: \quad \square \quad 30 \diamond 40 \Delta 50 \times 60 * 70 \bullet 80$

a)

b)

Figure 35. Local a) stator, b) rotor heat transfer coefficients by the Baldwin-Lomax turbulence model. The rotational speed is between $30000 \ldots 80000 \mathrm{RPM}$.

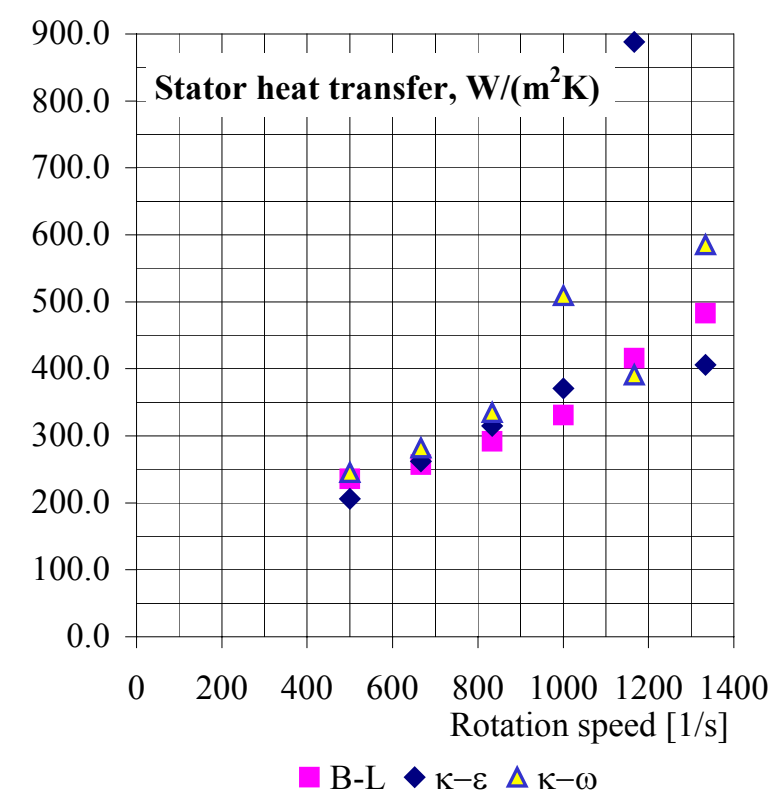

a)

Figure 36. Calculated mean heat transfer coefficients between a) stator and b) rotor and cooling air. The rotation speed is between $500-1333 \mathrm{~Hz}$. Three turbulence models are used: the algebraic BaldwinLomax turbulence model, the low-Reynold's number $k-\varepsilon$ model proposed by Chien and the $k-\omega$ SST turbulence model by Menter. (Measured data: figure 52)

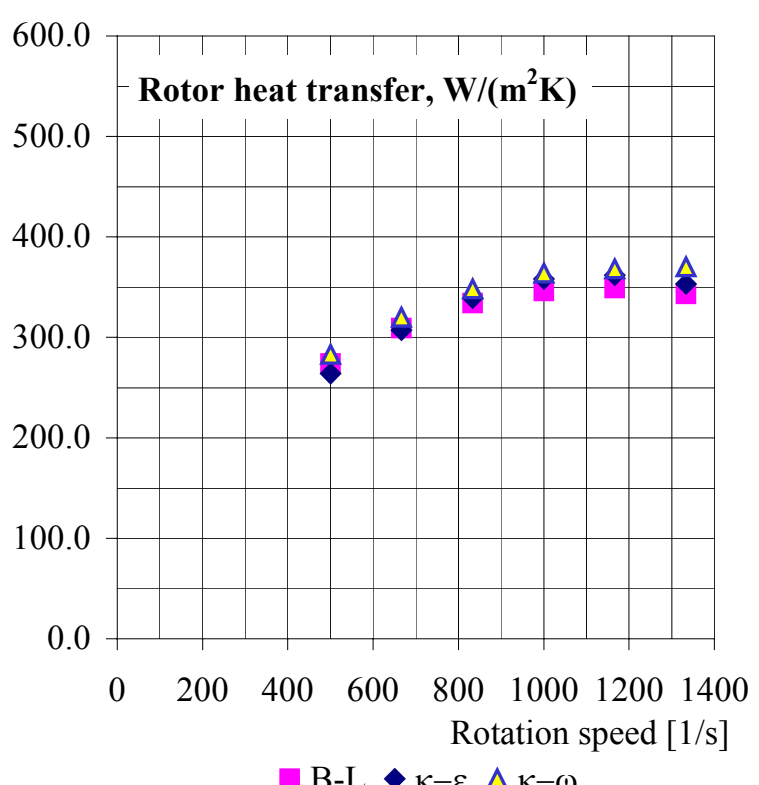

b) 


\section{Peak values}

All the three turbulence models predict the same average heat transfer, but exhibit some local differences. The local heat transfer coefficients of the rotor decrease in the axial direction while the stator coefficients are constant or increase. The mean values reflect a dependence on the rotational speed. There exists a peak value of the stator local heat transfer coefficient close the to area where heat flux changes its sign at 70 000-80 000 RPM speeds. This has an effect on the mean values as well (peak values, figure 36a). This is due to the fact that at these speeds the cooling air temperature exceeds the stator temperature in the end of the annular channel. In the following axial positions at 70000 RPM and 80000 RPM speeds the air flow temperature is higher than the stator temperature:

\section{$\underline{70000 ~ R P M}$}

$\begin{array}{lllllll}k-\varepsilon: & T_{\text {air }}> & T_{\text {stator }} & \text { at } & 93.7 \mathrm{~mm} \\ k-\omega: & T_{\text {air }}> & T_{\text {stator }} & \text { at } & 85.9 \mathrm{~mm} \\ \text { B }-\mathbf{L}: & T_{\text {air }}< & T_{\text {stator }} & & \end{array}$

\section{$\underline{80000 \text { RPM }}$}

$\begin{array}{llllll}k-\varepsilon: & T_{\text {air }}> & T_{\text {stator }} & \text { at } & 76.2 \mathrm{~mm} \\ k-\omega: & T_{\text {air }}> & T_{\text {stator }} & \text { at } & 76.2 \mathrm{~mm} \\ \text { B }-\mathrm{L}: & T_{\text {air }}> & T_{\text {stator }} & \text { at } & 93.7 \mathrm{~mm}\end{array}$

The turbulence model, the rotation speed, the axial position and the size of the stator peak values are presented in table 3. The peak value for the $k-\varepsilon$ turbulence model is found at 70 000 RPM speed. The peak values of the $k-\omega$ and B - L models are found at 80000 RPM speed. These peak values are in the axial positions, a small distance before the point where the air temperature exceeds the stator temperature. The peak values can be explained by a small temperature difference $\Delta T=T_{\mathrm{w}}-T_{\mathrm{f}}$ between the stator wall and the local mean fluid temperature. At the small temperature difference inaccuracy and uncertainty in the numeric method have a strong affect. Because of the big sizes of these values they are not visible in figures 33-35. These peak values increase the mean heat transfer coefficients in figure 36a at 70 000-80 000 RPM speeds. After these peak values the heat flux is turned towards the stator ( $T_{\text {air }}>T_{\text {stator }}$ ). In figure $34 \mathrm{a}$ at $80000 \mathrm{RPM}$ speed at the $\mathrm{x}>64.3 \mathrm{~mm}$ the local heat transfer coefficients towards the stator are included. 
Table 3. The rotation speed, the axial position and the size of the stator peak value $h_{\text {peak }}$ of the three turbulence models $k-\varepsilon, k-\omega$ and $\mathrm{B}-\mathrm{L}$.

\begin{tabular}{|c|c|c|c|}
\hline Turbulence model & Rotation speed, RPM & Position, $\mathrm{mm}$ & $h_{\text {peak }}, \mathrm{W} /\left(\mathrm{m}^{2} \mathrm{~K}\right)$ \\
\hline$k-\varepsilon$ & 70000 & 85.9 & 4223 \\
\hline$k-\omega$ & 80000 & 64.3 & 1970 \\
\hline $\mathrm{B}-\mathrm{L}$ & 80000 & 85.9 & 1640 \\
\hline
\end{tabular}

\subsection{Results of air gap with grooved stator}

A sector mesh of $10^{\circ}$ with 20 blocks and 113280 cells is made to calculate the flow in an air gap with a grooved stator (figure $37 \mathrm{a}$ ). The stator consists of 36 slots. The depth and the width of the slot are $2 \mathrm{~mm}$ and $2.5 \mathrm{~mm}$ (figure $2 \mathrm{~b}$ ). The flow rate $0.04 \mathrm{~kg} / \mathrm{s}$ through the air gap is twice the non-grooved rate $0.02 \mathrm{~kg} / \mathrm{s}$ (total $0.08 \mathrm{~kg} / \mathrm{s}$ ). The stator and rotor temperatures are 100 and $150{ }^{\circ} \mathrm{C}$. The rotational speed is $5,10,20,30$ and $4010^{3} \mathrm{RPM}$. The $k-\omega$ turbulence model is used. The temperature field is shown in figure 37b in Kelvin degrees (30 000 RPM). It is immediately evident that high temperatures are cumulated at the stator slot. The axial velocity and temperature profiles are presented on dimensionless sequenced axial positions in figure 38 (30 000 RPM).

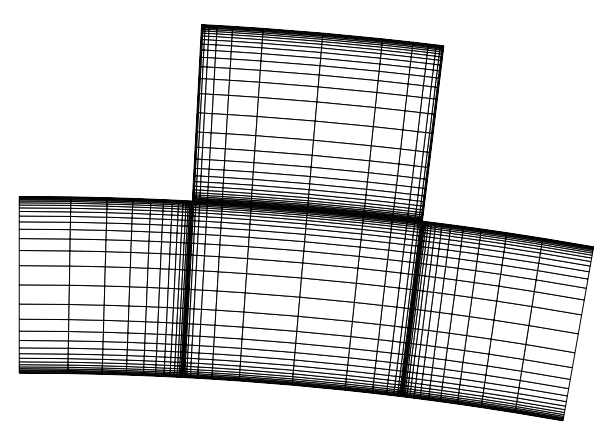

a)

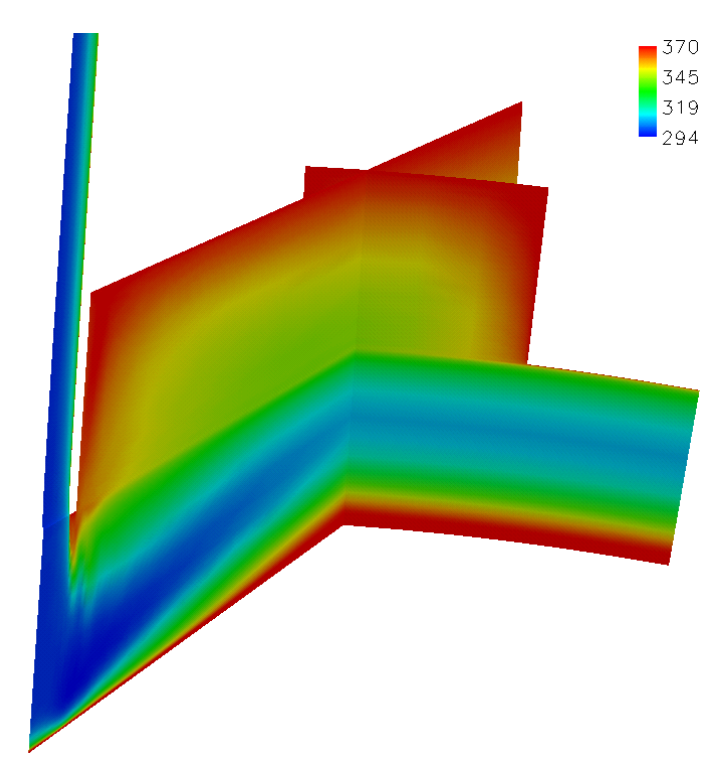

b)

Figure 37. Air gap with grooved stator: a) grid, b) temperature field (K). 
The sum of the dimensionless heights of the air gap and the slot is 2 in the following way: $y / y_{\max }=0$ : rotor surface, 1: stator slot begins, 2: stator slot ends. These velocity and temperature profiles show reasonable behaviour at the 30000 RPM speed.

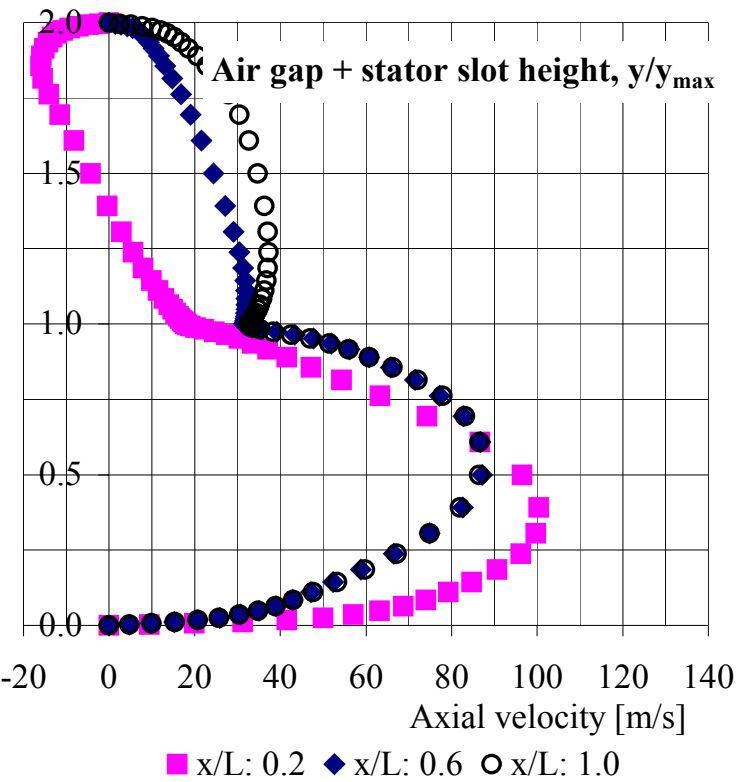

a)

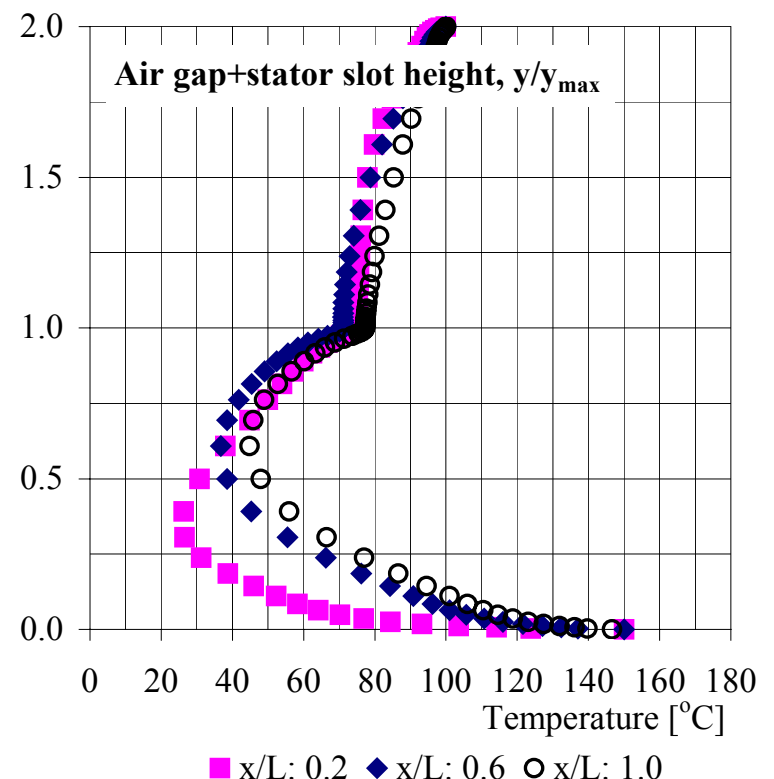

b)

Figure 38. a) Velocity, b) temperature profile in the axial direction, 30000 RPM, the $k-\omega$ model.

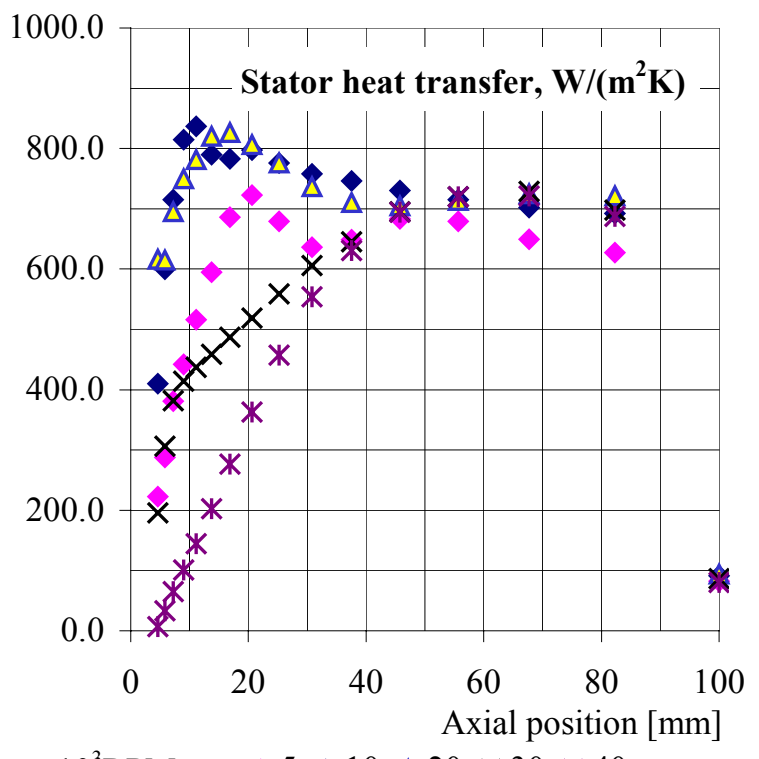

$10^{3} \mathrm{RPM}: \quad 5 \diamond 10 \Delta 20 \times 30 * 40$

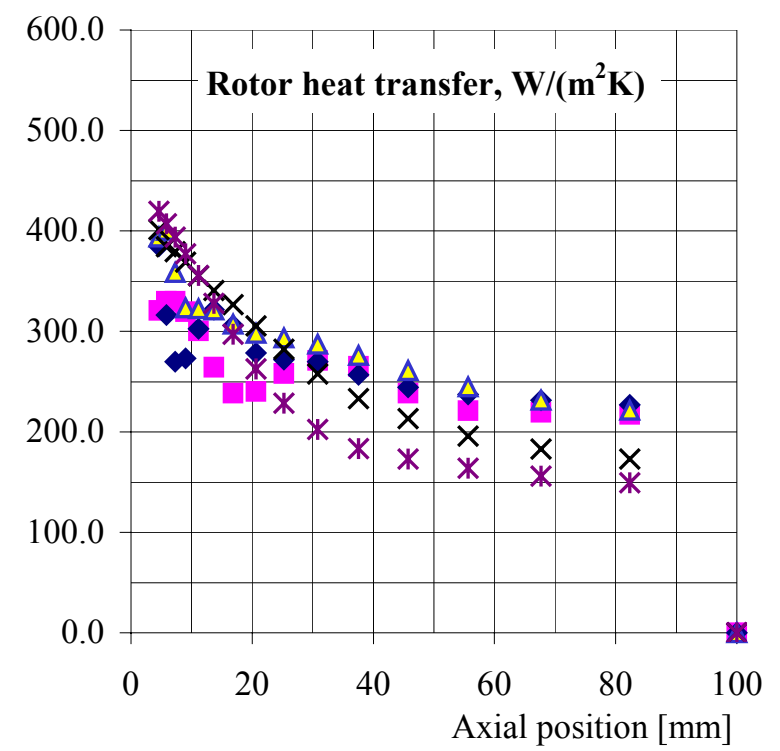

$10^{3}$ RPM: $\quad 5 \diamond 10 \Delta 20 \times 30 * 40$

a)

b)

Figure 39. Grooved stator and smooth rotor: a) the stator and b) the rotor local heat transfer coefficient as the function of the axial position of the air gap. The rotation speed is 5, 10, 20, 30 and $4010^{3} \mathrm{RPM}$. 
The local heat transfer coefficients of the stator-rotor combination as a function of the axial position of the air gap are presented in figure 39. The rotation speed is $5,10,20,30$ and 40 $10^{3} \mathrm{RPM}$. The figure 39 characterizes the heat transfer on the surfaces of the main parts of the test machine due to the grooves in the stator. According to figure $39 \mathrm{a}$ the stator heat transfer is increased by using these grooves. It is highest at 10 000-20 000 RPM speeds. The rotor heat transfer is decreased compared to the results with the smooth rotor-stator combination (figure $34 b)$.

\subsection{Summary of results}

A suitable sector grid with 42496 cells was introduced. The turbulence model did not affect the computational results significantly. The magnitudes of the attained mean heat transfer coefficients were almost the same with the different turbulence models. The two-equation models $k-\varepsilon$ and $k-\omega$ were used as main alternatives. The algebraic B $-\mathrm{L}$ model confirmed the simulation. The obtained results were qualitative. The absence of secondary Taylor vortices was evident. This was probably due to the Reynolds-averaged numeric simulation of the Navier-Stokes equations or the use of the isotropic turbulence assumption with one and two-equation eddy-viscosity models in the highly rotational flow. Comparison with measurements is necessary. This is done in the experimental part of the present work.

According to the calculations, the kinetic energy of turbulence is strongest in the beginning of the air gap after airflow impingement on the rotating rotor surface. Turbulent viscosity is also strongest in the first part of the annular channel. The velocity and temperature gradients are strongest close to the walls. As a result, high levels of friction and heat transfer are found in this region. Turbulence increases the amounts of friction and heat transfer at the surfaces of the stator and the rotor, and also in the air gap.

The friction coefficient $C_{\mathrm{f}}$ and velocity factor $k_{2}$ were calculated via the torque coefficients $C_{\mathrm{M}}$. The $C_{\mathrm{M}}$ was solved numerically. The Finflo software with the $k-\omega$ model was successfully used to solve the friction coefficient and velocity factor of the high-speed electric machine for a smooth stator-rotor combination. The magnitudes of these are quantitative and comparable to the existing semi-empiric data and measurements of Saari (1998). 
Heat is transferred from the hotter stator and rotor surfaces to the cooler air flow in the air gap, not from the rotor to the stator via the air gap. On a constant mass flow rate the rotor heat transfer coefficient attains a saturation point close to the rotation speed of $1166 \mathrm{~Hz}$. The heat transfer coefficient of the stator grows uniformly. All three turbulence models predict the same average heat transfer but exhibit some local differences. Peak values of the local heat transfer coefficients are detected at 70 000-80 000 RPM speeds in the end of the annular channel. The direction of the heat flux is changed towards the stator in the region where the cooling air temperature exceeds the stator temperature. This can be avoided by using bigger mass flow rates. However, these peak values increase the numerically simulated mean heat transfer coefficients of the stator. 


\section{EXPERIMENTAL WORK}

\subsection{Introduction}

The experimental part of this study consists of the testing of heat transfer probes and telemetry in a straight pipe, and measurements of mean heat transfer coefficients in an air gap of a high-speed electric test motor. These measurements are done at different axial flow velocities between $40-70 \mathrm{~m} / \mathrm{s}\left(\mathrm{Re}_{\mathrm{a}}\right.$ : 9449-13986) and rotor peripheral speeds between 40-150 $\mathrm{m} / \mathrm{s}\left(\mathrm{Re}_{\delta}:\right.$ 4725-14985). The heat transfer coefficients are measured by the heat fluxes normal to the walls, using the wall temperatures and the bulk temperature of the gas.

The test rotor is vertical and supported by gas bearings. The rotor has the same dimensions, cooling gas input temperature and mass flow rate as those used in the numerical modelling. In the previous part of the research by Saari in 1998, friction coefficients were measured and calculated using the same test rotor.

The first step in the implementation of the measurements was to find proper sensors for the heat transfer measurements. The selected sensors were Dantec CTA glue-on hot-film probe (Bruun 1995), a sensor made at LUT, and an RdF-sensor (Japikse 1986). The preliminary tests were performed inside a straight air flow pipe. The chosen axial mean flow velocity was equivalent to the flow velocity caused by the rotating rotor. During these tests the RdF-sensor was found to be the most proper instrument. Telemetry was needed to measure the heat transfer from the rotating rotor to the cooling air flow. Voltage signals were transmitted out of the rotor using infrared technology. This telemetry device has been designed and built at LUT. It was tested in the pipe conditions before mounting it in line at the end of the rotor. The heat transfer behaviour of the rotor was measured using the RdF-sensor, which was glued to the outer surface of the axis and connected by wire into the telemetric transmitter inside the central bore hole of the axis through an inclined bore. The centrifugal forces cause high stresses at the bore notches. These were minimized by locating the inclined bore optimally by using analytical models and FEM (Kuosa 2001).

Mean heat transfer coefficients are measured in the test machine on four cooling air mass flow rates at a wide velocity range (10 $000-40000$ RPM). 


\subsection{Design and implementation of measurements}

\subsubsection{Heat transfer sensors and thermocouples}

An effort was made to find the proper sensor for heat transfer measurements in this application. Three sensors were tested: Dantec CTA glue-on hot-film probe, a sensor made at LUT, and an RdF-sensor. The idea was that the sensors would first be tested in a straight pipe flow. After the tests the most promising sensor was selected to measure the heat transfer in the test machine. The pipe (inner diameter $24 \mathrm{~mm}$, upstream straight length $1 \mathrm{~m}$, figure 40) has been designed to have the same mean axial fluid velocity as the rotation speed of the test rotor. The advantage of this pipe flow arrangement is that it is easy to calculate the heat transfer coefficient in known flow conditions and compare them to the values measured by the test sensor. The sensor is calibrated when measured and calculated heat transfer coefficients from the semi-empiric equations are equal. Using this arrangement it is possible to test and calibrate sensors to find the most promising one. The calibration pipe and the LUT-sensor are presented in figures 40 and 44.

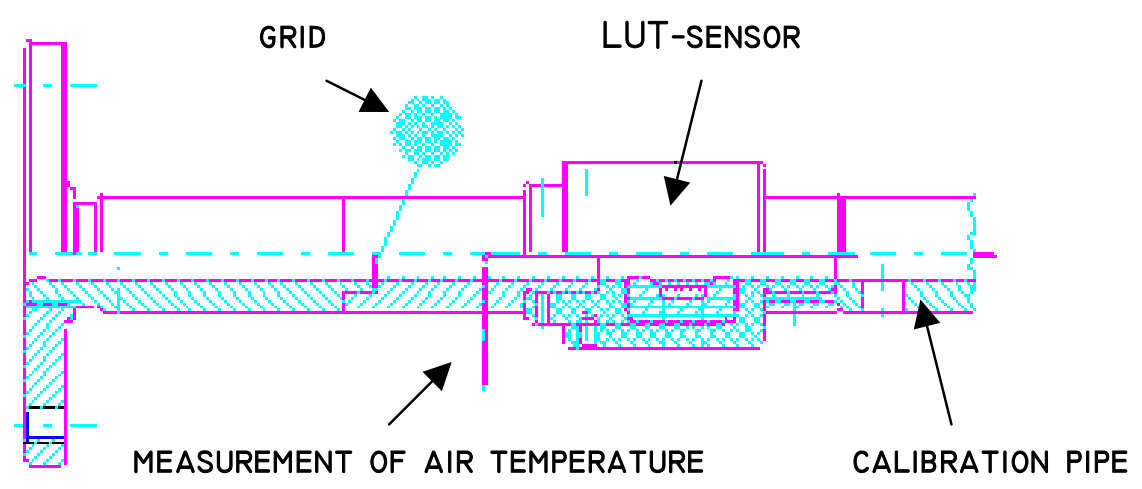

Figure 40. Calibration pipe and LUT sensor. Drawing: Jukka Lattu / LUT

It is known that a constant temperature anemometer gauge can be used to measure flow velocity and heat transfer. The Dantec CTA glue-on hot-film probe was first tested. The Dantec 56C17 CTA bridge was used to supply electric power to the film sensor to keep it at constant temperature in the cooling air flow. According to the preliminary tests performed at LUT the Dantec CTA glue-on hot-film probe was not a proper instrument for the heat transfer 
measurements. The measured heat transfer coefficients were $5038 \mathrm{~W} /\left(\mathrm{m}^{2} \mathrm{~K}\right)$ for $24 \mathrm{~m} / \mathrm{s}$ and $5625 \mathrm{~W} /\left(\mathrm{m}^{2} \mathrm{~K}\right)$ for $55 \mathrm{~m} / \mathrm{s}$ axial flow velocities. These values were far too high.

The LUT sensor (figures 40, 44) consists of a copper ring (wall thickness $3 \mathrm{~mm}$, length 30 $\mathrm{mm}$, inner diameter $24 \mathrm{~mm}$ ) is mounted to the end of a $1 \mathrm{~m}$ calibration pipe. The ring is heated by a resistance wire placed at the outer diameter. The ring is cooled by pipe air flow. Heat insulation is made by a brick K-23 casing. The brick is covered with plastic bush with an air pocket. Heat transfer is measured with adjusted ring temperature (thermocouple embedded in the ring), using flow temperature (thermocouple immersed into the centre of the flow passage) and by measuring the electric power to the wire. The drawback of this method is a heat radiation from the wires to the brick. The gained heat transfer coefficient is $505 \mathrm{~W} /\left(\mathrm{m}^{2} \mathrm{~K}\right)$ for $111 \mathrm{~m} / \mathrm{s}$. It correlates with the values of the semi-empiric equations (figure 45).

The function of the RdF-sensor (figure 41) is to measure the heat flux (loss or gain) through a surface. It does this by differentiating the temperature between the sides of certain rigid materials. It also measures surface temperature by a $\mathrm{T}$ type thermocouple. One sensor selection criterion was that the application would have the right heat flux range where the sensor was designed to work. During the tests the RdF-sensor was glued at the inner ring surface of the LUT-sensor.

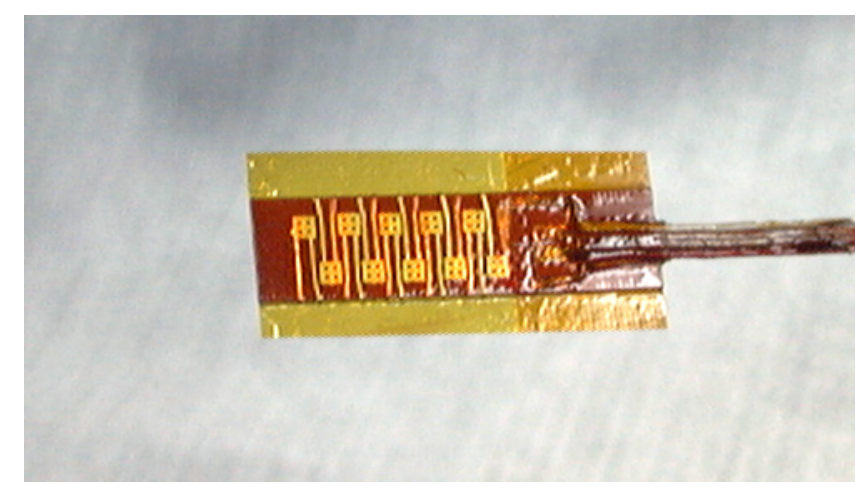

Figure 41. RdF-sensor. Photo: Timo Mikkola / LUT

Several thermocouples were placed in the calibration pipe and the test machine. The two most significant ones were fixed in the middle height of the channel (pipe or annulus) to measure the flow temperature in the vicinity of the heat transfer sensors. The others were placed to 
measure the pipe wall temperature, the embedded ring temperature of the LUT-sensor and the stator wall temperatures. The local rotor and stator wall temperatures were measured by RdFsensors. Supplying electric power to the LUT sensor made it possible to adjust the wall temperature of the ring to a common value with the preceding pipe. The pipe heating was done using a resistance coil (figure 44).

\subsubsection{Telemetry}

The RdF voltage signals were transmitted out of the rotor by using a telemetry device. This device has been designed and made in co-operation with the Department of Electrical Engineering at LUT. An analogous signal is changed to a digital form in the transmitter. An infrared signal is transmitted out from the rotor to the receiver and changed again to analogous form.

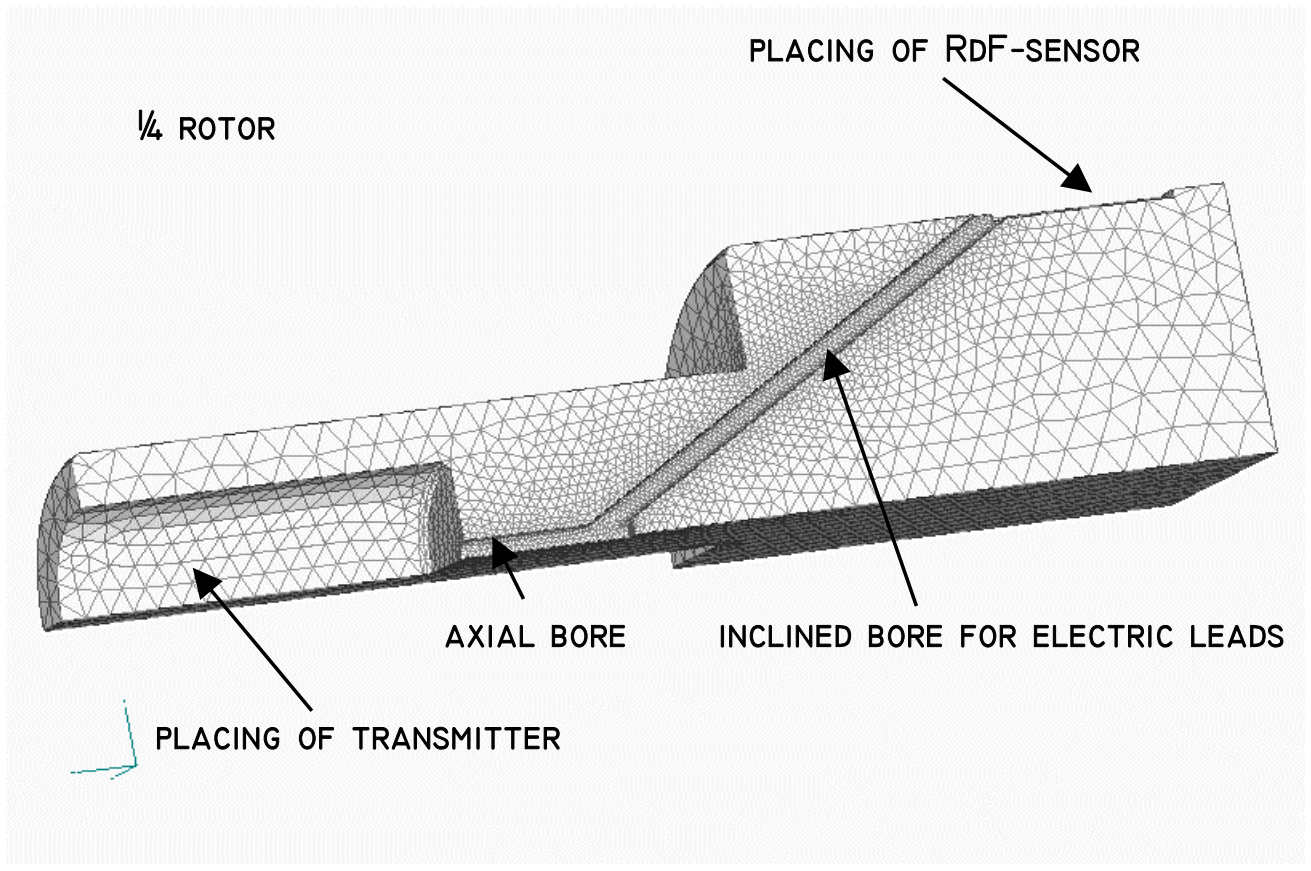

Figure 42. $1 / 4$ rotor, placing of RdF-sensor and transmitter, and bores for electric leads. (Kuosa 2001)

The transmitter was mounted on the end of the rotor in line with the axis to minimize centrifugal forces. The ground station consisted of a receiver and signal processing. $1 / 4$ of the rotor, the placing of the RdF-sensor and the transmitter and bores for electric leads are shown in figure 42. 
The telemetry transmitter and the receiver are set next to each other in figure 43 . The communication via infrared signals takes place through opposite lamps.

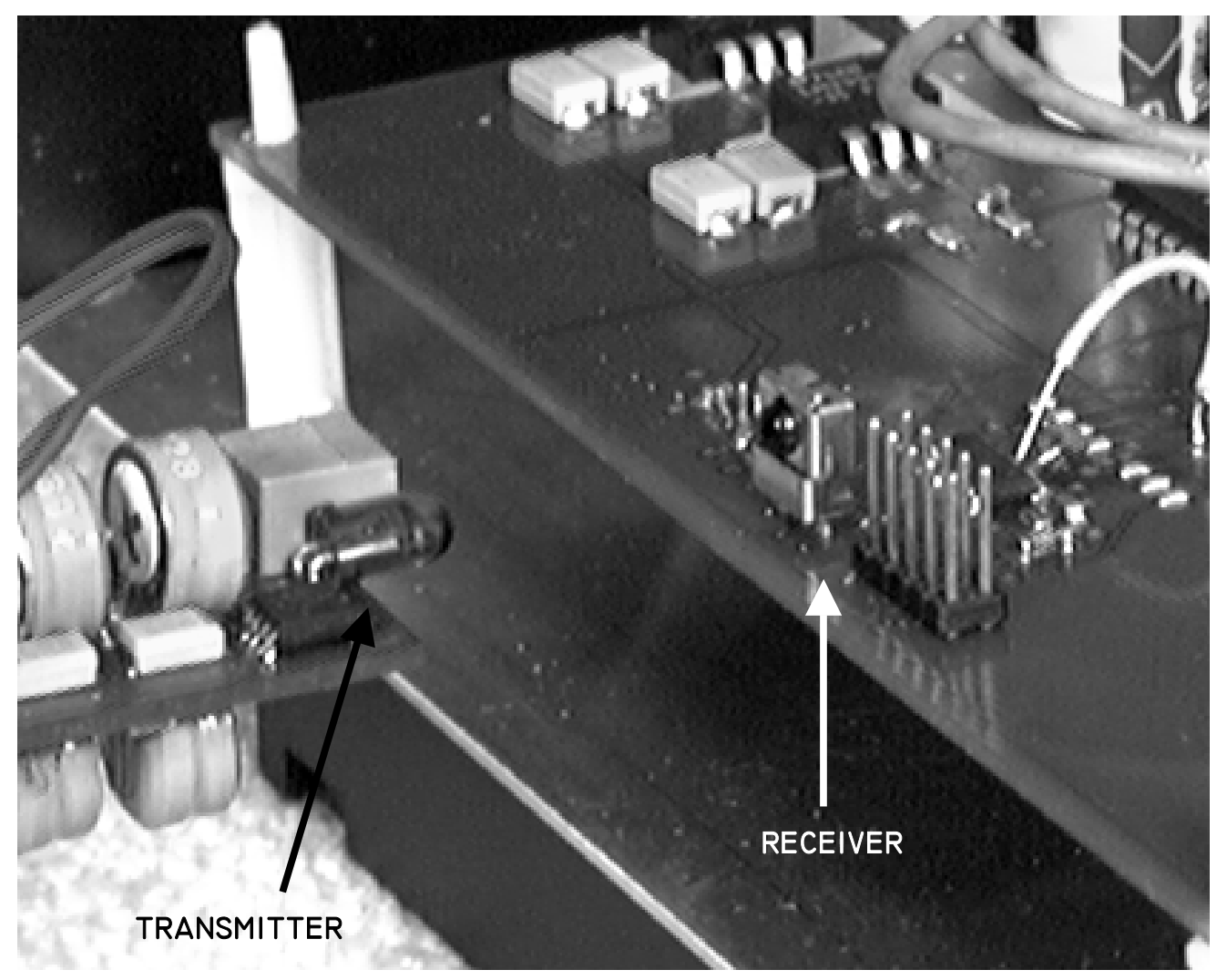

Figure 43. The transmitter and receiver of the telemetry device. Photo: Timo Mikkola / LUT

\subsubsection{Calibration}

Preliminary heat fluxes to the air gap were first estimated by Finflo calculation at constant rotor and stator surface temperatures. The RdF-sensor type was selected to operate on the simulated heat flux range. The sensor was calibrated at room temperature by the manufacturer. For the prevailing conditions, surface temperature correction needed to be done. A chart was provided to make this temperature correction. The measured heat flux was received as follows: the nominal sensitivity of the sensor was multiplied by the temperature dependent correction factor, and the RdF flux voltage output was divided by the multiplied value to get the heat flux. 
The telemetry was designed to transmit the magnitudes of the original voltage signal amplitudes out of the rotor. The estimated RdF heat flux signal voltage range was $0-25 \mathrm{mV}$. The measured maximum stator value was $3.8 \mathrm{mV}$ for $667 \mathrm{~Hz}$ rotor speed and total mass flow rate $50 \mathrm{~g} / \mathrm{s}$ through the air gap. The maximum rotor value was $6.6 \mathrm{mV}$ at the $254 \mathrm{~Hz}$ speed for the cooling air mass flow rate of $40 \mathrm{~g} / \mathrm{s}$. The telemetry heat flux signal transmission was tested using a Fluke 5101B calibrator. The first telemetry temperature signal transmission was simulated with Beamex TC305 calibrator. A separate type T thermocouple was immersed into a glycol and oil bath in a Brown Thermomix calibrator at a constant temperature. The temperature varied between $20-170{ }^{\circ} \mathrm{C}$. The output temperature signal of the telemetry was tabulated with the temperature values measured by a Fluke 8520 digital indicator with a temperature sensor Pt100. The voltages over the thermocouple were compared to the values achieved through infrared transmission. Linear fits were made between the telemetry input and output data for the heat flux and temperature.

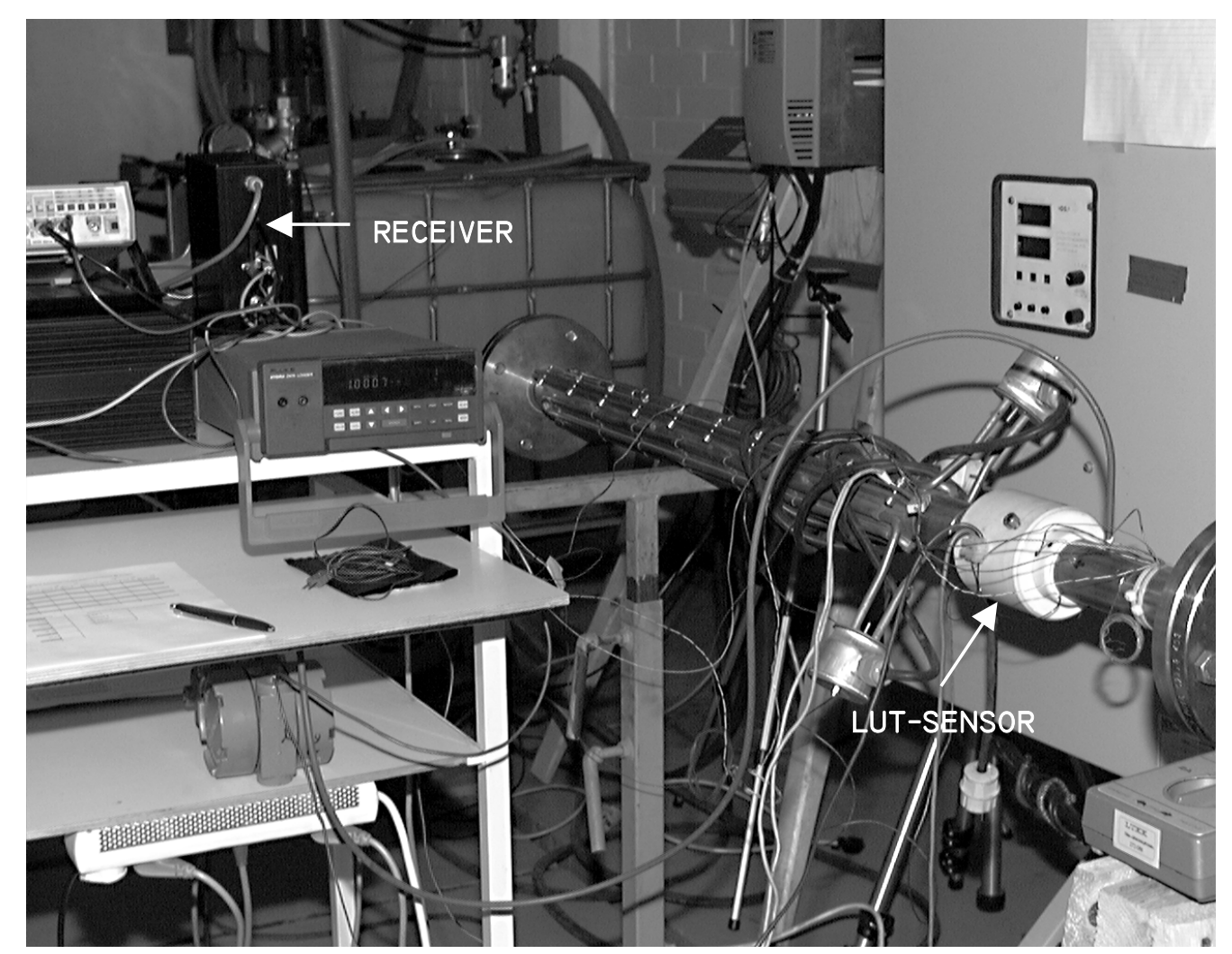

Figure 44. Calibration of the RdF-probe in the straight pipe. Photo: Timo Mikkola / LUT

The RdF-probe and signals with the telemetry were tested in straight pipe flow (figure 44). The probe was glued to the inner ring surface of the LUT-sensor. The flow velocity in the 
pipe was calculated from the measured mass flow rate. A straight section of $94 \mathrm{~mm}$ diameter line was mounted downstream in the pipe. The measurement of the mass flow rate took place via the flow velocity and temperature at the outlet of the line using a digital propeller anemometer (Technovent 4000).

In the first tests a linear curve for the heat transfer coefficients was attained between the two flow velocities in the straight pipe. These mean velocities were equivalent to the rotor rotation speeds of $111 \mathrm{~m} / \mathrm{s}$ and $232 \mathrm{~m} / \mathrm{s}(30000$ and $60000 \mathrm{RPM})$. The coefficients were compared to two mean values calculated from equations 68 (Holman 1989), 69 (VDI-Wärmeatlas1988) and 70 (Larjola et al. 1990). In equations 69-71 the length of the heated part of the pipe (ring) is $L=0.03 \mathrm{~m}$ and the mean heat transfer of the ring is calculated. The local heat transfer in the ring location $x=0.015 \mathrm{~m}$ where the RdF-sensor is glued on is calculated by equation 71 (Sukomel et al. in Isachenko et al. 1987). Equation 68 is for developed flow. It does not take into account the length of the heated walls of the ring.

$$
\begin{aligned}
& N u=0.023 \operatorname{Re}^{0.8} \operatorname{Pr}^{0.4} \\
& N u_{m}=\frac{\xi / 8(\operatorname{Re}-1000) \operatorname{Pr}}{1+12.7 \sqrt{\xi} / 8\left(\operatorname{Pr}^{\frac{2}{3}}-1\right)}\left[1+\left(\frac{d_{i}}{L}\right)^{\frac{2}{3}}\right] \\
& \xi=\left(1.82 \log _{10} \operatorname{Re}-1.64\right)^{-2} \\
& N u=0.0214\left(\operatorname{Re}^{0.8}-100\right) \operatorname{Pr}^{0.4}\left(1+\left(\frac{d}{L}\right)^{0.66}\right) \\
& N u=0.022 \operatorname{Re}^{0.8} \operatorname{Pr}^{0.43} \varepsilon_{l} \\
& \varepsilon_{l}=1.38\left(\frac{x}{d}\right)^{-0.12}
\end{aligned}
$$

Next measurement was done with nine axial airflow velocities. Tests were done with and without telemetry, and with and without heated walls of the pipe. The ring was kept warm to 
provide a heat flux through the sensor. The results (with the heated ring but without heated walls of the pipe) are presented in figure 45. The following conclusions can be made

- The calibration of sensors in a straight pipe is only an advisory step in the selection process.

- The heat flux of the ring to the cooling air flow is small for the sensitivity range of the RdF-sensor. This can be seen as lower heat transfer coefficient values compared to the equations on higher axial velocities.

- $\quad$ An RdF-sensor can be used to measure the local wall heat transfer coefficients on a proper heat flux range.

- The same measurement works well with signal transmission by a telemetry device.

- The heat transfer coefficients are attained as follows: the recovery temperature of the fluid, RdF heat flux and wall temperature components are inserted to Newton's cooling law (equation 15).

- Heat transfer depends on the flow velocity field. If the flow pipe is heated, the heat flux to the flow is considerably smaller. This is noticed by the same measurements with and without heated pipe walls.

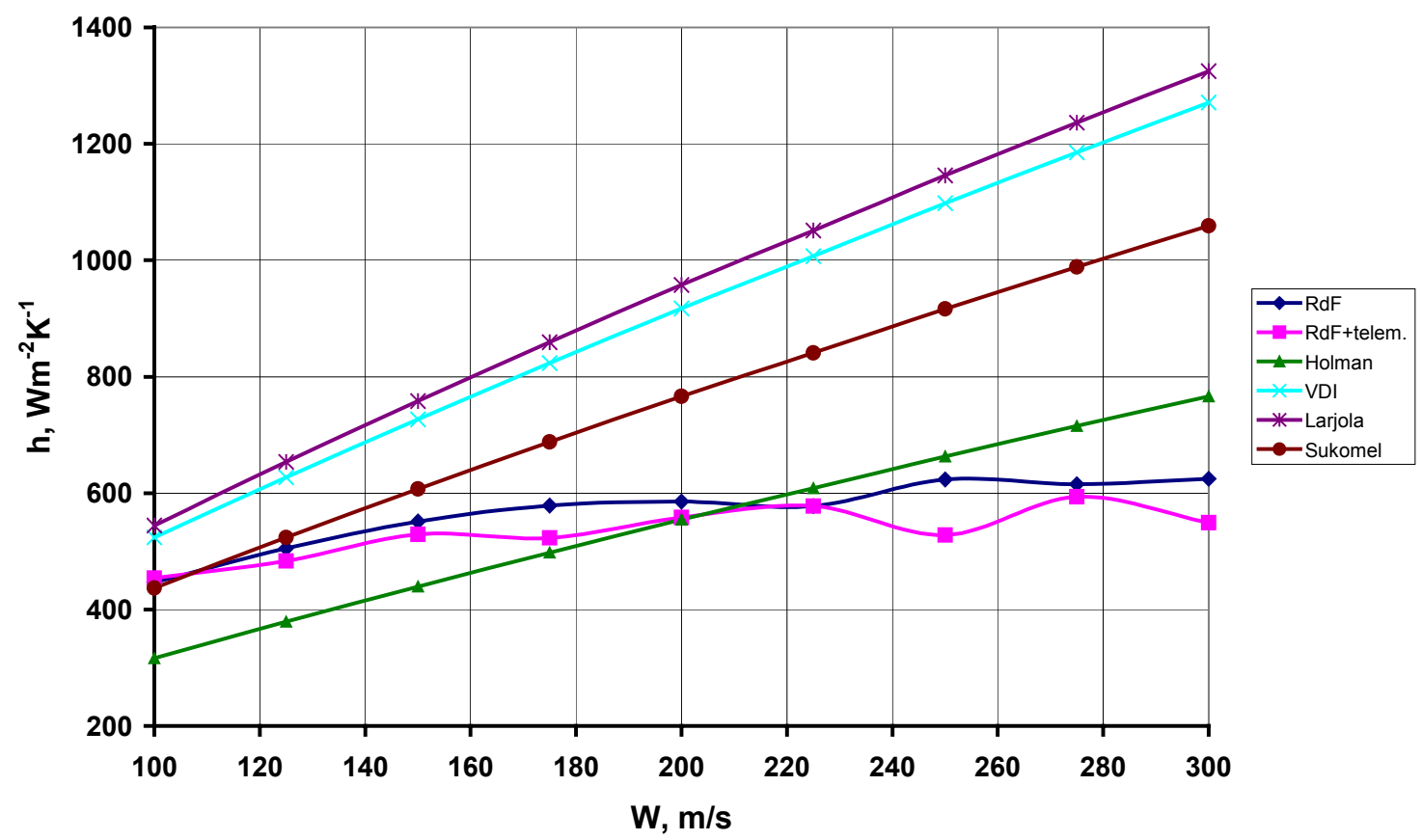

Figure 45. Test calibration of the RdF-sensor in the pipe flow with and without the telemetry device and comparing them to the equations. 
Figure 45 shows that the measured and calculated heat transfer coefficients correlate well at the lower axial velocities. The air fluid properties have been calculated using an incompressible turbulent flow assumption (Pfitzer, Beer 1992) to get a neat presentation. The real velocity range is between $88-223 \mathrm{~m} / \mathrm{s}$. It should be noted that equations $68-71$ are not valid at high Mach numbers. The chain of the signals in the telemetry device is: fixed gain, AD-conversion, IR-transportation, DA-conversion and buffering. The difference between the raw and telemetry based RdF-data (figure 45) arises probably due to the resolution of (the fixed gain before the 8 bit $\mathrm{AD}$ conversion) the transmitter.

\subsubsection{Rotor stresses}

Large centrifugal forces are exerted to high-speed rotors. In many cases the stresses are close to the yield limits of the rotor material (quenched and tempered steel). In this report the modelling of vaneless rotor stresses is discussed when considering an inclined bore hole from the outer surface of the main shaft to the axial hole inside the throat. In stress considerations the rotational speed 80000 RPM is set. As shown in figure 42, the sensor was glued to the outer periphery of the main shaft with the goal to measure the local surface temperature of the rotor and heat flux to the cooling air flow. The signal of the sensor was conducted from the outer periphery by wires through bores to the end of the rotor.

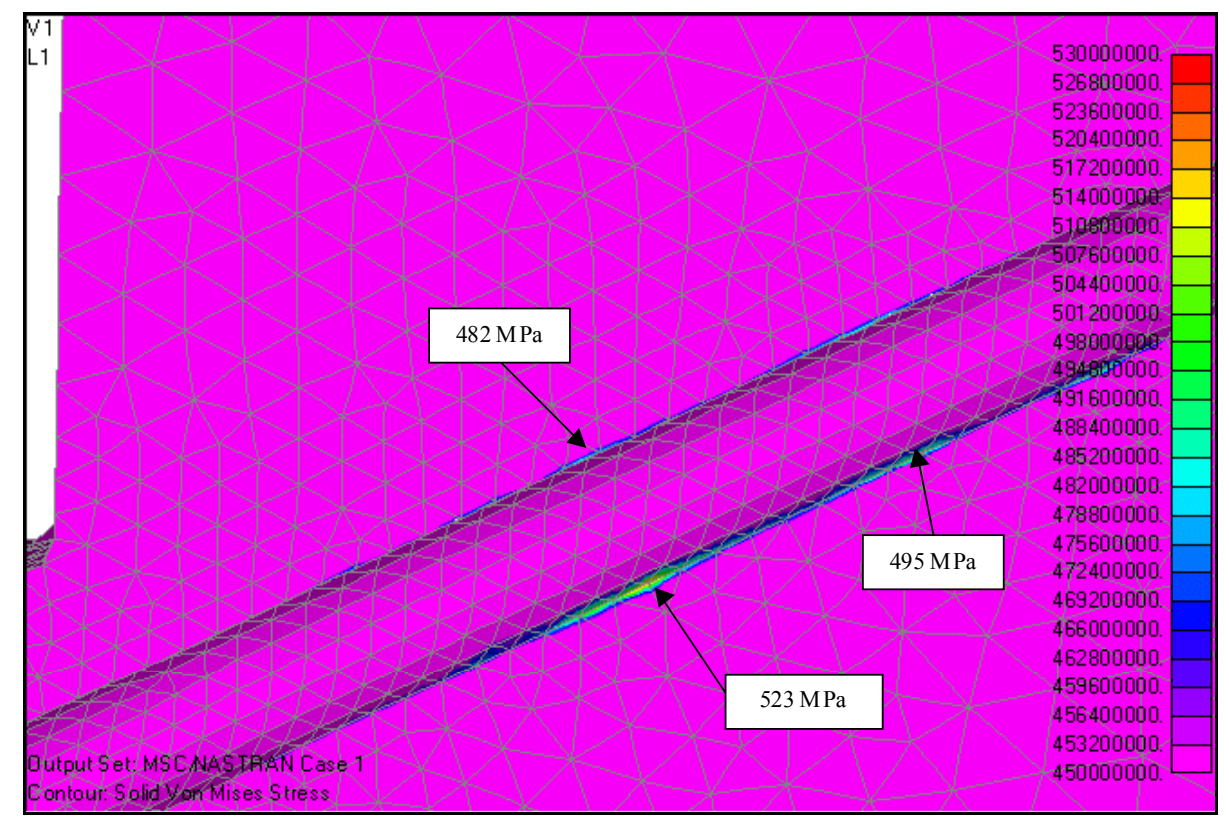

Figure 46. The Von Mises state of stress on inclined bore walls by FEM. (Kuosa 2001) 
The notch effect of an inclined bore was studied by four analytical models (Kuosa 2001). These theoretical results were compared with FEM results. The most critical stresses were situated on the walls of the inclined bore (figure 46), on the point where the axial and the inclined boreholes intersected, and on the curved edge of the opening where the borehole intersected the outer periphery. Considering the reliability of the analytical models the most probable value of the notch factor was over 2. By multiplying these nominal analytic stresses by this factor, nearly the same stresses were obtained as by FEM. The $\mathrm{R}_{\mathrm{p} 0.2}$ limit of the used Ovako 550 steel is $550 \mathrm{MPa}$. The critical Von Mises maximum strain on inclined borehole walls is $482 \ldots 523 \mathrm{MPa}$ (figure 46). The most likely damage mechanism is yielding close to the shoulder between the throat and middle periphery from the inclined borehole walls towards the middle centre.

\subsection{Measurements}

\subsubsection{Introduction}

Mean heat transfer coefficients were measured in a high-speed electric motor between 180$667 \mathrm{~Hz}$ rotation speeds $(40-150 \mathrm{~m} / \mathrm{s})$. The measurements were performed using a test machine at LUT. The vaneless rotor in the machine is vertical. More than 20 measurements were carried out with the test machine (figure 1). At a constant rotation speed the following data was collected to a PC once in 6 seconds.

- $\quad$ Time instant

- Temperatures at rotor and stator surfaces, at the inlet of the cooling gas, in the air gap flow, and in the end winding space

- $\quad$ Heat flux normal to wall at rotor and stator surfaces

- Cooling mass flow rate of the air

Some dimensions of the test machine and the location of RdF-sensors and thermocouples in the air gap are shown in figure 47. 


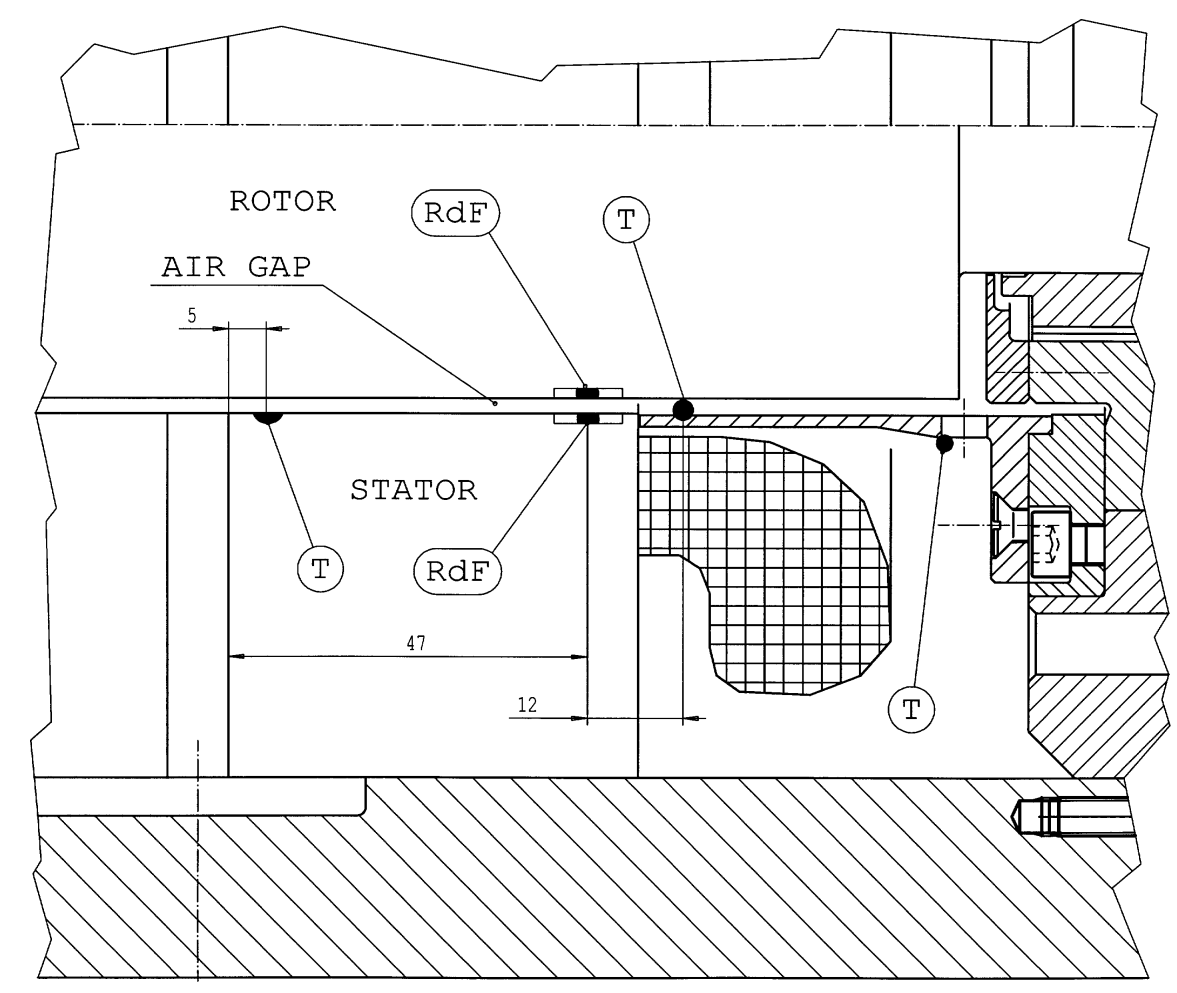

Figure 47. Some dimensions of the test machine, location of RdF-sensors and thermocouples in the air gap. Drawing: Jukka Lattu / LUT

The following measurements were performed:

- $\quad 7$ rotation speeds: $180,254,333,400,500,583$ and $667 \mathrm{~Hz}$

- $\quad 4$ mass flow rates: $40,50,60$ and $70 \mathrm{~g} / \mathrm{s}$

- 7 rotor heat transfer measurements with telemetry $(40-74 \mathrm{~m} / \mathrm{s})$

The mean heat transfer coefficients were measured by the heat fluxes normal to the wall, using the wall temperature and the bulk temperature of the gas. During the pipe calibration tests the RdF-probe was found to be the proper instrument for these measurements. It was glued on stator and rotor surfaces. The measured heat transfer coefficients at the stator and rotor were of the same magnitude. The standard deviation was on the average $28 \mathrm{~W} /\left(\mathrm{m}^{2} \mathrm{~K}\right)$. The measurement with telemetry was done at rotational speeds 10000,15000 and 20000 RPM. The heat fluxes and heat transfer coefficients were found to be higher at lower cooling air mass flow rates. The rotor temperature was twice and the heat flux 8 times higher than the values of the stator. It was noticed that the temperature difference $\Delta T=T_{\mathrm{w}}-T_{\mathrm{f}}$ and rotation speed $N$ should be sufficiently high to allow optimal conditions for the RdF-sensor. 


\subsubsection{Test facility}

The main components of the test facility are air supply, filter, piping, ISA1932 nozzle, an inverter (Strömberg Sami 20C380) adjusted blower, and an inverter (Vacon 45CX4A20) adjusted electric machine. The data acquisition system is Hydra data logger 2625. The number of revolutions is measured by a Hall gauge and amplified. The frequency is calculated by a Philips PM6670 high resolution (120 MHz) counter. The telemetric transmitter is embedded in the rotor. The receiver is located on the electric motor. A schematic diagram of the test facility at LUT is shown in figure 48. This facility, a photograph of which is shown in figure 49 , is used to measure the heat transfer coefficients of electric machines.

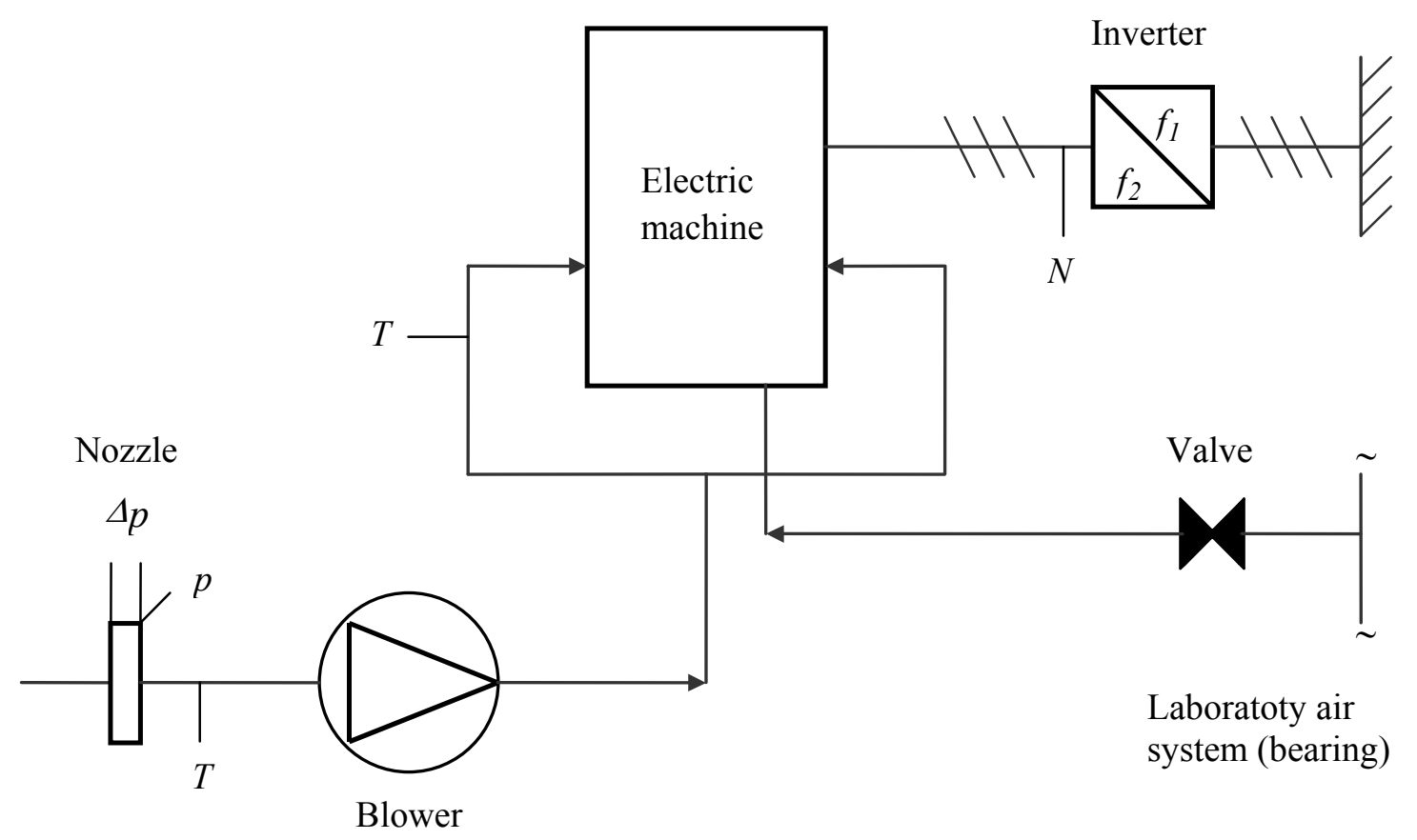

Cooling air from laboratory room

Figure 48. Flow schematic of the high-speed electric machine test facility.

Air for the axial gas bearings is supplied by the $600 \mathrm{kPa}$ air system of the laboratory. The cooling air is taken from the laboratory room. It is first filtered. A calibrated flow nozzle is located in the straight section of the $94.3 \mathrm{~cm}$ air supply line for the purpose of metering the mass flow rate of the air. Downstream from the flow nozzle is the blower. The air is diverted into two lines to provide dual entry of lower velocity air to the stator slot (these lines can be 
seen in figure $49 \mathrm{~b}$ ). After passing the air gap of the machine, the air is discharged to the laboratory room.

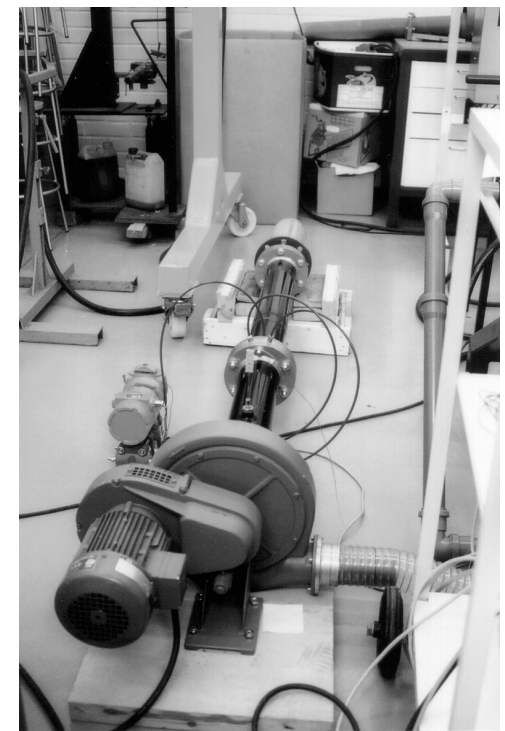

a)

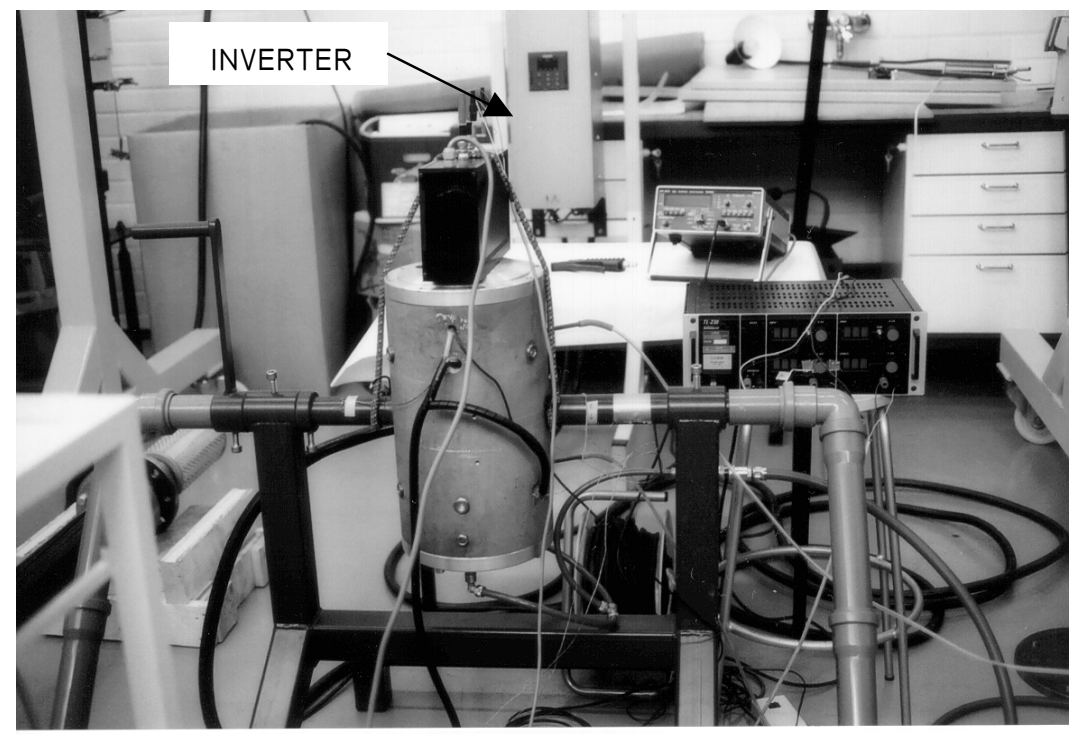

b)

Figure 49. High-speed machine test facility: a) Straight section of air supply line and blower. b) Test machine and inverter. A telemetric receiver is located in the black box on the electric motor. Photos: Petri Sallinen / LUT

\subsubsection{Measuring procedure}

The measuring procedure was as follows. First the barometric pressure was observed. The blower was started before the test motor. The setting voltage for the mass flow rate was calculated inversely. (The pressure conversion, static pressure, temperature and true mass flow rate of the nozzle were calculated from the measured data.) The rotation speed of the blower was set using this value. The desired mass flow rate was maintained by controlling the inverter manually. The measured quantities were:

- Inlet temperature of air at dual entry: 2 points

- $\quad$ Air temperature close to the stator coils of the electric machine: 4 points

- $\quad$ Axial surface temperature of the stator: 3 points

- $\quad$ Cooling air temperature in the air gap: 1 point

- $\quad$ Local heat flux of the stator: 1 point

- $\quad$ Rotor surface temperature and heat flux: 1 point each 
A bare thermocouple wire was exposed to the flow in order to measure the temperature in the air gap. The results were manually registered in a field book after the operation condition had flattened out. The test run for one rotation speed measurement took 10 minutes. The data was collected to a PC. The mean heat transfer coefficients of the stator and rotor were calculated with the Excel. One peripheral speed of the rotor with one mass flow rate was measured once. The adjacent points were achieved by changing $q_{\mathrm{m}}$. The mass flow rate was varied between $40-70 \mathrm{~g} / \mathrm{s}$ using $10 \mathrm{~g} / \mathrm{s}$ steps. The rotation speed $N$ was varied between $180-667 \mathrm{~Hz}$ by 5000 RPM steps. One measurement was confirmed by the adjacent point. The rotation speeds and mass flow ranges were as follows:

$$
\begin{aligned}
& \text { - } \quad \text { 180-400 Hz: 40, } 50 \text { and } 60 \mathrm{~g} / \mathrm{s} \\
& \text { - } \quad 500-667 \mathrm{~Hz}: 50,60 \text { and } 70 \mathrm{~g} / \mathrm{s}
\end{aligned}
$$

The setting values of the mass flow rates were estimated by the mean cooling air temperatures in the test machine. These were selected to give a desired axial flow velocity in the air gap for the cases: $w_{a x}=40,50,60$ and $70 \mathrm{~m} / \mathrm{s}$. For the dimensions of the test machine $d=71 \mathrm{~mm}, D=$ $75 \mathrm{~mm}, \delta=2 \mathrm{~mm}$ this gives the total mass flow rates of $\approx 40,50,60$ and $70 \mathrm{~g} / \mathrm{s}$.

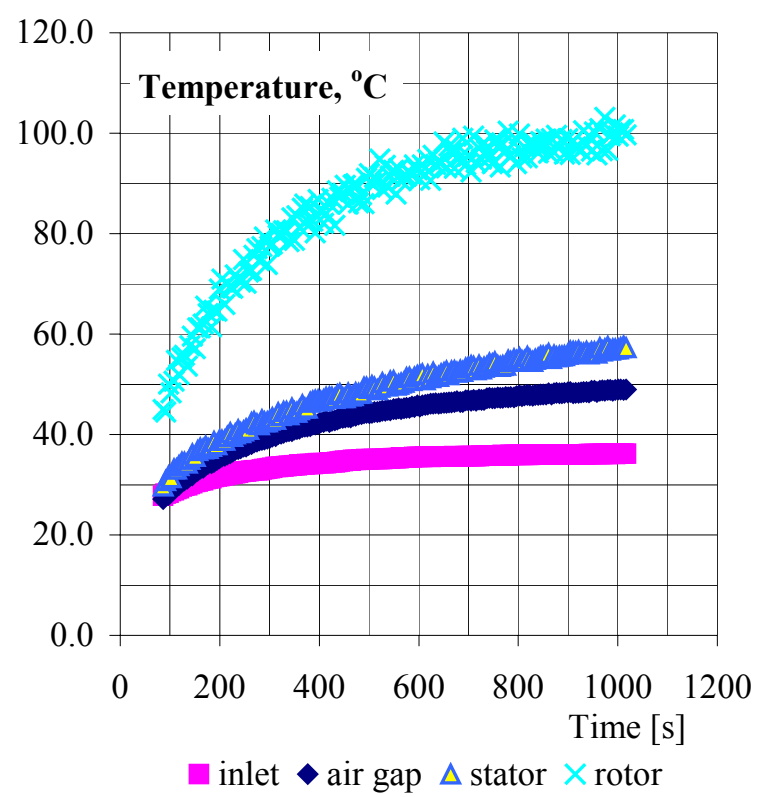

Figure 50. Temperatures at the inlet, air gap, stator and rotor during the measurement of $N=254 \mathrm{~Hz}$, $q_{m}=60 \mathrm{~g} / \mathrm{s}$.

A problem occurred concerning the fixing of the RdF-sensor. It was glued on the rotor surface (figure 42). The sensor was unfastened at $333 \mathrm{~Hz}$ speed. The positions of the radial gas 
bearings were changed when measuring 3 points during one test run. Once the air pressure of the axial thrust bearing was too low and the rotor jammed during the stopping of the rotor. Figure 50 shows the temperatures at inlet, cooling air temperature and stator and rotor temperatures during the measurement.

\subsection{Results}

The measured heat fluxes rose uniformly when the rotation speed increased (figure 51). The heat flux of the rotor gave eight times bigger values than the values of the stator. At lower speeds the heat flux rates $\Phi^{\prime \prime}$ of the stator were higher with bigger $q_{\mathrm{m}}$ values. At higher speeds the heat flux rate was highest with the smallest $q_{m}=50 \mathrm{~g} / \mathrm{s}$ (figure $51 \mathrm{a}$ ). This can be explained as follows. The value of the equation $h=\Phi^{\prime \prime} /\left(T_{\mathrm{w}}-T_{\mathrm{f}}\right)$ gives smaller values for $h$ if the temperature of the cooling air $T_{\mathrm{f}}$ gets lower (via bigger mass flow rate), even if the heat flux $\Phi^{\prime \prime}$ grows. The rotor heat flux was measured between 180-254 Hz. It gives the biggest values with a smaller $q_{\mathrm{m}}$ (figure $\left.51 \mathrm{~b}\right)$.

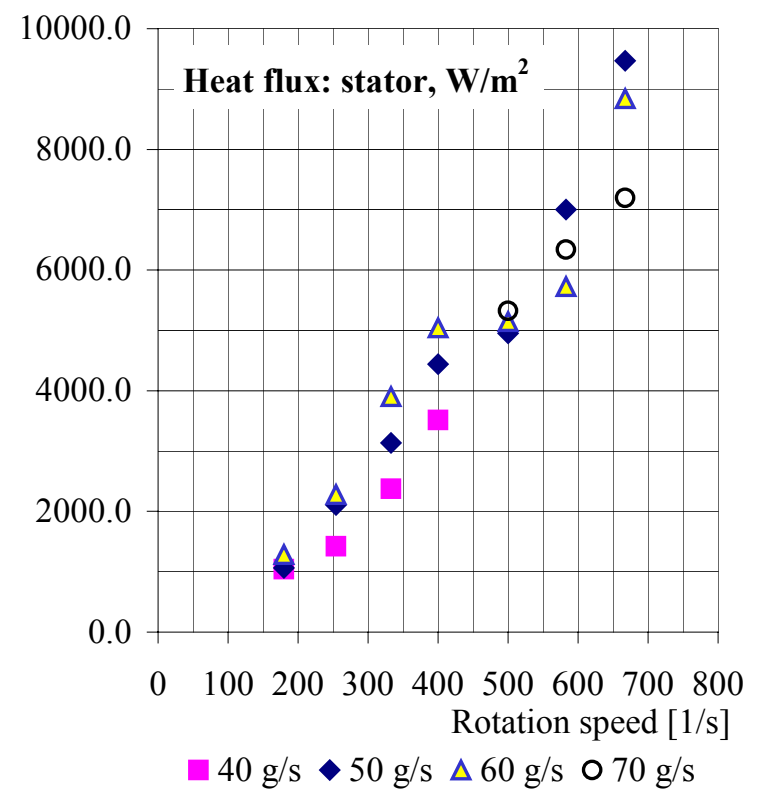

a)

Figure 51. Measured heat flux: a) the stator and b) the rotor.

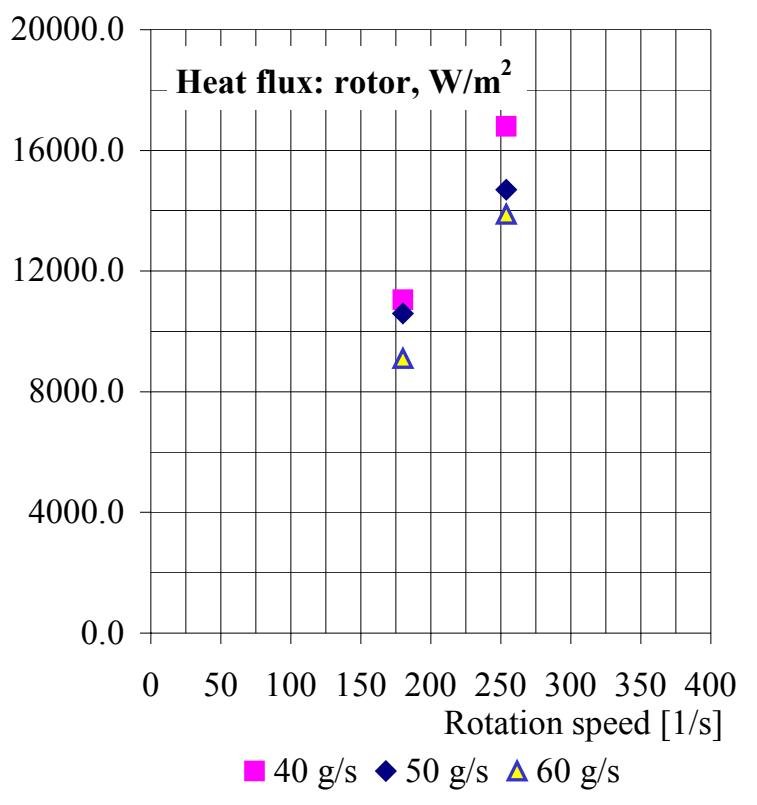

b)

The values of the mean heat transfer coefficients at the stator and rotor were of the same magnitude for the smooth stator-rotor combination (figure 52). This depended on the peripheral speed of the rotor $N$ and on the cooling air mass flow rate $q_{\mathrm{m}}$ (axial air flow 
velocity). In the velocity range between $180-667 \mathrm{~Hz}$ some oscillations of heat transfer coefficients were observed. This oscillation was greater at lower rotation speeds. The mean standard deviation for the heat transfer coefficients was $28 \mathrm{~W} /\left(\mathrm{m}^{2} \mathrm{~K}\right)$. The RdF-sensor seemed to operate most optimally at $400-500 \mathrm{~Hz}$ speeds. The deviation was smallest at $400 \mathrm{~Hz}$ speed $\left(q_{\mathrm{m}}=40 \mathrm{~g} / \mathrm{s}: 4.8 \mathrm{~W} /\left(\mathrm{m}^{2} \mathrm{~K}\right), q_{\mathrm{m}}=50 \mathrm{~g} / \mathrm{s}: 3.4 \mathrm{~W} /\left(\mathrm{m}^{2} \mathrm{~K}\right), q_{\mathrm{m}}=60 \mathrm{~g} / \mathrm{s}: 4.6 \mathrm{~W} /\left(\mathrm{m}^{2} \mathrm{~K}\right)\right)$. The combination of $500 \mathrm{~Hz}$ speed and $q_{\mathrm{m}}=40 \mathrm{~g} / \mathrm{s}$ gave a very high $h_{\text {stator }}=685 \mathrm{~W} /\left(\mathrm{m}^{2} \mathrm{~K}\right)$. At this speed the observed temperature difference was only $\Delta T=T_{\mathrm{w}}-T_{\mathrm{f}}=7{ }^{\circ} \mathrm{C}$. The value $\Delta T=14{ }^{\circ} \mathrm{C}$ and higher values gave more reliable results. The conclusion is that a higher rotation speed requires a bigger mass flow rate for the $\mathrm{RdF}$ measurement. The temperature measurement gave smooth values. The measured heat transfer coefficients are compared to the semiempiric data of equation 26 in figure 52. The mass flow rate is $q_{\mathrm{m}}=40 \mathrm{~g} / \mathrm{s}$ and the air gap height $\delta=2 \mathrm{~mm}$. The slope of the measured values follows the semi-empiric direction at mass flow rates between 40-70 g/s and at rotation speeds between 180-667 Hz. This confirms that the magnitudes of the measured data points are realistic. The measured stator values are higher at smaller mass flow rates (figure 52a). The measured values are, however, slightly lower than the semi-empiric data.

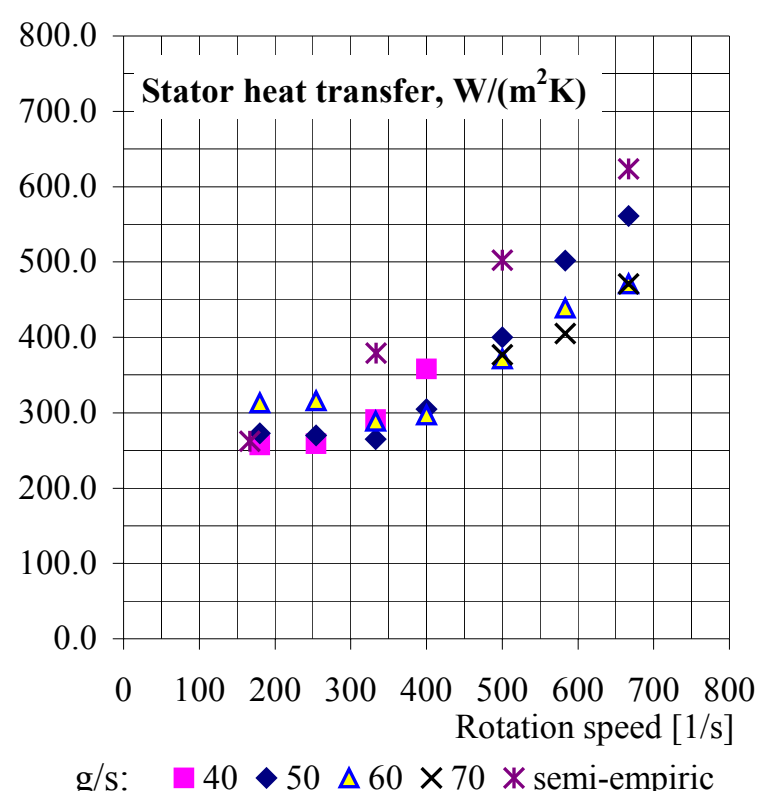

a)

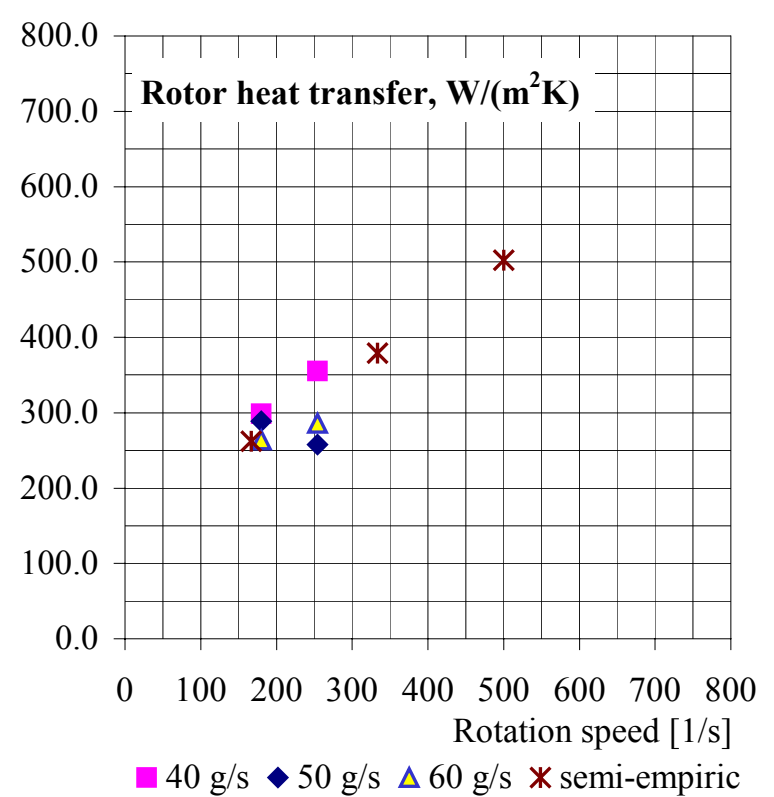

b)

Figure 52. Mean a) stator, b) rotor heat transfer coefficients of the test machine. The cooling air mass flow rate is $40,50,60$ and $70 \mathrm{~g} / \mathrm{s}$. The measured data is for rotation speeds between $180-667 \mathrm{~Hz}$ for the stator and $180-254 \mathrm{~Hz}$ for the rotor. The measured data is compared to the semi-empiric data of equation 26 with $q_{\mathrm{m}}=40 \mathrm{~g} / \mathrm{s}$ and $\delta=2 \mathrm{~mm}$. (Simulated data: figure 36) 


\subsection{Errors and uncertainty}

The perceived errors are in measuring the heat transfer coefficient and the mass flow rate. There are some deviations. The mean heat transfer coefficient $h$ was measured using the equation

$$
h=\frac{\Phi^{\prime \prime}}{T_{w}-T_{f}}
$$

where $\Phi^{\prime \prime}$ and $T_{\mathrm{w}}$ are the heat flux and wall temperature. They were measured with the RdFsensor. $T_{\mathrm{f}}$ is the fluid temperature in the air gap. It was measured with a thermocouple. By the methods of ISO 51681978 the uncertainty equation is

$$
\frac{\delta h}{h}=\left[\left(\frac{\delta \Phi^{\prime \prime}}{\Phi^{\prime \prime}}\right)^{2}+\left(\frac{\delta T_{w}}{T_{w}-T_{f}}\right)^{2}+\left(\frac{\delta T_{f}}{T_{w}-T_{f}}\right)^{2}\right]^{\frac{1}{2}}
$$

where $\delta h / h, \delta \Phi^{\prime \prime} / \Phi^{\prime \prime}, \delta T_{\mathrm{w}} /\left(T_{\mathrm{w}}-T_{\mathrm{f}}\right), \delta T_{\mathrm{f}} /\left(T_{\mathrm{w}}-T_{\mathrm{f}}\right)$ are relative uncertainties.

The error for the heat flux measurement with the RdF-sensor is not known accurately. On the basis of the available data it is estimated to be $\pm 2 \mathrm{~W} / \mathrm{m}^{2}$. The accuracy given by the manufacturer of the thermocouple is $\pm 1^{\circ} \mathrm{C}$. Thus we obtain from equation 73 as maximum error (at $180 \mathrm{~Hz}) \pm 37 \%$ for the stator and $\pm 4 \%$ for the rotor. A calculated absolute uncertainty of the stator heat transfer coefficient is shown in figure 53. It seems to decrease when the rotation speed increases. The calculation is made for mass flow rates 40, 50, 60 and $70 \mathrm{~g} / \mathrm{s}$ as a function of rotation speed. The uncertainty of the rotor heat transfer coefficient is presented in table 4.

Table 4. The uncertainty of the rotor heat transfer coefficient.

\begin{tabular}{|l|c|c|c|}
\hline \multicolumn{4}{|c|}{$\delta \boldsymbol{h}_{\text {rotor }}, \mathbf{W} /\left(\mathbf{m}^{2} \mathbf{K}\right)$} \\
\hline$N, 1 / \mathrm{s}$ & $40 \mathrm{~g} / \mathrm{s}$ & $50 \mathrm{~g} / \mathrm{s}$ & $60 \mathrm{~g} / \mathrm{s}$ \\
\hline 180 & 11.35 & 11.19 & 10.70 \\
\hline 254 & 10.28 & 6.54 & 8.16 \\
\hline
\end{tabular}




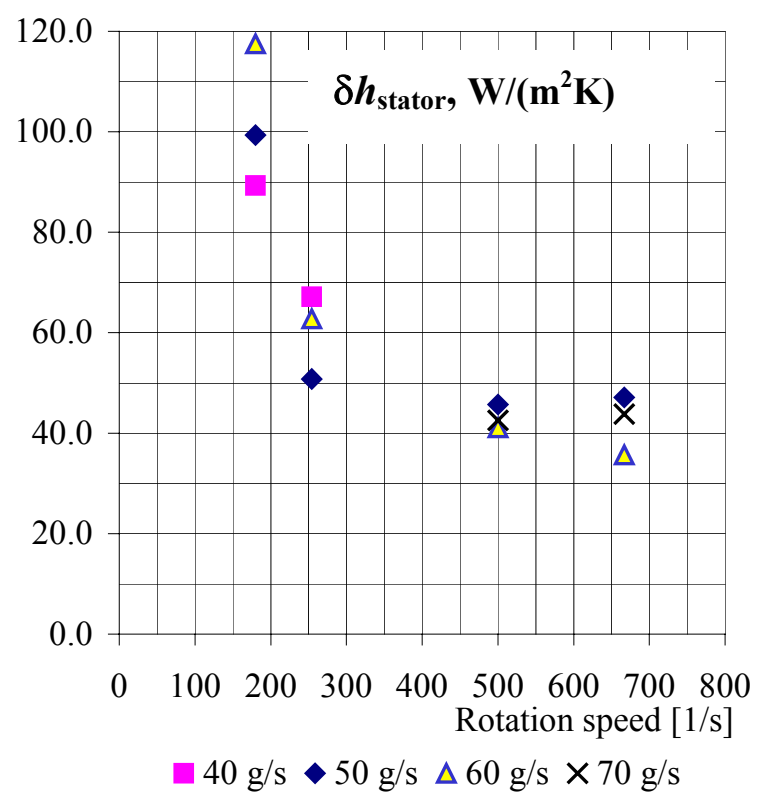

Figure 53. The uncertainty of the stator heat transfer coefficient as the function of rotation speed and mass flow rate: $\delta \Phi^{\prime \prime}= \pm 2 \mathrm{~W} /\left(\mathrm{m}^{2} \mathrm{~K}\right), \delta T_{\mathrm{w}}=\delta T_{\mathrm{f}}= \pm 1{ }^{\circ} \mathrm{C}$.

The reasons why the stator uncertainty is high at low rotational speeds can be explained by the smaller temperature difference $T_{\mathrm{w}}-T_{\mathrm{f}}$ in the denominator of equation 73 than at higher speeds. It is bigger for the rotor case. The heat flux uncertainty $\delta \Phi^{\prime \prime}$ is estimated as the constant value. Also the stator heat flux $\Phi^{\prime \prime}$ is increased (in the denominator) at higher speeds.

The measurement of mass flow rate took place on the straight section of the NS100 pipe (nozzle: $D=0.0943 \mathrm{~m}, d=0.038 \mathrm{~m}$, figure 49a). According to ISO 51671980 , the mass flow rate $q_{m}$ of the ISA 1932 nozzle is calculated as

$$
q_{m}=C E \varepsilon \frac{\pi}{4} d^{4} \sqrt{2 \Delta p \rho_{1}}
$$

where $C$ is the coefficient of discharge $(C=\alpha / E), E$ the velocity of the approach factor, $\varepsilon$ the expansion factor, $d$ the diameter of the throat, $\Delta p$ the differential pressure and $\rho_{1}$ the mass density of the fluid. According to ISO 51681978 the practical working formula for the uncertainty, $\delta q_{\mathrm{m}}$, of the mass flow is 


$$
\frac{\delta q_{m}}{q_{m}}=\left[\left(\frac{\delta \alpha}{\alpha}\right)^{2}+\left(\frac{\delta \varepsilon}{\varepsilon}\right)^{2}+4\left(\frac{\beta^{4}}{1-\beta^{4}}\right)^{2}\left(\frac{\delta D}{D}\right)^{2}+4\left(1+\frac{\beta^{4}}{1-\beta^{4}}\right)^{2}\left(\frac{\delta d}{d}\right)^{2}+\frac{1}{4}\left(\frac{\delta \Delta p}{\Delta p}\right)^{2}+\frac{1}{4}\left(\frac{\delta \rho_{1}}{\rho_{1}}\right)^{2}\right]^{\frac{1}{2}}
$$

The uncertainties of the flow and expansibility coefficients $(\delta \alpha / \alpha, \delta \varepsilon / \varepsilon)$ are given in the standard. The maximum value for $\delta D / D$ is taken as $\pm 0.4 \%$, while the maximum value for $\delta d / d$ is $\pm 0.07 \%$, both on the basis of the available manufacturing data. For flow density $\rho_{1}$ we get the uncertainty $\delta \rho_{1} / \rho_{1}$ (ISO5168 1978)

$$
\frac{\delta \rho_{1}}{\rho_{1}}=\left[\left(\frac{\delta \rho}{\rho}\right)^{2}+\left(\frac{\delta p_{1}}{p_{1}}\right)^{2}+\left(\frac{\delta T_{1}}{T_{1}}\right)^{2}\right]^{\frac{1}{2}}
$$

and derive the uncertainty

$$
\frac{\delta p_{1}}{p_{1}}=\left[\left(\frac{\delta p_{L}}{p_{L}-\Delta p_{1}}\right)^{2}+\left(\frac{\delta \Delta p_{1}}{p_{L}-\Delta p_{1}}\right)^{2}\right]^{\frac{1}{2}}
$$

where $p_{\mathrm{L}}$ is the pressure in the laboratory and $\Delta p_{1}$ the pressure between the NS100 pipe and the laboratory room. The static pressure inside the pipe is $p_{1}=p_{\mathrm{L}}-\Delta p_{1} . \Delta p$ was measured using a Valmet DP3E22W0 differential pressure gauge and $\Delta p_{1}$ by using a Rosemount E1151DP-4-A22 gauge. The errors for these are $\pm 7.5 \mathrm{~Pa}$ and $\pm 12.5 \mathrm{~Pa}$. The uncertainty of the $p_{\mathrm{L}}$ was estimated to be $0.4 \%$. Thus the accuracy for mass flow rate measurement is calculated to be \pm $3 \%$ (equation 75 ).

The error by the Hydra data logger 2625 was noticed to be negligible $\left(T: \pm 0.37{ }^{\circ} \mathrm{C}, \Delta p, \Delta p_{1}\right.$ : $\pm 0.6 \mathrm{~Pa}, \pm 0.2 \mathrm{~Pa}$ ), therefore it was not taken into consideration. 


\subsection{Conclusions from the experimental work and comparison of the results with different methods}

The values of the measured heat transfer coefficients increase when the rotation speed increases. At the measured speeds the values are higher when the mass flow rate is smaller. The lower axial flow seems to increase the turbulence level and the heat transfer in the air gap. At very low $\Delta T=T_{\mathrm{w}}-T_{\mathrm{f}}$ values the heat transfer to cooling gas ceases, however. This implies that some optimum $q_{\mathrm{m}}, N$ combination exists. This was noticed in the simulations as well. At 70 000-80 000 RPM speeds the stator peak values were detected before the heat flux changed its direction. The quantities of the measured coefficients follow the slope of the semiempiric equation but are slightly lower. The measured values for the rotor and stator are almost equal.

The semi-empiric heat transfer coefficients for the air gap heights of $1 \mathrm{~mm}, 2 \mathrm{~mm}$ and $3 \mathrm{~mm}$ are plotted in figure 11 . The axial velocity is $40 \mathrm{~m} / \mathrm{s}$ in the air gap. This indicates that a smaller air gap height gives a higher heat transfer coefficient than a bigger one. Axial velocity was kept constant. In this case the mass flow rate $q_{\mathrm{m}}$ increased with the growth of the air gap height $\delta$. Also according to the semi-empiric equation 26 the quantities of the rotor and stator heat transfer coefficients are equal.

The numerical result of the Finflo simulation is qualitative (figure 36). It gives clearly smaller heat transfer coefficient values for the smooth stator-rotor test machine combination than the semi-empiric data and the measured values in this work. Only the stator mean values at 70 000-80 000 RPM speeds due to the appeared peak values of the $k-\varepsilon$ and the $k-\omega$ models are closer to the measured and the semi-empiric results. A comparison of these values is presented in figure 54. The measured values are shown for $40 \mathrm{~g} / \mathrm{s}$ and $50 \mathrm{~g} / \mathrm{s}$ mass flow rates. The semi-empiric result is denoted by S-E. The heat transfer coefficients of the stator by the numeric method are slightly smaller than the values of the rotor at lower speeds, but higher at higher speeds. A saturation point is observed with the rotor values. A difference in the prevailing conditions can be noticed between the measurements and the modelling. The rotor and stator temperatures depend on the rotation speed of the machine. The temperatures and electrical and friction losses increase when the rotation speed is higher. In the theoretic calculations with CFD-models constant rotor and stator temperatures are used at all the 
rotation speeds. As noticed in section 2.5, the convection heat transfer is not, however, strongly dependent on the temperature.

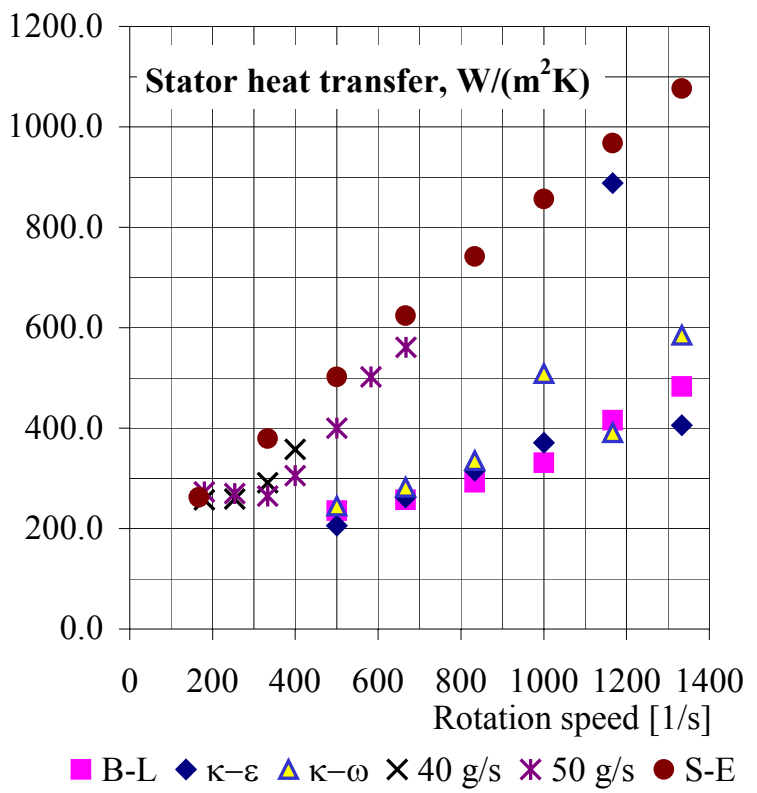

a)

Figure 54. Comparison of a) stator, b) rotor mean heat transfer coefficients with different methods. The simulated values of the $\mathrm{B}-\mathrm{L}, k-\varepsilon$ and $k-\omega$ models are compared with the measured results for $40 \mathrm{~g} / \mathrm{s}$ and $50 \mathrm{~g} / \mathrm{s}$ cooling air mass flow rates as a function of the rotational speed. Also the semiempiric result (S-E) is presented in the figure. The axial velocity of the cooling air is $40 \mathrm{~m} / \mathrm{s}$ in the simulation and for the $\mathrm{S}-\mathrm{E}$ result, $40 \mathrm{~m} / \mathrm{s}$ and $50 \mathrm{~m} / \mathrm{s}$ for the measured values.

The simulation underpredicted the local and the mean heat transfer coefficients for the smooth rotor-stator combination. This was partly due to the selected grid and input values, the use of the Reynolds-averaged Navier-Stokes equations, and the use of turbulence models that calculate the Reynolds stresses by the Boussinesq eddy-viscosity approximation. Isotropic turbulence was assumed in the highly rotational flow. The numerical method could not predict the secondary motions (Taylor vortices) of the centrifugal effects in the annular air gap flow. Trends increasing the rotational speed could be compared between the simulated results and the measured values for the stator case. Both of these grew smoothly when using the adequate cooling air mass flow. The grid sensitivity study by the B - L model gave $13 \%$ higher mean heat transfer coefficients on the finest grid level for 50000 RPM speed than on the used coarseness level 2. The height of the first row of cells as the $y^{+}$was everywhere close to the unity when the viscous sublayer height was $y^{+} \leq 5$ (White 1999, Rautaheimo, Siikonen 1999). The error boundaries of the measurements of the stator heat transfer were almost $40 \%$ for the lower speeds, but acceptable at higher speeds. The average uncertainty of the rotor heat transfer coefficient was less than $4 \%$. 


\section{CONCLUSIONS}

The cooling of a high-speed electric test machine through an air gap was analysed. According to the literature study no heat transfer data is available at these speeds. In a previous part of the research, the friction coefficient of a high-speed test motor was measured by Saari in 1998. The contribution of this thesis is enhancing the cooling air knowledge of compact electric machines. The work is made up of numerical and experimental modelling of fluid dynamics and heat transfer. The challenge comes from the fact that one of the main parts is moving. Thermal modelling is very complicated and includes a high degree of uncertainty. The cooling of high-speed electric machinery is based on axial fluid flow through an air gap. Heat transfer takes place between the cooling air flow and the surfaces of the stator and the rotor.

Theoretical basics were presented to estimate the fluid mode, friction and heat transfer. Some parts of the work of Saari (1998) were reviewed as an introduction. Dimensionless numbers, analytic and semi-empiric equations were discussed to understand the basic concepts and the nature of the problem. This knowledge is essential in the modelling of the flow field and for measuring the heat transfer. The estimated flow components were tangential flow, axial flow and secondary Taylor vortices. The resulting combination of these determines the flow pattern and heat transfer mechanism. The friction coefficient, roughness coefficient and velocity factor were discussed using analytic and semi-empiric equations and the results by Saari (1998). Heat conduction, convection and radiation occur, but it is convection which is the most important. A semi-empiric equation for the calculation of the heat transfer coefficient for a high-speed electric machine was introduced.

The Finflo software was used in the numeric simulation. The main equations of the numeric solver and calculation of turbulence with three turbulence models were presented. One half of the high-speed machine was modelled. The computational domain consisted of a stator slot and an annular channel. A 3D grid with 3.6 million cells and 8-processor parallel computing was first tested. By trial and error the annular channel was discretized and calculated with the sector mesh. To simplify the geometry, using a small number of cells gave reasonable results. The numeric results of the velocity and temperature profiles, distributions of turbulent viscosity and kinetic energy of turbulence at the air gap were presented. 
The friction coefficient was modelled by using $k-\varepsilon$ and the $k-\omega$ models. The calculation was based on the Finflo torque coefficient data and analytic equations. The simulated results by the $k-\omega$ model fitted well in the middle of the studied rotation speed range with the semiempiric data and the data presented by Saari (1998). The simulated velocity factor by the $k-$ $\omega$ model correlated well with the values of air measured by Saari (1998). These values were lower than the values predicted by Polkowski (1984). These numeric results were quantitative.

The local and mean heat transfer coefficients were calculated with the rotation speeds of 30 000-80 000 RPM via the heat flux normal to the wall, the constant wall temperature and the static gas bulk temperature of the air gap. The results with three turbulence models were of the same magnitude and qualitative. The helical velocity field did not match in every respect with the estimated flow mode. The absence of Taylor vortices was evident when using the Reynolds-averaged numeric simulation.

The one- and two-equation models (Baldwin-Lomax, $k-\varepsilon$ and $k-\omega$ ) give a isotropic turbulence. In the real situation the turbulence is anisotropic. The rotation causes changes in the turbulence. These can be taken upon consideration by the curvature corrections or by using the anisotropic (e. g. stress-transport) turbulence models. Regarding future work, the discrepancies between experimental and numerical data could be improved by some of these numerical means to gain more reasonable results.

The experimental work consisted of the design and implementation of a test facility, and measurements. Three sensors and telemetry were tested in a straight pipe. Calibration took place in conditions where the ability of the sensor could be easily checked. Telemetry was needed to measure the heat transfer at the rotor. It was designed and built at LUT. The centrifugal stresses of the rotor were calculated for the safe placing of the RdF-sensor, electric leads and telemetry transmitter into the rotor. Mean heat transfer coefficients were measured for rotation speeds between 10 000-40 000 RPM (180-667 Hz). The cooling air mass flow rates were 40, 50, 60 and $70 \mathrm{~g} / \mathrm{s}$. The axial velocity of the air gap was varied and set by the proper mass flow rate. The heat flux at the rotor was eight times bigger than the values at the stator. It rose uniformly when the rotation speed increased. The angular coefficient of the measured heat transfer coefficient data followed the result of the semi-empiric equation used at LUT. 
The heat transfer coefficients of the rotor and stator were slightly lower and of the same magnitude for the smooth rotor-stator combination.

Results were attained for a smooth rotor-stator combination. In the highly rotational flow the heat transfer coefficients with the numeric method were clearly smaller than the values of the semi-empiric data and the experimental method. Heat was transferred from the hotter stator and rotor surfaces to the cooler air flow in the air gap, not from the rotor to the stator via the air gap, although the stator temperature was lower than the rotor temperature. At constant mass flow rate the rotor heat transfer coefficient attained a saturation point at a higher speed. Over the speed the rotor heat transfer coefficient did not increase any more. The heat transfer coefficient of the stator grew uniformly. At 70000 and 80000 RPM speeds there existed peak values of the local heat transfer in the end of the annular channel a small axial length before the air temperature exceeded the stator temperature. This was noticed with all the three turbulence models. This could be considered as a critical cooling mass flow rate at these speeds.

The smooth high-speed rotor-stator combination was studied at the large velocity range. The gains and the industrial impacts that can be received from the results of this thesis are the levels and trends of the appeared heat transfer coefficients as function of rotation speed and cooling air mass flow rate through the air gap. These results confirm the applicability of the semi-empiric equation for the air gap flow on the studied new rotational speeds. According to the simulations of the air gap with the grooved stator, it increases the stator heat transfer mostly at lower peripheral speeds. The next challenge at LUT concerns other smooth and grooved rotor-stator combinations. The numeric simulations also confirmed the magnitudes of the measured friction coefficients and velocity factors in the previous part of the research. 


\section{REFERENCES}

Aura L., Tonteri J. 1986. Sähkömiehen käsikirja 2 Sähkökoneet. Werner Söderström Osakeyhtiö, (in Finnish). 373 p.

Ball K. S., Farouk B., Dixit V. C. 1989. An Experimental Study of Heat Transfer in a Vertical Annulus with a Rotating Inner Cylinder. Int. J. Heat and Mass Transfer, Vol. 32, No. 8, pp. $1517-1527$.

Baldwin B. S., Lomax H 1978. Thin Layer Approximation and Algebraic Model for Separated Turbulent Flows, Jan 1978, AIAA Paper 78-257.

Becker K. M., Kaye J. 1962. Measurement of Diabatic Flow in an Annulus with an Inner Rotating Cylinder. Transactions of the ASME, Journal of Heat Transfer,Vol. 84, May, pp. 97105.

Bilgen E. and Boulos R. 1973. Functional Dependence of Torque Coefficient of Coaxial Cylinders on Gap Width and Reynolds Numbers. Transactions of ASME, Journal of Fluids Engineering, Series I, Vol. 95, No. 1, pp. 122-126.

Bruun H. H. 1995. Hot-Wire Anemometry. Principles and Signal Analysis. Oxford University Press. 507 p.

Carew N. J. 1992. Experimental Determination of Heat Transfer Co-Efficients of Salient Pole Rotors. Thermal Aspects of Machines, IEE Colloquium, pages 8/1-8/8, London UK. Available: IEEE Xplore Data Base.

Chien K 1982. Predictions of Channel and Boundary-Layer Flows with a Low-ReynoldsNumber Turbulence Model. AIAA Journal, Vol. 20, No. 1, pp. 33-38, Jan 1982.

Dorfman L. A. 1963. Hydrodynamic resistance and heat loss of rotating solids. Oliver \& Boyd, Eidinburg and London, 244 p.

Finflo User Manual version 2.2, 1997. Helsinki University of Technology. 
Finflo User Guide version 3.0, 1998. Laboratory of Applied Thermodynamics. Helsinki University of Technology.

Gazley C. Jr. 1958. Heat-Transfer Characteristics of the Rotational and Axial Flow Between Cocentric Cylinders. Transactions of the ASME, Vol. 80, pp. 79-90.

Glassman A. J. 1975. Turbine Design and Application. Volume three, NASA SP-290, Edited by A. J. Glassman. 141 p.

Haapanen E. 1984. Aerodynamiikka, 2. painos. Suomen ilmailuliitto - Finlands Flygförbund ry (in Finnish). Auranen, Forssa. 102 p.

Hellsten A., Laine S. 1997. Extension of the k- $\omega$-SST Turbulence Model for Flows over Rough Surfaces. In 1997 AIAA Atmospheric Flight Mechanics Conference, pp. 252-260, New Orleans, Louisiana, Aug 1997. AIAA Paper 97-3577-CP.

Hellsten A., Laine S. 1998. Extension of the k- $\omega$ Shear-Stress Transport Turbulence Model for Rough-Wall Flows. AIAA Journal, Vol. 36, No. 9, 1998, pp. 1728-1729.

Holman J. P. 1989. Heat Transfer. SI Metric Edition. McGraw-Hill Book Company. 676 p.

Incropera F. P., DeWitt D. P. 1996. Fundamentals of Heat and Mass Transfer, Fourth Edition, John Wiley \& Sons, Inc. 879 p.

Isachenko V. P., Osipova V. A., Sukomel A. S. 1987. Heat Transfer. Third Printing, English Translation, Mir Publishers Moscov. 493 p.

ISO 5168 1978. Measurement of Fluid Flow - Estimation of Uncertainty of a Flow-Rate Measurement. 1. Ed. International Organization for Standardization. 26 p.

ISO 5167 1980. Measurement of Fluid Flow by Means of Orifice Plates, Nozzles and Venturi Tubes Inserted in Circular Cross-Section Conduits Running Full. First Edition. International Organization for Standardization. $65 \mathrm{p}$. 
Jakoby R., Kim S., Witting S. 1998. Correlations of the Convective Heat Transfer in Annular Channels with Rotating Inner Cylinder. Gas Turbine \& Aeroengine Congress \& Exhibition, Stockholm June 2-5, 1998. ASME Publ. No. 98-GT-97, 10p.

Japikse D. 1986. Advanced Experimental Techniques in Turbomachinery. Principal Lecture Series No. 1. Concepts ETI, INC. Norwich, Vermont 05055 USA.

Kaltenbacher M., Saari J. 1992. An Asymmetric Thermal Model for Totally Enclosed FanCooled Induction Motors. Report 38, Helsinki University of Technology, Laboratory of Electromechanics, Espoo, Finland. 62 p.

Kaye J., Elgar E. C 1958. Modes of Adiabatic and Diabatic Fluid Flow in an Annulus with Inner Rotating Cylinder. Trans. ASME 80, 753-765.

Kuosa M. 2001. Calculation of Stresses of a Notched Test Rotor. Turbomachinery Workshop (editor Jaakko Larjola), EN C-142 (in Finnish). Lappeenranta University of Technology, Department of Energy Technology. 17 p.

Larjola J., Lindgren O., Vakkilainen E. 1990: Pienoisvoimala - sähköä teollisuuden ja laivojen hukkalämmöstä. Research report EN B-68 (in Finnish), Lappeenranta University of Technology. 246 p.

Lee Y. N., Minkowycz W. J. 1989. Heat Transfer Characteristics of the Annulus of Two Coaxial Cylinders with One Cylinder Rotating. Int. J. Heat Mass Transfer. Vol. 32, No. 4, pp. $711-722$.

Liao C., Chen C-L., Katcher T. 1999. Thermal Management of AC Induction Motors Using Computational Fluid Dynamics Modeling. Electric Machines and Drives, 1999. International Conference IEMD '99. , pp. 189-191, 9-12 May 1999, Seattle, WA, USA. Available: IEEE Xplore Data Base.

Menter F. R. 1993. Zonal Two Equation k- $\omega$ Turbulence Models for Aerodynamic Flows, $24^{\text {th }}$ AIAA Fluid Dynamics Conference (Orlando, Florida), Jul 1983, AIAA Paper 93-2906-CP. 
Menter F. R. 1994. Two-Equation Eddy-Viscosity Turbulence Models for Engineering Applications. AIAA Journal, Vol. 32, No 8, pp. 1598-1605.

Negrea M., Rosu M. 2001. Thermal Analysis of a Large Permanent Magnet Synchronous Motor for Different Permanent Magnet Rotor Configurations. Electric Machines and Drives Conference, 2000 2001. IEEE International, pp. 777-781, 17-20 June 2001, Cambridge, MA, USA. Available: IEEE Xplore Data Base.

Pfitzer H., Beer H. 1992. Heat Transfer in an Annulus Between Independently Rotating Tubes with Turbulent Axial Flow. International Journal of Heat and Mass Transfer, Vol. 35, No. 3, pp. 623-633.

Polkowski J. W. 1984. Turbulent Flow Between Coaxial Cylinders with Inner Cylinder Rotating. Transactions of the ASME, Journal of Engineering for Gas Turbines and Power. Vol. 106, No. 1, pp. 128-135.

Rahman M., Rautaheimo P., Siikonen T. 1997. Numerical Study of Turbulent Heat Transfer from a Confined Impinging Jet Using a Pseudo Compressibility Method. Proceedings of the $2^{\text {nd }}$ International Symposium on Turbulence, Heat and Mass Transfer, pp. 511-520 June 1997.

Rautaheimo P, Siikonen T. 1999. Improved Solid-Wall Boundary Treatment in LowReynolds Number Turbulence Models. Helsinki University of Technology, Laboratory of Applied Thermodynamics, Report No. 122. 30 p.

Roe P. L. 1981. Approximate Riemann Solvers, Parameter Vectors, and Difference Schemes. Journal of Computational Physics, Vol. 43, pp. 357-372.

Saari J. 1995. Thermal Modelling of High-Speed Induction Machines. Acta Polytechnica Scandinavia. Electrical Engineering Series No. 82, Helsinki, 82 p.

Saari J. 1998. Thermal Analysis of High-Speed Induction Machines. Acta Polytechnica Scandinavica. Electrical Engineering Series No. 90. Helsinki, 73 p.

Schlichting H. 1979. Boundary-Layer Theory. McGraw-Hill Book Company. 817 p. 
Shaw C. T. 1992. Using Computational Fluid Dynamics. Prentice Hall International (UK) Ltd. $251 \mathrm{p}$.

Shih A. C., Hunt M. L. 1994. The Effect of Superimposed Axial Flow on Taylor-Couette Flow at Large Taylor-Numbers. 5 th Int. Symposium of Transport Phenomena and Dynamics of Rotating Machinery (Isromac-5), May 8-11, 1994, Maui, Hawaii. pp. 643-662.

Siikonen T. 1995. An Application of Roe's Flux-Difference Splitting for the k- $\varepsilon$ Turbulence Model. International Journal for Numerical Methods in Fluids, Vol. 21, No. 11, pp. 10171039 .

Siikonen T, Ojala J. 1997. Pyörimisliikekorjaus k-E turbulenssimalliin. CFD/TERMO-17b-97 (in Finnish). Helsinki University of Technology. 25 p.

Siikonen T., Rautaheimo P., Salminen E. 2001. Finflo User Guide, Version 3.0ß. Helsinki University of Technology, Laboratory of Applied Thermodynamics. 65 p.

Siikonen T., Ala-Juusela J. 2001. Simulation of an Air Flow Between Cooling Fins. CFD/Termo-38-2001. Helsinki University of Technology. 24 p.

Sissom L. E., Pitts D. R. 1972. Elements of Transport Phenomena, International Student Edition. McGraw-Hill Kogakusha, LTD. 814 p.

Stock H. W., Haase W. 1989. Determination of Length Scales in Algebraic Turbulence Models for Navier-Stokes Methods, Astronom. And Astrophys. 108, No. 76, 76-84.

Streeter V. L., Wylie E. B. 1985. Fluid Mechanics. First Metric Edition. International Student Edition. McGraw-Hill International Book Company. 562 p.

Tachibana F., Fukui S., Mitsumura H. 1960. Heat Transfer in an Annulus with an Inner Rotating Cylinder. Bulletin of JSME, Vol. 3, No 9, pp. 119-123. 
Van Leer B. 1982. Flux-Vector Splitting for the Euler Equations, Proceedings of the 8th International Conference on Numerical Methods in Fluid Dynamics (Aachen), (also Lecture Notes in Physics, Vol. 170, 1982).

VDI-Wärmeatlas 1988. Berechnungsblätter für den Wärmeübergang. Fünfte, erweiterte Auflage. VDI Verlag. Verlag des Vereins Deutscher Ingenieure, Düsseldorf.

Welty J. R., Wicks C. E., Wilson R. E. 1976. Fundamentals of Momentum, Heat, and Mass Transfer. Second Edition. John Wiley \& Sons, Inc. 789 p.

Wendt F 1933. Turbulente Strömungen zwischen zwei rotierenden konaxialen Zylindern. Ingenieur-Archiev, Vol. 9, pp. 577-595.

White F. M. 1999. Fluid Mechanics. Fourth Edition. McGraw-Hill Book Company. 826 p.

Wilcox D. C. 2000. Turbulence Modelling for CFD. Second Edition. DCW Industries, Inc. 5354 Palm Drive, LA Canada, California. 540 p.

Wilson D. G. 1985. The Design of High-Efficiency Turbomachinery and Gas Turbines, $2^{\text {nd }}$ printing. MIT Press, Massachusetts. USA. 496 p.

Yang L., Farouk B. 1992. Three-Dimensional Mixed Convection Flows in a Horizontal Annulus with a Heated Rotating Inner Circular Cylinder. Int. J. Heat and Mass Transfer, Vol. 35, No. 8, pp. 1947-1956. 
85. Welding Conference LUT JOIN'99. International Conference on Efficient Welding in Industrial Applications (ICEWIA). Ed. by Jukka Martikainen and Harri Eskelinen. 1999. 418 s.

86. PARTANEN, TEUVO. On the application of beam on elastic foundation theory to the analysis of stiffened plate strips. 1999. $102 \mathrm{~s}$. Diss.

87. ESKELINEN, HARRI. Tuning the design procedures for laser processed microwave mechanics. 1999. 172 s. Diss.

88.

ROUVINEN, ASKO. Use of neural networks in robot positioning of large flexible redundant manipulators. 1999. $71 \mathrm{~s}$. Diss.

89.

MAKKONEN, PASI. Artificially intelligent and adaptive methods for prediction and analysis of superheater fireside corrosion in fluidized bed boilers. 1999. 187 s. Diss.

90. KORTELAINEN, JARI. A topological approach to fuzzy sets. 1999. U.s. Diss.

91. SUNDQVIST, SATU. Reaction kinetics and viscosity modelling in the fusion syntheses of Caand Ca/Mg-resinates. 1999. U.s. Diss.

92. SALO, JUSSI. Design and analysis of a transversal-flux switched-reluctance-linear-machine pole-pair. 1999. 156 s. Diss.

93. NERG, JANNE. Numerical modelling and design of static induction heating coils. 2000. 86 s. Diss.

94. VARTIAINEN, MIKA. Welding time models for cost calculations in the early stages of the design process. 2000. 89 s., liitt. Diss.

95. JERNSTRÖM, EEVA. Assessing the technical competitiveness of printing papers. 2000. 159 s., liitt. Diss.

96. VESTERINEN, PETRI. On effort estimation in software projects. 2000. U.s. Diss.

97. LUUKKO, JULIUS. Direct torque control of permanent magnet synchronous machines analysis and implementation. 2000. 172 s. Diss.

98. JOKINEN, ARTO. Lobbying as a part of business management. 2000. 244 s. Diss.

99. JÄÄSKELÄINEN, EDUARD. The role of surfactant properties of extractants in hydrometallurgical liquid-liquid extraction processes. 2000. U.s. Diss.

100. Proceedings of $3^{\text {rd }}$ Finnish-French Colloquium on Nuclear Power Plant Safety. 2000. $118 \mathrm{s.}$

101. TANSKANEN, PASI. The evolutionary structural optimization (ESO) method: theoretical aspects and the modified evolutionary structural optimization (MESO) method. 2000. 67 s., liitt. Diss.

102.

103. JERNSTRÖM, PETTERI. The effects of real-time control
in plasma arc keyhole welding. 2000.69 s., liitt. Diss.

KAARNA, ARTO. Multispectral image compression using the wavelet transform. 2000. U.s. Diss.

104. KOTONEN, ULLA. Rahavirta-analyysit, erityisesti kassavirtalaskelma, kunnan talouden ohjauksen apuvälineenä. 2000. 209 s., liitt. Väitösk.

105. VARIS, JUHA. A novel procedure for establishing clinching parameters for high strength steel sheet. 2000. 84 s., liitt. Diss. 
107. SANDSTRÖM, JAANA. Cost information in engineering design - potentials and limitations of activity-based costing. 2001. 143 s., liitt. Diss.

108. TOIVANEN, JOUKO. Balanced Scorecardin implementointi ja käytön nykytila Suomessa. 2001. 216 s. Väitösk.

109. PESONEN, MAUNO. Applying AHP and A'WOT to strategic planning and decision making: case studies in forestry and forest industry. 2001. U.s. Diss.

110. Proceedings of Fifth International Seminar on Horizontal Steam Generators. Ed. by Juhani Vihavainen. 2001. $255 \mathrm{~s}$.

111. LAINE, PERTTI. Kohti vesiensuojelun aikaa: veden laadun muutokset eteläisellä Saimaalla. 2001. 264 s. Väitösk.

112. SILVENTOINEN, PERTTI. Electromagnetic compatibility and EMC-measurements in DC-voltage link converters. 2001. 115 s. Diss.

113. TERVONEN, ANTERO. Laadun kehittäminen suomalaisissa yrityksissä. 2001. 206 s. Väitösk.

114. SALMINEN, ANTTI. The effects of filler wire feed on the efficiency, parameters and tolerances of laser welding. 2001. 82 s., liitt. Diss.

115. HORTTANAINEN, MIKA. Propagation of the ignition front against airflow in packed beds of wood particles. 2001. U.s. Diss.

116. IKONEN, JOUNI. Improving distributed simulation in a workstation environment. 2001. U.s. Diss.

117. WU, HUAPENG. Analysis, design and control of a hydraulically driven parallel robot manipulator. 2001. U.s. Diss.

118. REUNANEN, ARTTU. Experimental and numerical analysis of different volutes in a centrifugal compressor. 2001. $150 \mathrm{~s}$. Diss.

119. TAAVITSAINEN, VELI-MATTI. Strategies for combining soft and hard modelling in some physicochemical problems. 2001. U.s. Diss.

120. SAVOLAINEN, RAIJA. The use of branched ketene dimers in solving the deposit problems related to the internal sizing of uncoated fine paper. 2001. U.s. Diss.

121. SARAVIRTA, ALI. Project success through effective decisions: case studies on project goal setting, success evaluation and managerial decision making. 2001. $286 \mathrm{~s}$. Diss.

122. BLOMQVIST, KIRSIMARJA. Partnering in the dynamic environment: the role of trust in asymmetric technology partnership formation. 2002. 296 s., liitt. Diss.

123. KARVONEN, VESA. Development of fiber recovery process. 2002. U.s. Diss.

124. KÄYHKÖ, JARI. The influence of process conditions on the deresination efficiency in mechanical pulp washing. 2002. 87 s., liitt. Diss.

125. SAVOLAINEN, PEKKA. Modeling of non-isothermal vapor membrane separation with thermodynamic models and generalized mass transfer equations. 2002. $179 \mathrm{~s}$. Diss.

126. KÄRKKÄINEN, HANNU. Customer need assessment: Challenges and tools for product innovation in business-to-business organizations. 2002. U. s. Diss. 